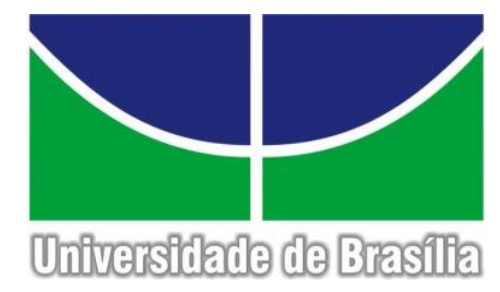

UNIVERSIDADE DE BRASÍLIA

CENTRO DE ESTUDOS AVANÇADOS MULTIDISCIPLINARES PROGRAMA DE PÓS-GRADUAÇÃO EM DESENVOLVIMENTO, SOCIEDADE E COOPERAÇÃO INTERNACIONAL

Luiz Alexandre Rodrigues da Paixão

Autopercepção da saúde em idosos: dimensões e fatores associados, com base nos dados da Pesquisa Nacional de Saúde de 2013 
UNIVERSIDADE DE BRASÍLIA

CENTRO DE ESTUDOS AVANÇADOS MULTIDISCIPLINARES PROGRAMA

DE PÓS-GRADUAÇÃO EM DESENVOLVIMENTO, SOCIEDADE E COOPERAÇÃO

INTERNACIONAL

Luiz Alexandre Rodrigues da Paixão

Autopercepção da saúde em idosos: dimensões e fatores associados, com base nos dados da Pesquisa Nacional de Saúde de 2013

Dissertação apresentada ao Programa de Pós-Graduação em Desenvolvimento, Sociedade e Cooperação Internacional da Universidade de Brasília, como requisito parcial para obtenção do título de Mestre em Desenvolvimento, Sociedade e Cooperação Internacional. Área de concentração: População, Desenvolvimento e Políticas Públicas.

Orientadora: Prof. ${ }^{\text {a } D r . ~}{ }^{a}$ Marília Miranda Forte Gomes

Brasília-DF, março de 2017 
CENTRO DE ESTUDOS AVANÇADOS MULTIDISCIPLINARES PROGRAMA

DE PÓS-GRADUAÇÃO EM DESENVOLVIMENTO, SOCIEDADE E COOPERAÇÃO

INTERNACIONAL

Luiz Alexandre Rodrigues da Paixão

\title{
Autopercepção da saúde em idosos: dimensões e fatores associados, com base nos dados da Pesquisa Nacional de Saúde de 2013
}

\begin{abstract}
Dissertação apresentada ao Programa de Pós-Graduação em Desenvolvimento, Sociedade e Cooperação Internacional da Universidade de Brasília, como requisito parcial para obtenção do título de Mestre em Desenvolvimento, Sociedade e Cooperação Internacional. Área de concentração: População, Desenvolvimento e Políticas Públicas.
\end{abstract}

\section{Banca Examinadora:}

Prof. ${ }^{a}$ Dr. ${ }^{a}$ Marília Miranda Forte Gomes (Orientadora) - Programa de Pós-Graduação em Desenvolvimento, Sociedade e Cooperação Internacional da Universidade de Brasília.

Prof. ${ }^{a}$ Dr. ${ }^{a}$ Ana Maria Nogales Vasconcelos (Presidente) - Programa de Pós-Graduação em Desenvolvimento, Sociedade e Cooperação Internacional da Universidade de Brasília.

Prof. ${ }^{a}$ Dr. ${ }^{a}$ Leides Barroso Azevedo Moura - Programa de Pós-Graduação em Desenvolvimento, Sociedade e Cooperação Internacional da Universidade de Brasília.

Prof. ${ }^{a}$ Dr. Andréa Mathes Faustino - Faculdade de Ciências da Saúde, Departamento de Enfermagem.

Prof. ${ }^{\circ}$ Dr. Joaquim José Soares Neto (Suplente) Programa de Pós-Graduação em Desenvolvimento, Sociedade e Cooperação Internacional da Universidade de Brasília.

Brasília-DF, março de 2017 


\section{AGRADECIMENTOS}

Primeiramente a Deus, por tudo.

A minha mãe que é um exemplo de força e atitude,

A todas as pessoas que direta ou indiretamente contribuíram para a realização deste trabalho, em especial a querida amiga Mary kawauchi que de todas as formas contribui para minha melhoria como ser humano,

A minha orientadora Marília Miranda Forte Gomes pela paciência e compreensão face às situações que surgiram.

A todos os professores do Departamento e aos demais alunos que também serviram de inspiração. 


\section{APRESENTAÇÃO}

O tema deste trabalho, autopercepção de saúde que envolve os idosos chegou até a mim como um presente visto que tenho estudado a importância do autoconhecimento para a tomada de decisões mais adequadas, com o intuito de evolução e amadurecimento.

Inicialmente, considerei quase impossível analisar a autopercepção de saúde e pontuar determinantes que influenciariam a percepção, visto que considerava sua dinamicidade, ou seja, depende de diversos fatores que podem ocorrer de um dia para o outro, e, por isso, a dificuldade em ser avaliada. No entanto, optou-se pelo tratamento do indicador e, assim, obter um retrato da saúde dos idosos naquele momento. Até este ponto, o que me incomodava era o fato da autopercepção poder ser tratada como um fenômeno devido à característica dinâmica e de representação do estado real do indivíduo naquele momento. Questões simples como responder como o sujeito avalia sua saúde já faz com que o próprio pense no assunto e possa mudar a forma como se autoavalia. Em seguida, questões que levantam comportamentos, alimentação, estilos de vida, entre outras foram levantadas, o que proporciona a possibilidade da pessoa se conhecer melhor e, a partir daí, já mudar alguns hábitos.

Pela física quântica, quem observa pode transformar. Assim, o autoconhecimento pode interferir na percepção de saúde, visto que não se podia ser a mesma pessoa, com as mesmas afirmações, depois de tantas questões respondidas pela pesquisa. No entanto, pela revisão bibliográfica, percebi que diversos determinantes influenciam a percepção de saúde e que isso merece ser levantado e apresentado, pela importância da visibilidade ao tema.

Levantar, apresentar e discutir estes determinantes sociais e como podem interferir na saúde do indivíduo é relevante e de suma importância, que podem servir de subsídios para ações e políticas públicas específicas. Por este lado, eu considerei o indicador de autopercepção de saúde como legítimo, mesmo acreditando que, tempos depois, somente pelo fato dos idosos terem pensado sobre o assunto, após a entrevista, eles pudessem mudar a forma de como se percebem.

Com isso, eu fico feliz em fazer parte do grupo de pessoas que traz questões importantes e que podem promover mudanças de paradigmas e preconceitos e, ainda, mais interessado em estudar o tema sob outros aspectos. 


\section{RESUMO}

Diante do cenário do envelhecimento da população brasileira, surge a necessidade de se estudar as características do segmento populacional composto de pessoas com 60 anos ou mais de idade com o objetivo identificar e promover oportunidades contínuas de saúde, tendo em vista as desigualdades sociais e econômicas que permeiam a sociedade e que afetam a saúde. A autopercepção da saúde é um indicador válido e com potencial para predição da mortalidade e do declínio funcional. Ele representa uma visão holística, dinâmica e subjetiva de como o idoso percebe sua saúde. O objetivo deste trabalho é analisar a autopercepção de saúde de pessoas idosas em relação aos determinantes sociais, observando as diferenças entre os sexos segundo as informações contidas na Pesquisa Nacional de Saúde, realizada em 2013, em todo o território nacional.

Os resultados mostram que a idade e os idosos negros tiveram associação com a autopercepção negativa da saúde, porém, quando controlado pelo nível de instrução do idoso, a idade e a raça deixaram de ser significativa tanto do sexo masculino quanto feminino. Observou-se que quanto maior o grau de instrução dos idosos e das idosas, menor a chance de avaliar a saúde de forma negativa, especialmente nas regiões Norte e Nordeste do país. O modelo final mostrou maior prevalência das doenças crônicas não transmissíveis e pela variável de capacidade funcional, sendo altamente associadas com a percepção negativa de saúde, principalmente para os idosos do sexo masculino residentes na região Norte e Nordeste do país. Atribui-se ao envelhecimento ativo e saudável questões de bem estar e qualidade de vida relacionadas com uma melhor nível educacional e à comportamentos saudáveis livre de doenças consideradas evitáveis uma vez que aja estímulo a hábitos de vida saudáveis.

Palavras-chave: Envelhecimento, Autopercepção de saúde, idosos, determinantes sociais 


\begin{abstract}
Due the aging scenario of the Brazilian population, it is necessary to study the characteristics of the population segment composed by people of 60 years of age or older, with the objective of identifying and promoting continuous health opportunities, given the social and economic inequalities that Permeate society and affect health. Self-perception of health is a valid indicator and has potential for predicting mortality and functional decline. This represents a holistic, dynamic and subjective view of how the elderly perceive their health.

The objective of this study is to analyze the elderly's self-perception of the health associated of the social determinants and to verify the differences between the sexes, using the information contained in the National Health Survey, conducted in 2013, throughout the national territory.

The results show that age and the black elderly were associated with negative selfperception of health, but when controlled by the level of education of the elderly, age and race were no longer significant for both males and females. It was observed that the higher the educational level of the elderly and the elderly, the lower the chance of evaluating health in a negative way, especially in the North and Northeast regions of the country. The final model showed a higher prevalence of chronic non-communicable diseases and functional capacity variable, being highly associated with negative health perception, especially for the male elderly living in the North and Northeast of the country. It is suggested that healthy and active aging is related to better education and healthy behaviors once that some diseases are considered to be avoidable when their lifestyle habit acts as a stimulus to healthy life.
\end{abstract}

Keywords: Aging, Self-perception of health, elderly, social health determinants 


\section{SUMÁRIO}

1. INTRODUÇÃ

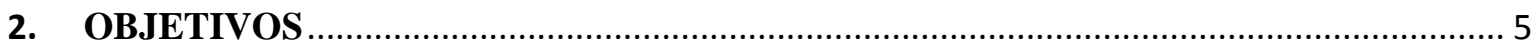

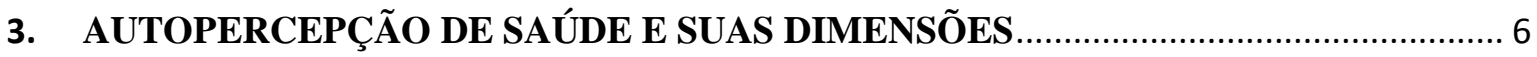

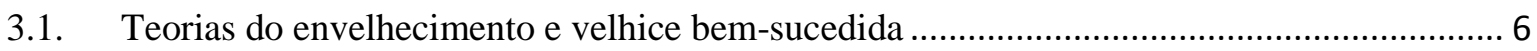

3.2. Conceitos correlacionados com a autopercepção de saúde ................................................... 8

3.3. Autopercepção de saúde: considerações ........................................................................ 10

3.4. Fatores associados à autopercepção de saúde ................................................................ 12

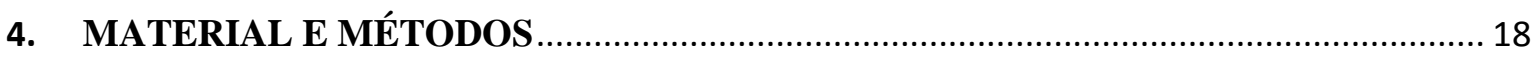

4.1. Fonte dados - a Pesquisa Nacional de Saúde (PNS) …....................................................... 18

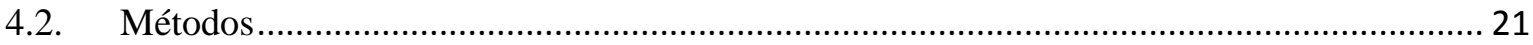

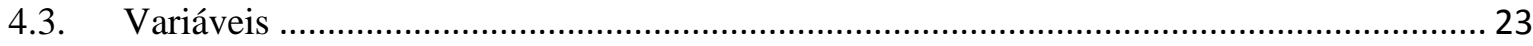

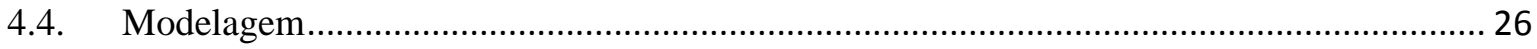

5. RESULTADOS

5.1. Análise descritiva da população e determinantes sociais utilizados...................................... 28

5.2. Determinantes da autopercepção de saúde dos idosos ........................................................ 38

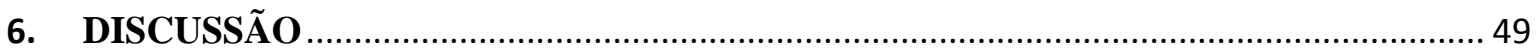

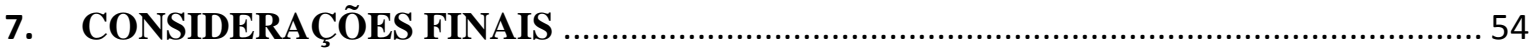

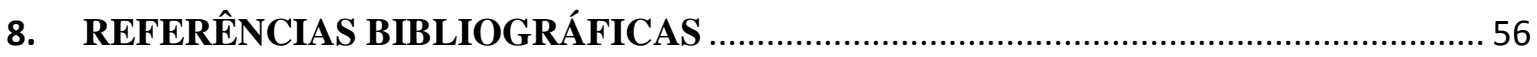

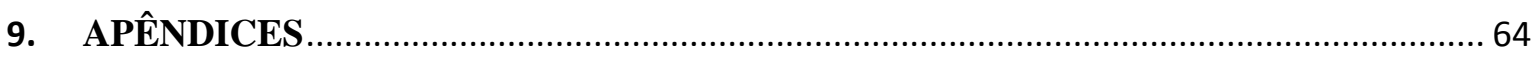

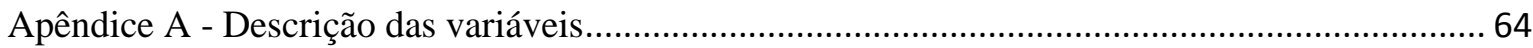

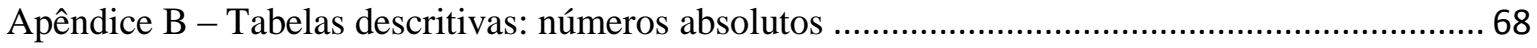

Apêndice C - Razões de chances e Intervalos de Confiança ............................................................ 72 


\section{LISTA DE ILUSTRAÇÕES}

Tabela 1 - Distribuição da população por faixa etária segundo o sexo - PNS, 2013

Tabela 2 - Distribuição da população total e número de idosos segundo as regiões geográficas, de acordo com o sexo - PNS, 2013

Tabela 3 - Distribuição de mulheres e homens idosos segundo a autopercepção de saúde PNS, 2013

Tabela 4 - Distribuição de mulheres e homens idosos segundo a autopercepção agregada de saúde - PNS, 2013

Tabela 5 - Distribuição relativa dos idosos segundo as variáveis sociodemográficas, de acordo com o sexo e a forma como auto avaliaram sua saúde - PNS, 2013

Tabela 6 - Distribuição relativa dos idosos segundo a região geográfica de residência, de acordo com o sexo e a forma como auto avaliaram sua saúde - PNS, 2013

Tabela 7 - Distribuição relativa dos idosos segundo o nível de escolaridade, de acordo com o sexo e a forma como auto avaliaram sua saúde - PNS, 2013

Tabela 8 - Distribuição relativa dos idosos segundo as variáveis de estilo de vida, de acordo com o sexo e a forma como auto avaliaram sua saúde - PNS, 2013

Tabela 9 - Distribuição relativa dos idosos segundo a quantidade de doenças crônicas não transmissíveis, de acordo com o sexo e a forma como auto avaliaram sua saúde - PNS, 2013

Tabela 10 - Distribuição relativa dos idosos segundo a presença doenças crônicas não transmissíveis, de acordo com o sexo e a forma como auto avaliaram sua saúde - PNS, 2013

Tabela 11 - Distribuição relativa dos idosos segundo a capacidade funcional, de acordo com o sexo e a forma como auto avaliaram sua saúde - PNS, 2013

Tabela 12 - Distribuição dos idosos segundo a dependência nas atividades básicas da vida diária, de acordo com o sexo e a forma como auto avaliaram sua saúde - PNS, 2013

Tabela 13 - Distribuição dos idosos segundo a dependência nas atividades instrumentais da vida diária, de acordo com o sexo e a forma como auto avaliaram sua saúde - PNS, 2013

Tabela 14 - Razões de Chances (RC) do modelo de regressão logística binária para autopercepção negativa de saúde, segundo o sexo do idoso - modelo 1, PNS 2013 
Tabela 15 - Razões de Chances $(\mathrm{RC})$ do modelo de regressão logística binária para autopercepção negativa de saúde, segundo o sexo do idoso - modelo 2, PNS 2013

Tabela 16 - Razões de Chances (RC) do modelo de regressão logística binária para autopercepção negativa de saúde, segundo o sexo do idoso - modelo 3, PNS 2013

Tabela 17 - Razões de Chances (RC) do modelo de regressão logística binário para autopercepção negativa de saúde, segundo o sexo do idoso - modelo 4, PNS 2013

Tabela 18 - Razões de Chances $(\mathrm{RC})$ do modelo de regressão logística binário para autopercepção negativa de saúde, segundo o sexo do idoso - modelo 5, PNS 2013

Tabela 19 - Razões de Chances $(\mathrm{RC})$ do modelo de regressão logística binário para autopercepção negativa de saúde - idosos do sexo masculino - modelo final, PNS 2013

Tabela 20 - Razões de Chances $(\mathrm{RC})$ do modelo de regressão logística binário para autopercepção negativa de saúde - idosos do sexo feminino - modelo final, PNS 2013

Quadro 1 - Variáveis independentes e modelos estruturados 


\section{INTRODUÇÃO}

O envelhecimento da população é um fator característico da Transição Demográfica, que pode ser definida como uma sucessão de etapas caracterizadas por mudanças nas taxas de natalidade ${ }^{1}$, de mortalidade $^{2}$ e de crescimento vegetativo $^{3}$ da população (SOARES, 2000). Concomitantemente à transição demográfica, ocorre a transição epidemiológica, que é definida como alterações nos padrões de morbidade e mortalidade dos países (ARAÚJO, 2012).

Em consequência, o aumento do contingente da população considerada idosa irá proporcionar o surgimento de novas demandas para a área de saúde, bem como na área social, pois os maiores de 60 anos representarão um peso relativo em crescimento, alterando as relações intergeracionais, como a composição da força de trabalho, as estruturas familiares e as transferências dentro das famílias, sobretudo devido aos novos arranjos familiares (PINHEIRO, 2009).

Essas questões apontam para a necessidade do fornecimento de serviços e benefícios que irão permitir uma vida mais digna e ativa, ou seja, uma rede adequada de proteção social. Mais ainda, segundo a Conferência sobre População e Desenvolvimento do Cairo, de 1994, foram propostos objetivos mais concretos em relação à população idosa: fortalecimento da autoconfiança e a promoção da capacidade para o trabalho pelo tempo possível e desejável; desenvolvimento de sistemas de assistência à saúde, de seguridade social adequados e de apoio social, com vistas a ressaltar a capacidade das famílias de cuidarem de seus idosos.

O relatório sobre políticas de saúde para um envelhecimento ativo da Organização Mundial de Saúde aponta para a necessidade de políticas e programas

(...) baseados em direitos, necessidades e habilidades de pessoas mais velhas, bem como incluir uma perspectiva de curso de vida que reconheça a importante influência das experiências de vida para a maneira como os indivíduos envelhecem. (OMS, 2005, p.8)

\footnotetext{
${ }^{1}$ Número de nascidos vivos, por mil habitantes, na população residente em determinado espaço geográfico, no ano considerado.

${ }^{2}$ Número total de óbitos, por mil habitantes, na população residente em determinado espaço geográfico, no ano considerado.

${ }^{3}$ Diferença entre a taxa de natalidade e a taxa de mortalidade.
} 
Considerado como um avanço social, o envelhecimento da população evidencia o aumento da longevidade, sendo, assim, considerado pela Organização Mundial de Saúde (OMS, 2005) como uma história de sucesso para políticas de saúde pública, assim como para o desenvolvimento social e econômico, representando uma conquista da humanidade. Este processo traz consigo novos desafios, no sentido de proporcionar bem-estar físico, social e mental ao longo do curso da vida a esta população em processo de envelhecimento, ou seja, um envelhecimento ativo.

O envelhecimento ativo é um processo de otimização das oportunidades de saúde, participação e segurança, com o objetivo de melhorar a qualidade de vida, à medida que as pessoas ficam mais velhas e com a participação contínua nas questões sociais, econômicas, civis, culturais e espirituais, os idosos seguem com uma vida saudável, participativa, com independência, dignidade e seguridade social (OMS, 2005).

Neste contexto, surgem novas necessidades de explorar as questões de saúde, bem como a assistência à população idosa e no entendimento do envelhecer, para desenvolver políticas de saúde voltadas a este segmento populacional. Saúde é definida pela Organização Mundial de Saúde como estado de bem-estar físico, psíquico e social, não simplesmente ausência de doença ou enfermidade (OMS, 2005).

Com isso, entender os determinantes socioeconômicos e comportamentais relacionados às condições de saúde entre os idosos é fundamental para a elaboração de políticas que possam prevenir ou retardar os problemas de saúde, o que permite uma velhice ativa e o bem-estar dessa população, permitindo, assim, que o idoso possa usufruir integralmente os anos proporcionados pelo avanço da ciência (VERAS, 2007).

É sabido que há desigualdades entre os indivíduos; aqueles mais vulneráveis em relação à escolaridade, à alimentação adequada e, principalmente, a oportunidades, à assistência social e serviços de saúde, dentre outros aspectos, tendem a sofrer mais quando envelhecem (PAGOTTO, 2011). A equidade é, assim, um dos desafios colocados, principalmente, porque um envelhecimento saudável depende de vários fatores.

Com isso, novos estudos devem ter como finalidade analisar este segmento populacional, especialmente na área de saúde, tanto do ponto de vista social e coletivo quanto do individual, uma vez que este processo tem consequências importantes que envolvem a vida das pessoas, de suas famílias, da comunidade em que se inserem e, principalmente, dos órgãos responsáveis pela assistência social. 
Um dos indicadores mais utilizados na avaliação do estado de saúde é a autopercepção de saúde, uma vez que ela contribui para a predição da mortalidade e do declínio funcional (BLAZER, 2008). O autorrelato da saúde reflete uma percepção integrada do indivíduo que inclui as dimensões biológicas, psicossocial e social, além de ser, como dito anteriormente, um preditor da mortalidade. É um indicador subjetivo e está relacionado com a demanda por saúde; é simples, sendo feita apenas a pergunta de como o indivíduo avalia a sua saúde.

Este trabalho é um estudo descritivo e de associação, baseado em dados da Pesquisa Nacional de Saúde (PNS), realizada pelo Ministério da Saúde, em 2013, em parceria com o Instituto Brasileiro de Geografia e Estatística (IBGE). A PNS traz como objetivo geral a produção de dados sobre a situação de saúde e os estilos de vida da população brasileira.

Para descrever aspectos relacionados às condições de saúde da população brasileira, a PNS abordou a percepção individual da saúde em várias dimensões. Investigou-se, particularmente, a autoavaliação de saúde, indicador que tem sido utilizado para estabelecer diferenças de morbidade em subgrupos populacionais.

A PNS foi divulgada em três etapas, abordando: a percepção do estado de saúde, estilos de vida e doenças crônicas; o acesso e utilização dos serviços de saúde, acidentes e violências; e ciclos de vida. As informações levantadas englobaram tanto componentes físicos quanto emocionais dos idosos, além de aspectos do bem-estar e da satisfação com a própria vida, a questão da autopercepção de saúde, na qual o indivíduo idoso classificou sua saúde como muito boa, boa, regular, ruim ou muito ruim.

Dessa forma, este trabalho visa analisar a autopercepção de saúde de homens e mulheres considerando os fatores socioeconômicos, demográficos e de estilo de vida e de condição de saúde. Com isso, busca identificar em que medida os fatores ou determinantes podem interferir na forma como o idoso percebe sua saúde.

Para o presente trabalho, a população pesquisada compreendeu moradores de 60 anos de idade ou mais, residentes em domicílios particulares do Brasil, exceto os localizados nos setores censitários especiais como quartéis, bases militares, alojamentos, acampamentos, embarcações, penitenciárias, presídios, asilos e hospitais, entre outros.

Uma das abordagens para o presente estudo relaciona-se à análise de algumas informações prestadas pelos respondentes - tais como raça ou cor da pele, escolaridade, consumo de bebidas alcoólicas e tabagismo - para analisar se estas variáveis se 
constituem, dentre outras, como determinantes sociais da saúde, bem como se possuem efeitos, e em que medida, nas escolhas do estilo de vida das pessoas idosas e na autopercepção de seu estado de saúde. Além disso, pretende-se verificar se os determinantes atuam de forma diferenciada na percepção da saúde de idosos do sexo masculino e feminino. Desse modo, busca-se analisar se indivíduos com pior autopercepção possuem atributos, hábitos ou contextos sociais comuns, que possam interferir em sua condição de saúde ou no modo como a percebem.

O segmento populacional composto por pessoas de 60 anos ou mais de idade compreendeu 26,4 milhões de pessoas consideradas idosas, em 2013, o que correspondia a 13,2\% da população brasileira. Entre os eles, $60,7 \%$ possuíam entre 60 e 70 anos de idade, sendo que 31,9\% tinham idades entre 60 e 64 anos, e 6,8 milhões de pessoas, ou seja, 25,3\% tinham mais de 74 anos de idade.

Foi identificada a existência de variáveis que atuaram como determinantes da autopercepção negativa da saúde, considerando o sexo, tais como a baixa escolaridade, a presença de doenças crônicas não transmissíveis e a dependência funcional. 


\section{OBJETIVOS}

\subsection{Objetivo geral}

Como objetivo geral, este trabalho busca analisar a autopercepção de saúde entre idosos do sexo masculino e feminino em relação aos determinantes sociais segundo dados da Pesquisa Nacional de Saúde, realizada em 2013.

\subsection{Objetivos específicos}

Pretende-se, especificamente, identificar se determinantes sociais apontados na literatura se relacionam significativamente com a forma com que o idoso e a idosa avaliam a sua saúde, considerando as diferenças de sexo, seguindo os seguintes processos:

- Descrever as frequências das categorias de saúde da população idosa;

- Verificar se determinantes sociodemográficos, como idade e raça/etnia exercem alguma influência na autopercepção da saúde dos idosos;

- Verificar a percepção da saúde do idoso segundo o local de residência, ou seja, grandes regiões geográficas;

- Verificar se os comportamentos ou estilos de vida como consumo de bebidas alcoólicas, tabagismo e práticas religiosas influenciam na percepção da própria saúde;

- Verificar se a presença de doenças crônicas não transmissíveis e a capacidade funcional da pessoa idosa tem associação com o autorrelato acerca da própria saúde;

- Identificar as variáveis que apresentam a maior força de associação prevalência - com cada uma das categorias da avaliação de saúde. 


\section{AUTOPERCEPÇÃO DE SAÚDE E SUAS DIMENSÕES}

Esta seção levanta as principais teorias do envelhecimento e as questões acerca da velhice bem-sucedida. Ainda, traz as principais características, vantagens e desvantagens do indicador de autopercepção de saúde bem como os fatores associados a ele.

\subsection{Teorias do envelhecimento e velhice bem-sucedida}

A velhice era considerada como responsabilidade da família e uma questão de previdência individual que se transforma em questão pública devido ao envelhecimento populacional. Assim, surge o idoso que se firmou como uma categoria cultural que impõe um recorte novo à geografia social, o que exige a prática de modos específicos de gestão (DEBERT, 2011).

Com relação às teorias do envelhecimento, há autores que consideram uma visão positiva (ATCHLEY, 1999; HAVIGHURST, 1987). Para Fernandez-Ballesteros (2009), o envelhecer é um processo psicológico e social do desenvolvimento do ser humano, no qual se fazem necessárias adaptações constantes em busca de novos equilíbrios internos e externos, pois este processo aumenta a vulnerabilidade em relação a doenças crônicas e agudas.

Para Debert (2011), a tendência contemporânea é rever os estereótipos associados ao envelhecimento, como a ideia de um processo de perdas que tem sido substituída pela consideração de que esse é um momento propício para novas conquistas. No entanto, questões e estereótipos ainda permeiam a sociedade.

Birman (1995, p. 29-48) já trazia uma reflexão, que se pode dizer atual, acerca dos termos sobre o envelhecimento, como idoso, velhice e terceira idade:

Velho na percepção dos "envelhecidos" das camadas médias e superiores está associada à pobreza, à dependência e à incapacidade, o que implica que o velho é sempre o outro. Já a noção de "terceira idade" torna-se sinônimo dos "jovens velhos", os aposentados dinâmicos que se inserem em atividades sociais, culturais e esportivas. Idoso, por sua vez, é a designação dos "velhos respeitados". A expressão "idoso" designa uma 
categoria social, no sentido de uma corporação, o que implica o desaparecimento do sujeito, sua história pessoal e suas particularidades. Além disso, uma vez que é considerado apenas como categoria social “o idoso é alguém que existiu no passado, que realizou o seu percurso psicossocial e que apenas espera o momento fatídico para sair inteiramente da cena do mundo".

O termo idoso é caracterizado por todo e qualquer indivíduo acima de 60 ou 65 anos, ou seja, é o sujeito do envelhecimento; a velhice é o último ciclo da vida; e terceira idade é a fase entre a aposentadoria e o envelhecimento que traz as demandas de cuidado com a saúde em prol de um envelhecimento com mais qualidade de vida. $\mathrm{O}$ processo de envelhecimento é norteado por desafios no aspecto físico, psicológico e social (SILVA, 2005).

Fonseca (2005) traz o conceito de envelhecimento bem sucedido. Para o autor, o sucesso do envelhecimento é caracterizado pelo equilíbrio entre as capacidades do indivíduo e as exigências do ambiente no qual ele se encontra.

Atualmente, o conceito de envelhecimento bem-sucedido ultrapassa a diferença entre saúde e doença, embora a ausência e a incapacidade sejam um componente do envelhecimento bem-sucedido (KEONG, 2010). Fonseca (2005) pontua que comportamentos e características como baixo risco de doença e incapacidade, elevada função mental e física, bem como um compromisso ativo para com a vida podem ser traduzidos como envelhecimento bem-sucedido.

Em uma perspectiva psicológica, Fernández-Ballesteros (2009) pontua a satisfação com a vida e o compromisso social, o ato de sentir-se bem consigo e conduzir-se segundo seus próprios valores ou crenças.

Diante disso, percebe-se que as teorias do envelhecimento bem-sucedido permeiam o sujeito ativo, que vive com qualidade de vida.

Ron (2007) aponta que pessoas que definiram o seu estado de saúde de forma negativa, apresentavam mais atitudes e percepções do envelhecimento negativas do que os sujeitos que definiram a sua saúde como boa ou excelente. As pesquisas indicam que a maioria das pessoas sabe muito pouco acerca da idade avançada e a maioria tem percepções erradas, estereotípicas e negativas (RON, 2007).

Ainda no contexto de envelhecimento bem-sucedido existe o termo resiliência que foi associada à baixa probabilidade de doença, manutenção da funcionalidade tanto 
física como cognitiva, bem-estar e comprometimento com a vida como indicadores de velhice bem-sucedida, como apontado por Rowe e Kahn (citado por FONTES, 2015).

Em sua revisão da literatura acerca dos termos resiliência e velhice, Fontes (2015) ainda aponta que os idosos resilientes são aqueles com capacidade de se adaptar depois de serem afetados por adversidades e que recuperam seus níveis de bem-estar objetivo e subjetivo. Dessa forma, tornam-se importantes elementos como autoconceito e autoestima representados pelo suporte familiar e com os relacionamentos com a comunidade.

\subsection{Conceitos correlacionados com a autopercepção de saúde}

Indicadores como mortalidade infantil e esperança de vida ao nascer têm relação direta com as condições de saúde, ou seja, melhorias nas condições de vida proporcionadas por políticas púbicas e avanços tecnológicos como escolarização, campanhas de vacinação, saneamento básico, avanços da medicina, etc; e as taxas de fecundidade e a urbanização estão vinculadas a estas condições. A estrutura etária da população se apresenta vinculada à demanda por serviços de saúde e, sendo assim, mudanças nesta estrutura ocasionam mudanças na demanda por serviços de saúde (OMS, 2005).

Diante desta mudança na estrutura etária, que é caracterizada pelo aumento relativo de pessoas idosas, associado à maior longevidade da população, o desafio posto para as políticas públicas é o fornecimento de serviços e benefícios que permitam a esses indivíduos idosos uma vida digna e ativa, o que depende especificamente das políticas de seguridade social, a fim de prevenir ou atenuar o desamparo das gerações mais velhas (WONG, 2006).

A Organização Mundial de Saúde (2005) define saúde como um estado de bemestar físico, mental e social. Com isso, propõe um envelhecimento ativo caracterizado principalmente pela participação de idosos na sociedade de acordo com suas necessidades e anseios, além de proteção e segurança quando da sua necessidade.

Neste sentido, identificar e analisar as associações entre aspectos socioeconômicos e comportamentais da pessoa idosa com o processo de envelhecimento ativo é um ponto importante para elaboração de políticas públicas visando ao bem-estar e à equidade desse segmento populacional. Um ponto inicial seria analisar as desigualdades sociais, econômicas e demográficas e buscar compreender os 
fatores que mais afetam a qualidade de vida, vista não somente pelo estado de saúde, mas também de uma forma mais abrangente de bem-estar.

Uma das possibilidades de executar estas análises é utilizar informações provenientes da percepção de idosos em relação ao seu próprio estado de saúde, que engloba questões objetivas de saúde e como esses indivíduos as encaram, e o bem-estar subjetivo dentro de suas realidades (ALVES, 2004).

A autopercepção de saúde da pessoa idosa é produto de múltiplos fatores, incluindo idade, sexo, estado conjugal, oportunidades de educação, capacidade funcional, condições crônicas de saúde e estilos de vida, entre outros. Diversos estudos mostram correlação da autopercepção da saúde com variáveis demográficas e socioeconômicas, bem como comportamentais e com outras medidas de condições de saúde, tais como doenças crônicas e capacidade funcional (BAILIS et al., 2003; BARON-EPEL, 2001).

$\mathrm{Na}$ análise das desigualdades sociais em saúde, Blaxter (1989) considera três dimensões: 1) a dimensão médica, que considera o número de doenças em que a morbidade é definida como desvio de uma norma fisiológica delimitada por um critério objetivo; 2) a dimensão do estado funcional, em que a morbidade é definida pela falta de habilidade para desempenhar alguma tarefa que seria habitual; e 3) a dimensão subjetiva, representada pela autoavaliação de saúde, em que a morbidade é definida a partir da percepção das pessoas acerca de sua saúde.

Blazer (2008) aponta que, além do autorrelato da saúde ser um preditor de mortalidade e de declínio funcional, ele é tão importante quanto a dimensão objetiva da saúde, ou seja, quando da presença de doenças. O autor relaciona ainda as percepções de saúde e de bem-estar com o contexto social no qual as percepções de saúde são moldadas.

Lopes e Rabelo (2006) afirmam que, de modo geral, um idoso com qualidade de vida é aquele que tem boa saúde física, realiza em suas escolhas de modo consciente e leva a vida com significado. No entanto, a qualidade da saúde do idoso leva em consideração não somente o aspecto físico, mas o psicológico, o social e o espiritual.

O termo "qualidade de vida" é dinâmico, assim como a percepção da saúde, pois varia entre as pessoas e em relação ao tempo, como descrito por Rabelo (2010), em seu trabalho sobre qualidade de vida e autopercepção da saúde entre idosos hipertensos e não hipertensos. Citando Chamovich, Trentini e Fleck, Rabelo aborda a dificuldade de definição do termo qualidade de vida na velhice, pois estes autores consideram como 
um fenômeno multideterminado e multidimensional, que envolve critérios objetivos e subjetivos que podem ser alterados ao longo do tempo.

Neri (2007) ainda menciona a importância da subjetividade na avaliação da saúde dos idosos, uma vez que determina como os idosos se sentem e se percebem a respeito de suas vidas, ainda que considerando os fatores objetivos como aqueles de natureza socioeconômica, por exemplo.

Dessa forma, considerando principalmente a pessoa idosa, a autopercepção da saúde aponta para a questão da qualidade de vida, que consiste em se sentir bem, mesmo com a presença de doenças que podem comprometer sua independência funcional. Além de englobar condições médicas e incapacidades funcionais, o autorrelato da saúde envolve fatores considerados não clínicos, tais como o estado de humor, as redes de relações sociais e as comparações sociais. (RABELO, 2010).

\subsection{Autopercepção de saúde: considerações}

A autopercepção do estado de saúde tem sido utilizada em diversos estudos (BAILIS et al., 2003; BARON-EPEL, 2001; CAMPOS, 2009; HARTMANN, 2008). É considerado um indicador confiável e válido, pois observa vários aspectos da saúde física, cognitiva e emocional das pessoas (LEBRAO, 2005).

Souza (2012) aponta um estudo desenvolvido pelo projeto Saúde, Bem-Estar e Envelhecimento $\left(\mathrm{SABE}^{4}\right)$ que a autoavaliação ruim foi um fator de risco de mortalidade, sendo consideravelmente maior que aqueles que se referiram à própria saúde como excelente.

Hartmann (2008), em seu estudo realizado em Porto Alegre, entre dezembro de 2005 e novembro de 2006, identificou uma avaliação positiva da saúde em idosos com maior escolaridade, melhor condição socioeconômica, que não necessitavam de auxílio para atividades da vida diária e com ausência de diversas doenças crônicas como diabetes e bronquite.

Um estudo realizado por Marcellini et al. (2002) apontou que idosos que relataram a saúde negativamente apresentaram um risco maior de todas as causas de mortalidade que aqueles com autorrelato de saúde excelente.

\footnotetext{
${ }^{4}$ Projeto desenvolvido pela Organização Pan-americana de Saúde que tem como objetivo principal de produzir informações que permitam avaliar as condições de saúde e bem-estar das pessoas idosas (disponível em http://www.fsp.usp.br/sabe/).
} 
Além da vantagem da autopercepção retratar o estado real do indivíduo idoso naquele momento, é um indicador de baixo custo e de fácil operacionalização para o desenvolvimento de pesquisas (SOUZA, 2012).

Uma desvantagem que pode ser citada é que, em certos inquéritos populacionais, a condição de saúde do idoso é relatada por outra pessoa no domicílio, devido a problemas físicos ou cognitivos, o que pode não representar a saúde percebida pelo próprio indivíduo idoso. Sendo assim, deve-se ter cautela nas interpretações (HARTMANN, 2008).

Outra questão que deve ser considerada é a diferença nas percepções em diferentes culturas e grupos sociais e suas formas de considerarem a qualidade da saúde. Fonseca (2010) aponta que, pela busca da equidade em saúde, deve-se considerar as universalidades e especialidades das identidades masculinas e femininas no contexto saúde-sociedade. O estudo traz uma reflexão sobre o impacto da interseção indivíduocultura sobre o comportamento em saúde.

Neste sentido, Carvalho et al. (2015), no trabalho sobre desigualdades na autoavaliação de saúde, destaca que a qualidade descrita da saúde e do bem-estar está relacionada com as expectativas que diferentes grupos e culturas possuem e que refletem de forma diferente pela valorização diferenciada que cada grupo estabelece para cada necessidade humana. Com isso, o trabalho chama a atenção para os cuidados nas comparações dos resultados das populações de diferentes países ou regiões.

Sadana et al. (2002) apontam que o limite entre a saúde e o bem-estar pode variar em diferentes subpopulações, contextos geográficos e culturais e, com isso, alguns grupos conceituam a saúde, ou a forma de como a avaliam, de acordo com critérios subjetivos, e outros podem considerar aspectos mais objetivamente mensuráveis (citado por CARVALHO, 2015).

Salomon et al. (2004) corroboram o problema das comparações, pois as variações nas percepções de saúde e do status da autoavaliação da saúde podem estar relacionados, em parte, a diferentes expectativas de saúde inseridas em um contexto específico.

No entanto, apesar dessas observações que podem ser consideradas como limitações dos estudos, a identificação dos determinantes socioeconômicos e comportamentais, o entendimento de como eles se relacionam uns com os outros e como estes determinantes podem gerar desigualdades em saúde, a análise dos determinantes ainda se torna essencial para o bem-estar dos idosos (CAMPOS, 2009). 
A identificação dos determinantes que podem afetar a forma como o idoso avalia a sua saúde pode ajudar na adoção de medidas preventivas e na implementação de políticas públicas que se destinariam a atenuar os efeitos negativos sobre o estado de saúde população idosa (ALVES, 2004).

\subsection{Fatores associados à autopercepção de saúde}

Para analisar os fatores associados à percepção de saúde, ou mais especificamente, à saúde, Michel Marmot (2004) abordou em sua obra Status Syndrome a questão do gradiente social de saúde, no qual ele menciona como a posição social pode afetar a saúde e a expectativa de vida do indivíduo. Segundo o autor, a desigualdade no que se refere à autonomia e participação que levaria à ocorrência de doenças.

Marmot aponta que o determinante de bem-estar e longevidade vai além de renda ou estilo de vida. Ele considera que a participação social plena tem um efeito profundo na saúde das pessoas. Este marco conceitual também foi contemplado pelo relatório "Saúde das Américas" (OPAS, 2012) que aborda determinantes de saúde estruturais e intermediários, sendo os primeiros caracterizados pelas diferentes culturas e religiões, pelo mercado de trabalho, pelo sistema educacional, que geram diferentes estratos sociais por sexo e raça. Os determinantes intermediários seriam aqueles que determinam as condições de vida da população (comportamentos de risco e acesso a recursos, por exemplo), e são derivados dos estratos sociais provocados pelos determinantes estruturais.

Determinantes sociais da saúde e demográficos, bem como a presença de doenças crônicas e estilos de vida estão correlacionados e podem influenciar na forma como as pessoas, em especial, as idosas, avaliam a sua saúde. Dessa forma, identificar e entender os fatores socioeconômicos e comportamentais que determinam as condições de saúde é de suma importância e pode proporcionar uma velhice ativa (CAMPOS, 2009).

A seguir, estão descritos os principais determinantes sociais que podem interferir na autopercepção da saúde da pessoa idosa, de acordo com a literatura pesquisada. No entanto, nem todos eles foram abordados neste trabalho.

O panorama do envelhecimento, embora representado por ambos os sexos, retrata a chamada "feminização" do envelhecimento, como mostrado nos trabalhos de Silva (2006) e Torres (2009), que apontaram para o estado do envelhecimento ser mais significativo para as mulheres que para os homens (SOUZA, 2012). As mulheres têm 
menor exposição a fatores de risco como tabagismo e uso de álcool, bem como diferenças quanto à atitude em relação a doenças e incapacidades funcionais. Dessa forma, o sexo será considerado uma variável de controle, pois se entende que há diferenças na percepção da saúde dependendo do sexo.

Segundo o estudo sobre envelhecimento ativo da Organização Mundial de Saúde, as mulheres têm maior expectativa de vida e o número de viúvas é significativamente maior do que de homens nesta situação; com isso, as idosas que vivem sozinhas são altamente vulneráveis à pobreza e ao isolamento social (OMS, 2005). Dessa forma, como abordado por Romero (2002), os homens e mulheres experimentam a velhice de forma diferente e estudos sobre os diferenciais de saúde para os sexos tornam-se cada vez mais necessários.

Pelo fato de a questão da percepção de saúde estar envolvida por aspectos subjetivos, se a resposta é dada por outra pessoa que não o próprio indivíduo pode acarretar em alguma diferença de percepção. $\mathrm{O}$ objetivo de incluir esta variável nas análises é exatamente o de avaliar se as respostas fornecidas por outra pessoa diferem daquelas fornecidas pelo próprio informante e em qual medida.

Igualmente com relação ao sexo, o fator idade é considerado um determinante fundamental na autoavaliação de saúde, pois reflete o cenário de desigualdades sociais no Brasil (PAGOTTO et al., 2011). Diversos trabalhos, como o de DACHS (2002), apontam que, com o avançar da idade, aumenta-se a probabilidade de avaliação negativa da saúde.

Um dos exemplos desses trabalhos é o estudo realizado em 2001, a partir da PNAD $^{5}$ de 1998, sobre as desigualdades na autoavaliação do estado de saúde, que apontou exatamente que a classificação de saúde autoavaliada piora com o avançar da idade (DACHS, 2001). Dessa forma, este fator torna-se um determinante demográfico a ser considerado e que pode influenciar na autopercepção da saúde do idoso, como aponta Crimmins e Seeman (citado por CAMPOS, 2009), com base em estudos do Centro Biodemográfico USC/UCLA, nos quais destacam características como idade, raça ou cor da pele como determinantes diretos das condições de saúde das pessoas.

A variável raça ou cor da pele são características inerentes aos indivíduos e, dessa forma, não são passíveis de intervenções. Em geral, são usadas como variável de controle e estão, assim, presentes em todos os modelos.

\footnotetext{
${ }^{5}$ Pesquisa Nacional por Amostra de Domicílios.
} 
Dóra Chor (2013) aborda em seu texto "Desigualdades em saúde no Brasil: é preciso ter raça" que os temas raça e saúde são controversos e aponta a falta de estudos empíricos sobre a influência das desigualdades raciais na saúde do indivíduo.

Neste sentido, a utilização da variável raça/cor da pele como significado de identidade da origem geográfica ou como marcador genético faz-se sem sentido uma vez que a ciência já demostrou que há mais variação genética entre indivíduos com características fenotípicas semelhantes do que entre aqueles com fenotípicos diferentes (ARAÚJO, 2009).

Contudo, as informações referentes à raça/cor aqui serão utilizadas como marcadores do risco de discriminação ou de exposições sociais, visto que, no Brasil, ainda existe a discriminação racial, o que proporciona desigualdades econômicas e sociais a grupos discriminados (ARAÚJO, 2009).

As desigualdades regionais e sociais são fatores que permeiam a sociedade brasileira. A transição demográfica se manifesta em caráter múltiplo, principalmente, devido aos desequilíbrios sociais, mas também devem ser considerados os regionais (BRITO, 2008). As transformações na população não ocorrem de forma simultânea em todas as regiões do país, apresentando diferenças regionais consideráveis, principalmente devido aos diferentes índices de fecundidade e de mortalidade apresentados nas regiões. Na Região Nordeste, por exemplo, a população alcançou os 60 anos de idade em 2010, sendo que nas demais regiões esse fato já havia ocorrido na década anterior. (VASCONCELOS; GOMES, 2012).

O local de moradia - urbano ou rural - também pode ser investigado para avaliar a qualidade de vida dos indivíduos idosos e relacioná-la com o autorrelato de sua saúde. Santos et al. (citado por TAVARES, 2015), apontam que a qualidade de vida pode ser influenciada pelo local de moradia.

Outro fator relacionado com a percepção de saúde é a escolarização, ou seja, o nível de instrução da pessoa idosa, que pode também ser estruturado em número de anos de estudo; é uma variável de importância na saúde dos indivíduos idosos que, em alguns casos, compõe o grupo das variáveis socioeconômicas. Trabalhos como os de Freedman, Martin e Lauderdale apontam para a importância do nível de escolarização como determinante de saúde, uma vez que possibilita a habilidade de se informar melhor e tomar as decisões que mais convém à pessoa e, sendo assim, tem efeito direto na geração de renda, alimentação e hábitos saudáveis e cuidados com a saúde. 
Uma questão importante que compõe o comportamento dos indivíduos é a participação em atividades sociais. Este fato se relaciona ao apoio social. Segundo a OMS (2005), é fundamental reduzir os riscos da solidão e do isolamento social, por meio de apoio aos grupos ou programas que podem estimular a interação social. Uma forma de sociabilização é a participação em cultos ou religião que serve, além de outras questões, para o indivíduo idoso ter contato com outras pessoas.

Os comportamentos de risco também podem interferir na saúde e na percepção da saúde de idosos: o consumo de bebidas alcoólicas, tabagismo, sedentarismo, alimentação inadequada.

Estudos realizados por Jernigan, em 2000, acerca do consumo de álcool e sua relação com a saúde pública, apontaram para a tendência da redução desse consumo entre os indivíduos idosos; mas, devido a características inerentes ao envelhecimento, a ingestão de doses, mesmo que reduzidas, pode aumentar os riscos de doenças relacionadas ao consumo de bebidas alcoólicas, devido à alteração do metabolismo que é inerente ao processo de envelhecimento (OMS, 2005).

A Organização Mundial de Saúde (2002) aponta que o uso de tabaco aumenta os riscos de doenças não transmissíveis, leva a perdas de capacidade funcional pelo aumento das taxas de declínio de densidade óssea, força muscular e de função respiratória. Além disso, é considerado o fator mais evitável como causa de morte prematura. O tabagismo é um dos principais fatores de risco evitáveis à saúde, podendo contribuir para o desenvolvimento de várias doenças crônicas, tais como doenças cardiovasculares, diversos tipos de câncer, doenças pulmonares obstrutivas crônicas, pneumonias e asma, problemas oculares, como catarata e cegueira, entre outras.

A alimentação não saudável - tanto do ponto de vista da desnutrição quanto do consumo em excesso de calorias - é considerada como o principal fator de risco à saúde, contribuindo para a ocorrência, por exemplo, de diabetes e pressão alta (WHO, 2002). O consumo excessivo do sal está relacionado ao aumento no risco de Doenças Crônicas Não Transmissíveis (DCNT), tais como hipertensão arterial, doenças cardiovasculares e doenças renais, e o consumo em excesso de calorias aumenta o risco de obesidade e deficiências durante o processo de envelhecimento (OMS, 2005).

A prática regular de exercícios físicos ou esportes é avaliado como fator de proteção à saúde das pessoas. É considerado um importante indicador, que pode estar relacionado à redução do surgimento de doenças crônicas. Esta prática regular, aliada à boa alimentação e a hábitos saudáveis, pode diminuir o aparecimento de doenças 
crônicas em idosos saudáveis ou doentes crônicos (OMS, 2005). Por outro lado, a falta de atividade física pode representar o declínio da capacidade funcional de pessoas idosas (CAMPOS, 2009). No mais, as atividades físicas podem ajudar os idosos a permanecerem independentes e reduzir o número de quedas, o que pode representar benefícios econômicos com relação a gastos médicos (WHO, 1998).

A Organização Mundial de Saúde levantou a questão do envelhecimento ativo, em relação à autonomia e à independência dessas pessoas e, diante disso, vem buscando destacar a importância da saúde mental e das relações sociais para o bem-estar físico, mental e social das pessoas idosas (OMS, 2005).

Assim, a incapacidade funcional está intrinsecamente relacionada a outros fatores de risco, tais como a ausência de atividades físicas e o tabagismo como apontado em Who (2002). Isso mostra a interdependência entre os fatores de risco que, em idades mais avançadas, pode causar a perda da autonomia e da independência dos idosos.

Dessa forma, como apontado por Ramos (2003), é necessária a consideração de questões que abordem a capacidade funcional dos idosos, quando se pretende medir seu estado de saúde (citado por ALVES, 2005).

A presença de doenças crônicas também pode estar relacionada à autopercepção da saúde da pessoa idosa. Damian et al. (1999) apontam que o aumento do número de doenças está relacionado com a percepção negativa da saúde.

Segundo a OMS (2005), nos países tanto desenvolvidos como em desenvolvimento, como no caso do Brasil, as doenças crônicas não transmissíveis são causas importantes e dispendiosas de deficiência e pior qualidade de vida. Assim, com o passar dos anos, estas deficiências tendem a intensificar os obstáculos no processo de envelhecimento. Alguns deles podem ser inerentes ao processo, como artrite, por exemplo, e outros poderiam ter sido evitados, como câncer de pulmão ou diabetes. Neste contexto, a OMS defende que muitas doenças crônicas podem ser evitadas ou adiadas, proporcionando um envelhecimento saudável e com menos gastos individuais e para a sociedade.

Com relação à variável arranjo familiar, na qual os indivíduos idosos podem ser classificados como morando sozinhos ou acompanhados, pode ser estruturado abarcando-se o estado conjugal e as redes sociais, denominados de capital social. Segundo Ramos (2002), o apoio familiar e social tem influência positiva no bem-estar psicológico, pela manifestação de afeição, preocupação e assistência, o que faz com que 
os idosos se sintam amparados para enfrentar os problemas de saúde inerentes ao estado de envelhecimento e isso pode impactar na autoavaliação de sua saúde.

Outro fator importante é o estado civil do indivíduo idoso. Esta variável está diretamente relacionada ao arranjo familiar que, neste sentido, também considera a presença ou não do ente familiar para auxiliar no combate à solidão.

A bibliografia traz divergências acerca do estado de saúde de pessoas idosas e o estado civil. Hartmann (2008) aponta, por exemplo, que os viúvos experimentam mais autonomia e liberdade, o que contribuiria para a melhor autopercepção da saúde. No entanto, a autora aponta também que os idosos viúvos podem apresentar maiores problemas de saúde, o que contribuiria para a percepção negativa da saúde.

Aqueles que possuem planos privados de saúde têm melhor acesso aos cuidados preventivos e utilizam mais os serviços de saúde (PAIM et al., 2011). Este fato pode influenciar na autopercepção da saúde do idoso e corrobora as desigualdades no acesso aos serviços de saúde. A existência de planos privados de saúde aponta para questões referentes à desigualdade no sistema de saúde e à autopercepção da saúde, mediante a chance de as pessoas idosas obterem algum tratamento, quando acometidas por doenças nesta fase da vida. 


\section{MATERIAL E MÉTODOS}

Este capítulo apresenta a fonte dos dados pesquisada neste trabalho, bem como a metodologia utilizada. Está dividido em duas seções: material e métodos. A primeira considera a fonte de dados, buscando descrever a base de dados explorada para os fins deste estudo. A seção de métodos traz a metodologia adotada, apresentando o modelo estatístico escolhido, a descrição das variáveis utilizadas e a modelagem dos dados, abordando com detalhes o modelo de regressão adotado para verificar a associação das variáveis explicativas com a variável dependente.

\subsection{Fonte dados - a Pesquisa Nacional de Saúde (PNS)}

Segundo Schmidt (2011), no Brasil ocorre uma modificação nos padrões de saúde e de doença, a chamada transição epidemiológica, que está relacionada com fatores demográficos, econômicos, sociais, culturais e ambientais (IBGE, 2014). Esta transição proporciona um crescimento dos agravos crônico-degenerativos que causam sofrimento, dor e incapacidade, além de provocar pressão sobre os serviços de saúde.

Diante disso, as informações sobre o que envolve o termo saúde vêm-se tornando cada vez mais importantes para o planejamento e a gestão das intervenções nesta área, sobretudo quando se consideram as mudanças do padrão epidemiológico e a investigação dos determinantes relacionados, bem como a avaliação das estratégias que visem ao alcance de maior equidade. Era mais que necessário a construção de um conjunto de indicadores que possa retratar, tanto no seu estado atual como em comparação à situação passada, a capacidade de resposta do sistema de saúde, frente às necessidades da população (IBGE, 2014).

Neste sentido, dando continuidade ao desenvolvimento de inquéritos sistemáticos, no campo da avaliação do desempenho do sistema nacional de saúde, a Pesquisa Nacional de Saúde (PNS), realizada no Brasil, em 2013, tem como um de seus principais objetivos o de suprir dados, em âmbito nacional, que permitam a elaboração de parâmetros consistentes para subsidiar a formulação de políticas públicas e o alcance da maior efetividade das ações de saúde. Trata-se de uma pesquisa com base domiciliar representativa para Brasil, Grandes Regiões, Unidades da Federação, Capitais, áreas urbanas e áreas rurais do país. Foi uma iniciativa do Ministério da Saúde (MS), em 
parceria com o Instituto Brasileiro de Geografia e Estatística (IBGE), tornando-se parte do Sistema Integrado de Pesquisas Domiciliares (SIPD) do IBGE (SIPD 2007).

Com o objetivo de identificar a situação de saúde e os estilos de vida da população, a PNS é composta por questionário domiciliar referente às características do domicílio, tanto o relativo a todos os moradores do domicílio quanto aos indivíduos, que foi respondido por morador de 18 anos ou mais de idade, selecionado com equiprobabilidade entre todos os residentes elegíveis. O trabalho de campo teve início em agosto de 2013 e foi finalizado em fevereiro de 2014. A divulgação dos módulos de estilos de vida, autopercepção da saúde e doenças crônicas ocorreu em dezembro de 2014 (DAMACENA et al., 2015).

O plano de amostragem da PNS foi desenvolvido a partir da Amostra Mestra do SIPD $^{6}$. Sendo assim, é caracterizada como uma subamostra, cuja abrangência geográfica compreende os setores censitários da Base Operacional do Censo Demográfico de 2010. A Amostra Mestra assegura infraestrutura de amostragem única para todas as pesquisas, com o fim de viabilizar a organização sistêmica das diversas fontes de dados tal como desejada.

O plano amostral, considerado complexo, foi elaborado mediante uma amostragem por conglomerados em três estágios de seleção. No primeiro estágio, foram selecionados os setores censitários das Unidades Primárias de Amostragem; no segundo estágio, foram selecionados os domicílios, por amostragem aleatória simples, de domicílios selecionados no estágio anterior; e, no terceiro estágio, por amostragem aleatória simples, foi selecionado um morador de 18 anos ou mais de idade entre todos os moradores adultos do domicílio, para responder ao questionário individual.

Para o cálculo do tamanho da amostra foram considerados: o nível de precisão, o efeito do plano de amostragem - uma vez que é amostragem por conglomerados em

\footnotetext{
${ }^{6}$ Um dos pontos fundamentais do Sistema Integrado de Pesquisas Domiciliares (SIPD) é a construção de uma estrutura amostral que atenda a todas as pesquisas domiciliares. Esta estrutura é a Amostra Mestra, definida como um conjunto de setores censitários selecionados com probabilidade proporcional a uma medida do tamanho de um Cadastro Mestre. Este é constituído pelos setores que cobrem todo o território nacional, cujos limites foram definidos pela Base Operacional Geográfica de 2000 compatibilizada com a malha municipal de 2001. A cada um dos setores foram associadas informações sobre divisões administrativas, contagens populacionais e outras características sociodemográficas obtidas no Censo Demográfico 2000. A partir da Amostra Mestra podem ser construídas subamostras de setores ou domicílios para as diversas pesquisas que compõem o SIPD.
} 
múltiplos estágios -, número de domicílios selecionados por unidades primárias e o número de domicílios com pessoas na faixa etária de interesse (SOUZA-JUNIOR et al., 2015).

A organização do trabalho de coleta de dados ocorreu sob a responsabilidade do IBGE. Todos os entrevistadores, os supervisores e coordenadores foram capacitados para compreender todos os objetivos da pesquisa e as entrevistas foram feitas com a utilização de PDAs (Personal Digital Assistance), computadores de mão, programados adequadamente para processos de crítica das variáveis.

Após o processo de seleção da amostra, a pessoa responsável ou outro morador do domicilio selecionado foi contatado. Neste contato, foi informado o escopo da pesquisa, os objetivos, a relevância da participação e foi elaborada uma lista de todos os moradores adultos do domicílio.

Foram identificados, o informante que respondeu ao questionário domiciliar e todos os moradores do domicílio, bem como o morador adulto que responderia à entrevista individual, e que seria selecionado por meio de programa de seleção aleatória no PDA. As entrevistas foram agendadas nas datas e horários mais convenientes para os informantes, prevendo-se duas ou mais visitas em cada domicílio.

Como limitações da pesquisa, podem-se citar as dificuldades inerentes a qualquer estudo de corte transversal baseado, principalmente, em relatos individuais: os efeitos de seleção da amostra e, no caso da PNS, a ausência de moradores localizados nos setores censitários especiais como quartéis, bases militares, alojamentos, acampamentos, embarcações, penitenciárias, colônias penais, presídios, cadeias, orfanatos, conventos e, mais especificamente, como limitação deste trabalho, pessoas em hospitais e asilos.

Entretanto, o Ministério da Saúde e o IBGE, com esta pesquisa ampliam o conhecimento sobre as características de saúde da população brasileira. Com isso, os profissionais, pesquisadores e agentes no setor de saúde têm em mãos um conjunto de informações que auxiliam na formulação, acompanhamento e avaliação das políticas de saúde do país.

O projeto da Pesquisa Nacional de Saúde - PNS foi aprovado pela Comissão Nacional de Ética em Pesquisa - Conep, do Conselho Nacional de Saúde - CNS, em junho de 2013. 


\subsection{Métodos}

O presente estudo possui natureza transversal, com a finalidade de identificar a associação da autopercepção de estado de saúde da pessoa idosa com o uso dos dados da PNS. Foram considerados como indivíduos idosos aqueles com 60 anos ou mais de idade. Para as análises, foi utilizado o software estatístico SPSS (Statistical Package for the Social Sciences.

O trabalho realizado compreendeu um estudo com dados secundários, respeitando-se a amostragem complexa. Assim, foi realizada a expansão da amostra para as análises multivariadas. Foram utilizadas as variáveis constantes no questionário do morador selecionado nas análises. As questões foram respondidas pelo morador de 60 anos ou mais de idade selecionado, com exceção daqueles que não possuíam condições de responder pessoalmente, por motivos de saúde física ou mental. Neste caso, outra pessoa, moradora ou não, pôde responder pelo idoso selecionado.

$\mathrm{Na}$ análise estatística será utilizada a regressão logística binária, que tem como objetivo produzir um modelo que permita a predição de valores tomados por uma variável categórica (autopercepção de saúde), a partir de outras variáveis explicativas (variáveis independentes).

A variável dependente, neste estudo, é a autopercepção de saúde, uma medida que dependerá das demais variáveis que são os determinantes sociais (variáveis independentes), associados à percepção da saúde da pessoa idosa. Assim, variações ou alterações nas variáveis independentes provocam mudanças na variável dependente, ou seja, na forma como essas pessoas percebem sua saúde.

Depara-se, aqui, com duas questões importantes: de um lado, o princípio da parcimônia, que permitiria um modelo mais estável, com um número reduzido de variáveis; e, de outro, a inclusão de todas as variáveis cientificamente relevantes para o modelo, para que se faça um controle completo dos fatores de confusão (CAMPOS, 2009). Buscou-se, neste trabalho, por um meio-termo, considerando, por esse motivo, a utilização de dez variáveis dentre as mais citadas na literatura e aquelas que tiveram significância estatística no primeiro momento das análises. Assim, as variáveis selecionadas foram organizadas em cinco grupos: variáveis sociodemográficas, região geográfica de residência, nível de escolaridade, de estilo de vida e de condição de saúde. Ressalte-se que, apesar de as regiões geográficas e escolaridade serem pertinentes ao grupo das variáveis sociodemográficas, pretende-se identificar, isoladamente, para a 
finalidade deste trabalho, se a região de moradia do indivíduo idoso, assim como seu nível mais elevado de instrução, tem algum efeito no autorrelato da saúde.

Neste trabalho, adotou-se o processo stepwise de inclusão das variáveis, sendo que cada um dos cinco grupos foi incorporado de forma sequencial no modelo, até que as variáveis de condição de saúde completassem o processo, conforme mostra o Quadro 1.

Quadro 1 - Variáveis independentes e modelos estruturados

\begin{tabular}{|c|c|c|c|c|c|}
\hline Variáveis independentes & Modelo 1 & Modelo 2 & Modelo 3 & Modelo 4 & Modelo 5 \\
\hline Informante & $\mathrm{x}$ & $\mathrm{x}$ & $\mathrm{x}$ & $\mathrm{x}$ & $\mathrm{x}$ \\
\hline \multicolumn{6}{|l|}{ Variáveis sociodemográficas } \\
\hline Idade & $\mathrm{x}$ & $\mathrm{x}$ & $\mathrm{x}$ & $\mathrm{x}$ & $\mathrm{x}$ \\
\hline Raça/cor & $\mathrm{x}$ & $\mathrm{x}$ & $\mathrm{x}$ & $\mathrm{x}$ & $\mathrm{x}$ \\
\hline \multicolumn{6}{|l|}{ Região de moradia } \\
\hline Grandes regiões geográficas & & $\mathrm{x}$ & $\mathrm{x}$ & $\mathrm{x}$ & $\mathrm{x}$ \\
\hline \multicolumn{6}{|l|}{ Escolaridade } \\
\hline Nível de instrução mais elevado & & & $\mathrm{x}$ & $\mathrm{x}$ & $\mathrm{x}$ \\
\hline \multicolumn{6}{|l|}{ Variáveis de estilo de vida } \\
\hline Consumo de bebidas alcoólicas & & & & $\mathrm{x}$ & $\mathrm{x}$ \\
\hline Tabagismo & & & & $\mathrm{x}$ & $\mathrm{x}$ \\
\hline Atividades religiosas & & & & $\mathrm{x}$ & $\mathrm{x}$ \\
\hline \multicolumn{6}{|l|}{ Variáveis de condição de saúde } \\
\hline Doenças crônicas não transmissíveis & & & & & $\mathrm{x}$ \\
\hline Capacidade funcional & & & & & $\mathrm{x}$ \\
\hline
\end{tabular}

A variável informante bem como as variáveis idade e raça/cor dos idosos estão contempladas no primeiro modelo. O modelo 2 considera a região de residência do idoso, além das variáveis utilizadas no modelo anterior. No terceiro modelo, a variável de escolaridade está contemplada, sendo somada às demais variáveis. O modelo 4 leva em consideração as variáveis de estilo de vida, tais como o consumo de bebidas alcoólicas, o hábito de fumar e a prática de atividades religiosas. No último modelo, agregam-se as variáveis de condições de saúde que abarcam as doenças crônicas não transmissíveis e a capacidade funcional dos idosos.

Por fim, estão apresentados dois modelos finais, uma para cada sexo, que contém as variáveis que foram estatisticamente significativas e que mostram a intensidade de associação com a autopercepção de saúde. 
Em seguida, serão apresentadas as variáveis que compuseram os modelos, suas características e também a descrição do modelo de regressão logística escolhido para as análises estatísticas. As informações das variáveis originais contidas no questionário da PNS se encontram reproduzidas no Apêndice A.

\subsection{Variáveis}

\section{Variável dependente:}

A variável dependente é a que se refere à autoavaliação da saúde. A questão elaborada pela PNS acerca do tema é “Como o(a) sr(a) avalia a sua saúde?”. As categorias de resposta disponíveis eram: Muito boa, boa, regular, ruim e muito ruim. Para a regressão logística binária, foi construída uma variável com duas categorias, a partir da original, na qual as percepções Muito boa e Boa refletem uma avaliação positiva e as demais, negativa.

\section{Variáveis independentes:}

As variáveis independentes estão alocadas em cinco blocos, como descrito, a seguir.

Variáveis sociodemográficas:

- $\quad$ Idade: variável contínua que compreende a idade, em anos, no momento da entrevista;

- Raça/cor: corresponde à raça ou cor da pele autodeclarada do indivíduo. Foi elaborada uma variável com três categorias: brancos; negros (pretos e pardos) e outros (amarelos e indígenas);

Variável região geográfica de residência:

- Grandes regiões geográficas: corresponde à região em que o domicílio de moradia do idoso se encontrava. Foi elaborada a partir da agregação das 27 unidades da federação apontadas no questionário e respeitada a classificação territorial definida pelo IBGE. 
Variável de escolaridade:

- $\quad$ Escolaridade: corresponde ao nível de instrução mais elevado alcançado pelo idoso ao longo da vida. A variável foi obtida através de uma variável derivada do questionário do morador e foram elaboradas cinco categorias para este trabalho:

"Até o ensino fundamental incompleto": contempla os idosos que não tinham instrução alguma e aqueles com ensino fundamental incompleto ou equivalente;

$>\quad$ "Ensino fundamental completo e ensino médio incompleto": considera os idosos que terminaram o ensino fundamental ou ensino equivalente, bem como aqueles que ingressaram no ensino médio ou ensino equivalente, porém sem tê-lo concluído;

$>$ "Ensino médio completo e ensino superior incompleto": nesta categoria os idosos concluíram o ensino médio ou ensino equivalente e não continuaram os estudos e aqueles que ingressaram no ensino superior ou ensino equivalente sem tê-lo concluído;

"Ensino superior completo": os idosos que concluíram o ensino superior.

Variáveis de estilo de vida:

Bebidas alcoólicas - compreende o estilo de vida, considerando-se o uso e a frequência de bebidas alcoólicas, definido em três categorias: idosos que não bebiam nunca, idosos que consumiam bebidas alcoólicas menos de uma vez por mês, e aqueles que bebiam uma vez ou mais por mês;

- $\quad$ Tabagismo - considera a utilização de charutos, cigarrilha, cachimbo, narguilé. A questão não considera como tabagismo aqueles que não fazem fumaça, como o rapé, nem o cigarro de maconha. Nesta questão, foram criadas três categorias: idosos que nunca haviam fumado, os idosos fumantes, e aqueles que não tinham mais este hábito; 
- $\quad$ Participação em atividades religiosas - foi verificado se as pessoas idosas compareceram a cultos ou atividades religiosas com frequência nos últimos 12 meses da entrevista. Neste item, não se considerava as situações de casamento, batizado ou enterro. As três categorias foram definidas como:

"Frequentemente": que participaram semanalmente das atividades, independentemente da frequência;

$>\quad$ "Raramente": que participaram das atividades uma ou algumas vezes durante o ano;

$>\quad$ "Não frequentava": para aqueles que afirmaram não frequentar atividades religiosas nos últimos 12 meses.

\section{Variáveis de condição de Saúde:}

- Doenças crônicas não transmissíveis: se o idoso possuía alguma doença crônica não transmissível. Foram consideradas as seguintes doenças crônicas: hipertensão arterial, diabetes, colesterol alto, doenças do coração (infarto, angina, insuficiência cardíaca ou outra), derrame ou acidente vascular cerebral, asma ou bronquite asmática, artrite ou reumatismo, problemas de coluna (como dor crônica nas costas ou no pescoço, lombalgia, dor ciática, problemas nas vértebras ou disco), doença do pulmão (enfisema pulmonar, bronquite crônica ou doença pulmonar obstrutiva crônica), câncer ou insuficiência renal crônica. As categorias foram: não possui doença alguma, possui uma doença, possui de duas a três doenças e possui mais de três das doenças crônicas consideradas;

- $\quad$ Capacidade funcional: esta variável procurou medir a capacidade funcional dos idosos por meio das dificuldades em executar algumas tarefas classificadas em AVD (atividades básicas da vida diária) e AIVD (atividades instrumentais da vida diária). Considerou-se como dependentes aqueles idosos que não conseguiam executar pelo menos uma das atividades de forma autônoma ou que tinham pequena ou muita dificuldade em qualquer uma delas; e como 
independentes aqueles que não tinham dificuldade em executar as atividades.

As atividades básicas da vida diária (AVDs) foram classificadas em:

$>\quad$ comer e beber com um prato colocado à sua frente, incluindo segurar um garfo, cortar alimentos e beber em um copo;

tomar banho incluindo entrar e sair do chuveiro ou banheira;

$>\quad$ ir ao banheiro sozinho incluindo sentar e levantar do vaso sanitário;

$>\quad$ vestir-se incluindo calçar meias e sapatos, abrir e fechar o zíper e botões;

$>\quad$ andar em casa sozinho de um cômodo a outro, em um mesmo andar, como do quarto para a sala e cozinha;

$>\quad$ deitar ou levantar-se da cama;

$>\quad$ sentar ou levantar-se da cadeira.

As atividades instrumentais da vida diária (AIVDs) foram classificadas em:

$>$ fazer compras, por exemplo, de alimentos, roupas ou medicamentos;

$>\quad$ administrar as finanças, ou seja, cuidar do próprio dinheiro;

$>\quad$ tomar os remédios;

$>\quad$ ir ao médico;

$>\quad$ sair de casa utilizando um transporte como ônibus, metrô, táxi, carro etc.

\subsection{Modelagem}

Neste trabalho será utilizado o modelo de regressão logística binária, para verificar as associações entre os determinantes sociais da saúde e a autopercepção da saúde. Este modelo relaciona um conjunto de $\mathrm{n}$ de variáveis independentes $\left(\mathrm{X}_{1}, \mathrm{X}_{2}, \ldots\right.$, $\mathrm{X}_{\mathrm{n})}$ a uma variável independente $(\mathrm{Y})$, que assume valores 0 ou 1 , e possibilita a 
estimação da probabilidade de ocorrência de um evento (Y=1) (HOSMER; LEMESHOW, 1989), conforme fórmula a seguir:

$$
\begin{gathered}
P(Y=1)=\frac{e^{(\beta 0+\beta x 1+\cdots+\beta n x n)}}{1+e^{(\beta 0+\beta x 1+\cdots+\beta n x n)}} \\
P(Y=0)=1-P(Y=1), \text { assim: } \\
P(Y=0)=\frac{1}{1+e^{(\beta 0+\beta 1 x 1+, \ldots+\beta n x n)}}
\end{gathered}
$$

onde $\beta \mathrm{i}, \mathrm{i}=1,2, \ldots, \mathrm{n}$, são os parâmetros do modelo estimados pelo método de máxima verossimilhança.

Com isso, pode-se estabelecer uma relação de dependência entre a variável resposta e o conjunto de variáveis independentes quantitativas ou qualitativas, descritas na seção anterior. Este trabalho propõe a dicotomização da variável resposta autopercepção de saúde - em positiva (muito boa e boa) e negativa (regular, ruim e muito ruim).

Uma das grandes justificativas do modelo logístico é que a exponencial do parâmetro fornece a odds ratio $(\mathrm{OR})$ ou razão de chance $(\mathrm{RC})$. Esta estatística mede a força da associação entre um determinado fator e a variável dependente. Assim, a razão de chance irá expressar quantas vezes é maior a chance de encontrar a condição analisada entre os expostos em relação aos não expostos. Além disso, o modelo de regressão logística é fácil de ser utilizado e permite uma interpretação de resultados rica e direta (HOSMER; LEMESHOW, 1989).

Dessa forma, uma razão de chance menor que 1 significa que a variável independente funciona como protetor; quando maior que 1, a variável atua como um fator de risco de autopercepção negativa da saúde. 


\section{RESULTADOS}

\subsection{Análise descritiva da população e determinantes sociais utilizados}

Neste capítulo serão apresentados os principais resultados obtidos a partir das análises realizadas. A primeira seção traz a análise descritiva (distribuição relativa) da população e dos determinantes que foram utilizados para testar a associação com a autopercepção negativa de saúde dos idosos. Em seguida, na segunda seção, estão descritos os resultados das regressões logísticas realizadas. No Apêndice B, encontramse as tabelas com os números absolutos relativos às análises descritivas realizadas, bem como as tabelas de razões de chances com os intervalos de confiança para todos os modelos, de uma forma que a comparação seja facilitada (Apêndice C).

Segundo a PNS, a população, no ano de 2013, era composta por 200,6 milhões de pessoas, sendo que 93,1 milhões, ou seja, 46,4\% possuíam menos de 30 anos de idade (Tabela 1). Pode-se observar que os percentuais diminuem à medida que a idade aumenta, independentemente do sexo do indivíduo, indicando uma população ainda jovem, sendo que $28,6 \%$ dos homens e $25,6 \%$ das mulheres tinham de 0 a 17 anos de idade; já a população idosa (60 anos ou mais de idade) era composta por $48,1 \%$ de homens e $56,4 \%$ de mulheres.

Tabela 1 - Distribuição da população por faixa etária segundo o sexo - PNS, 2013

\begin{tabular}{lccc|ccc}
\hline \multirow{2}{*}{ Faixa etária } & \multirow{2}{*}{$\begin{array}{c}\text { Total } \\
\text { população }\end{array}$} & \multicolumn{6}{c}{ Sexo (\%) } \\
\cline { 3 - 7 } & & Masculino & Feminino & Total & Masculino & Feminino \\
\hline 0 a 17 anos & 54.265 .049 & 28,6 & 25,6 & 100,0 & 51,0 & 49,0 \\
18 a 29 anos & 38.839 .368 & 20,0 & 18,8 & 100,0 & 49,7 & 50,3 \\
30 a 39 anos & 30.961 .573 & 15,2 & 15,6 & 100,0 & 47,5 & 52,5 \\
40 a 49 anos & 27.129 .450 & 13,2 & 13,9 & 100,0 & 46,9 & 53,1 \\
50 a 59 anos & 22.970 .236 & 11,1 & 11,8 & 100,0 & 46,5 & 53,5 \\
60 anos ou mais & 26.407 .831 & 11,9 & 14,3 & 100,0 & 43,6 & 56,4 \\
\hline Total & $\mathbf{2 0 0 . 5 7 3 . 5 0 7}$ & $\mathbf{1 0 0 , 0}$ & $\mathbf{1 0 0 , 0}$ & $\mathbf{1 0 0 , 0}$ & $\mathbf{4 8 , 1}$ & $\mathbf{5 1 , 9}$ \\
\hline \hline Fonte: Microdados da PNS 2013. Elaboração própria. & & & &
\end{tabular}

Em todas as faixas etárias, exceto na de 0 a 17 anos, o contingente feminino é maior, ultrapassando os $52 \%$ na faixa de 30 a 39 anos de idade e chegando a $56,4 \%$ de 
mulheres idosas contra 43,6\% de homens com idades acima de 60 anos, o que corrobora o fato da longevidade feminina.

A Tabela 2 traz o percentual de idosos em todas as regiões geográficas do país, bem como a distribuição por sexo. Ao todo, o segmento populacional composto por pessoas de 60 anos ou mais de idade compreendia 13,2\% da população do país em 2013. A concentração da população está nas regiões Nordeste e Sudeste do país que somam $70 \%$ da população residente. O número absoluto de idosos também segue esta distribuição, totalizando $73 \%$ de idosos naquelas regiões. No entanto, em termos relativos, a concentração de idosos pode ser notada nas regiões Sudeste $(15,0 \%)$ e Sul $(13,8 \%)$. Os idosos residentes na região Norte do Brasil correspondem a 8,5\% da população, o que representa o menor contingente, em termos absolutos e relativos, de idosos no país, seguido pela região Centro-Oeste $(11,3 \%)$.

Tabela 2 - Distribuição da população total e número de idosos, segundo as regiões geográficas, de acordo com o sexo - PNS, 2013

\begin{tabular}{lcc|cccc}
\hline \multirow{2}{*}{ Regiões } & \multicolumn{2}{c|}{ Populaçao total } & \multicolumn{4}{c}{ Pessoas com 60 anos ou mais de idade } \\
\cline { 2 - 7 } & Total & $\%$ & $\%$ & Total & Masculino & Feminino \\
\hline Norte & 16.720 .720 & 8,3 & 8,5 & 1.428 .558 & 47,6 & 52,4 \\
Nordeste & 55.673 .188 & 27,8 & 12,0 & 6.661 .215 & 44,1 & 55,9 \\
Sudeste & 84.511 .908 & 42,1 & 15,0 & 12.651 .274 & 42,9 & 57,1 \\
Sul & 28.776 .697 & 14,3 & 13,8 & 3.980 .813 & 43,2 & 56,8 \\
Centro-Oeste & 14.890 .994 & 7,4 & 11,3 & 1.685 .971 & 44,9 & 55,1 \\
\hline Total & $\mathbf{2 0 0 . 5 7 3 . 5 0 7}$ & $\mathbf{1 0 0 , 0}$ & $\mathbf{1 3 , 2}$ & $\mathbf{2 6 . 4 0 7 . 8 3 1}$ & $\mathbf{4 3 , 6}$ & $\mathbf{5 6 , 4}$ \\
\hline \hline Fonte: Microdados da PNS 2013. Elaboração própria.
\end{tabular}

Em todas as regiões geográficas, observa-se a predominância de idosos do sexo feminino com 60 anos ou mais de idade e, embora isso se repita em quase todas as faixas etárias (conforme visto na Tabela 1), este fato sugere a "feminização" do envelhecimento em todas as regiões.

A distribuição dos idosos, segundo a forma como eles avaliaram a saúde e de acordo com o sexo, pode ser observada na Tabela 3. No total, 43,5\% dos indivíduos avaliaram sua saúde como regular e $38,4 \%$ perceberam a saúde como boa. Estas duas categorias foram as mais presentes tanto em mulheres como em homens idosos. Observa-se, ainda, que, em níveis mais extremos de avaliação negativa da saúde, o percentual de mulheres é maior que o de homens idosos. 
Tabela 3 - Distribuição de mulheres e homens idosos, segundo a autopercepção de saúde - PNS, 2013

\begin{tabular}{|c|c|c|c|c|c|c|}
\hline \multirow{2}{*}{ Percepção de saúde } & \multicolumn{2}{|c|}{ Homens } & \multicolumn{2}{|c|}{ Mulheres } & \multicolumn{2}{|c|}{ Total } \\
\hline & $\mathrm{N}$ & $\%$ & $\mathrm{~N}$ & $\%$ & $\mathrm{~N}$ & $\%$ \\
\hline Muito boa & 707.894 & 6,1 & 887.998 & 6,0 & 1.595 .891 & 6,0 \\
\hline Boa & 4.711 .231 & 40,9 & 5.422 .031 & 36,4 & 10.133 .263 & 38,4 \\
\hline Regular & 4.842 .185 & 42,0 & 6.648 .554 & 44,7 & 11.490 .739 & 43,5 \\
\hline Ruim & 1.013 .983 & 8,8 & 1.425 .043 & 9,6 & 2.439 .027 & 9,2 \\
\hline Muito ruim & 242.340 & 2,1 & 506.571 & 3,4 & 748.911 & 2,8 \\
\hline Total & 11.517.634 & 100,0 & 14.890 .197 & 100,0 & 26.407.831 & 100,0 \\
\hline
\end{tabular}

Fonte: Microdados da PNS 2013. Elaboração própria.

A Tabela 4 traz a mesma informação da tabela anterior com a diferença na categorização das percepções de respostas relativa à qualidade da saúde percebida. Dessa forma, com duas categorias: positiva (muito boa e boa) e negativa (regular, ruim e muito ruim), pode-se notar melhor que o número de idosos é maior na avaliação mais negativa da saúde. Neste sentido, o percentual de homens idosos que autoavaliaram sua saúde de forma negativa $(52,9 \%)$ é superior ao do percentual de mulheres idosas $(44,7 \%)$, embora o número absoluto de idosas seja mais elevado.

Tabela 4 - Distribuição de mulheres e homens idosos, segundo a autopercepção agregada de saúde - PNS, 2013

\begin{tabular}{|c|c|c|c|c|c|c|}
\hline \multirow{2}{*}{ Percepção de saúde } & \multicolumn{2}{|c|}{ Homens } & \multicolumn{2}{|c|}{ Mulheres } & \multicolumn{2}{|c|}{ Total } \\
\hline & $\mathrm{N}$ & $\%$ & $\mathrm{~N}$ & $\%$ & $\mathrm{~N}$ & $\%$ \\
\hline Positiva & 5.419 .125 & 47,1 & 6.310 .029 & 42,4 & 11.729 .154 & 44,4 \\
\hline Negativa & 6.098 .509 & 52,9 & 8.580 .168 & 44,7 & 14.678 .677 & 55,6 \\
\hline Total & 11.517.634 & 100,0 & 14.890 .197 & 100,0 & 26.407 .831 & 100,0 \\
\hline
\end{tabular}

Fonte: Microdados da PNS 2013. Elaboração própria.

Em seguida, foram agregadas as percepções de saúde para homens e mulheres de acordo com o grupo de variáveis selecionadas previamente para as análises de associação. A Tabela 5 mostra as características sociodemográficas dos idosos, segundo o sexo e a autopercepção da saúde. Considerando o respondente das informações de saúde da pesquisa, observa-se que 78,5\% dos idosos selecionados na amostra foram responsáveis pelo fornecimento das respostas. Tanto para homens quanto para 
mulheres, as avaliações mais negativas de saúde foram apontadas quando o respondente era outro morador ou outra pessoa que não o próprio idoso.

Em geral, o percentual de idosos que perceberam sua saúde de forma positiva vai diminuindo conforme a idade vai aumentando. Verifica-se que a condição de percepção negativa da saúde é mais frequente nas mulheres idosas na faixa etária de 75 a 80 anos, enquanto $61,7 \%$ dos homens idosos perceberam negativamente sua saúde na faixa de 71 a 74 anos de idade.

Tabela 5 - Distribuição relativa dos idosos, segundo as variáveis sociodemográficas, de acordo com o sexo e a forma como autoavaliaram sua saúde -

PNS, 2013

\begin{tabular}{|c|c|c|c|c|c|c|c|c|c|}
\hline \multirow{3}{*}{ Variáveis Sóciodemográficas } & \multirow{2}{*}{\multicolumn{3}{|c|}{ Sexo }} & \multicolumn{6}{|c|}{ Sexo/Autopercepção da saúde } \\
\hline & & & & \multicolumn{3}{|c|}{ Mulheres } & \multicolumn{3}{|c|}{ Homens } \\
\hline & Homens & Mulheres & Total & Positiva & Negativa & Total & Positiva & Negativa & Total \\
\hline Total & 100,0 & 100,0 & 100,0 & 46,5 & 53,5 & 100,0 & 43,9 & 56,1 & 100,0 \\
\hline \multicolumn{10}{|l|}{ Informante } \\
\hline Próprio idoso & 73,6 & 82,4 & 78,5 & 47,2 & 52,8 & 100,0 & 43,9 & 56,1 & 100,0 \\
\hline Outro informante & 26,4 & 17,6 & 21,5 & 46,6 & 53,4 & 100,0 & 35,1 & 64,9 & 100,0 \\
\hline \multicolumn{10}{|l|}{ Faixa etária } \\
\hline 60 a 64 anos & 31,5 & 32,2 & 31,9 & 51,7 & 48,3 & 100,0 & 46,0 & 54,0 & 100,0 \\
\hline 65 a 70 anos & 29,3 & 28,4 & 28,8 & 48,0 & 52,0 & 100,0 & 42,7 & 57,3 & 100,0 \\
\hline 71 a 74 anos & 14,5 & 13,6 & 14,0 & 47,5 & 52,5 & 100,0 & 38,3 & 61,7 & 100,0 \\
\hline 75 a 80 anos & 13,5 & 13,7 & 13,6 & 36,9 & 63,1 & 100,0 & 38,9 & 61,1 & 100,0 \\
\hline Mais de 80 anos & 11,2 & 12,1 & 11,7 & 42,9 & 57,1 & 100,0 & 40,6 & 59,4 & 100,0 \\
\hline \multicolumn{10}{|l|}{ Raça/cor } \\
\hline Negros (pretos e pardos) & 45,7 & 44,2 & 44,9 & 40,3 & 59,7 & 100,0 & 35,9 & 64,1 & 100,0 \\
\hline Brancos & 52,7 & 54,3 & 53,6 & 52,5 & 47,5 & 100,0 & 47,7 & 52,3 & 100,0 \\
\hline Amarelos e Indígenas & 1,6 & 1,4 & 1,5 & 60,4 & 39,6 & 100,0 & 43,0 & 57,0 & 100,0 \\
\hline
\end{tabular}

Com relação à raça/cor, a maioria dos idosos negros avaliou sua saúde de forma negativa, tanto mulheres $(59,7 \%)$ quanto homens $(64,1 \%)$. Quanto aos que se declararam brancos, 52,5\% das idosas avaliaram sua saúde de forma positiva e 52,3\% dos idosos do sexo masculino, de forma negativa. As mulheres indígenas ou de etnia amarela tiveram uma percepção mais positiva da saúde $(60,4 \%)$ contra $43 \%$ dos homens idosos que eram indígenas ou amarelos.

A tabela 6 apresenta a distribuição da população idosa respondente, segundo as grandes regiões do país.

Na região Norte, $37,4 \%$ dos homens idosos e 34,7\% das mulheres responderam que a sua saúde era muito boa ou boa; no Nordeste, $37,6 \%$ dos homens e $33 \%$ das 
mulheres responderam da mesma forma. Com isso, as regiões Norte e Nordeste do país se destacam pelos menores percentuais de avaliações positivas da saúde, em ambos os sexos.

A região Sudeste se destaca pela maior concentração de avaliações positivas entre os homens $(53,2 \%)$ e este mesmo indicador é apontado para 47,6\% das mulheres idosas residentes naquela região.

Tabela 6 - Distribuição relativa dos idosos, segundo a região geográfica de residência, de acordo com o sexo e a forma como autoavaliaram sua saúde - PNS, 2013

\begin{tabular}{|c|c|c|c|c|c|c|c|c|c|}
\hline \multirow{3}{*}{ Região de residência } & \multirow{2}{*}{\multicolumn{3}{|c|}{ Sexo }} & \multicolumn{6}{|c|}{ Sexo/Autopercepção da saúde } \\
\hline & & & & \multicolumn{3}{|c|}{ Homens } & \multicolumn{3}{|c|}{ Mulheres } \\
\hline & Homens & Mulheres & Total & Positiva & Negativa & Total & Positiva & Negativa & Total \\
\hline Total & 100,0 & 100,0 & 100,0 & 47,1 & 52,9 & 100,0 & 42,4 & 57,6 & 100,0 \\
\hline Norte & 5,9 & 5,0 & 5,4 & 37,4 & 62,6 & 100,0 & 34,7 & 65,3 & 100,0 \\
\hline Nordeste & 25,5 & 25,0 & 25,2 & 37,6 & 62,4 & 100,0 & 33,0 & 67,0 & 100,0 \\
\hline Sudeste & 47,1 & 48,5 & 47,9 & 53,2 & 46,8 & 100,0 & 47,6 & 52,4 & 100,0 \\
\hline Sul & 14,9 & 15,2 & 15,1 & 47,3 & 52,7 & 100,0 & 44,4 & 55,6 & 100,0 \\
\hline Centro-Oeste & 6,6 & 6,2 & 6,4 & 47,9 & 52,1 & 100,0 & 40,1 & 59,9 & 100,0 \\
\hline
\end{tabular}

Com relação ao nível de escolaridade dos idosos, a Tabela 7 mostra que quanto mais elevado o grau de instrução dos idosos mais eles percebem de forma positiva sua saúde. Assim, 64,7\% dos idosos do sexo masculino e 70,1\% dos idosos do sexo feminino que não tinham instrução alguma avaliaram a saúde de forma negativa, contra $17,7 \%$ dos homens e $24,3 \%$ das mulheres que possuíam o ensino superior completo.

A avaliação mais negativa da saúde é mais frequente junto àqueles que não têm instrução ou não completaram o ensino fundamental, com 65,4\% das avaliações negativas apontadas pelas mulheres idosas e 59,9\% da percepção negativa apontada pelos do sexo masculino.

Entre os idosos que haviam concluído o ensino médio ou equivalente e tinham ingressado no ensino superior mas não concluíram, percebe-se uma diferença entre homens e mulheres. Para as idosas com este nível de instrução, $61 \%$ perceberam sua saúde de forma positiva, contra 56,5\% dos homens. 
Tabela 7 - Distribuição relativa dos idosos, segundo o nível de escolaridade, de acordo com o sexo e a forma como autoavaliaram sua saúde - PNS, 2013

\begin{tabular}{|c|c|c|c|c|c|c|c|c|c|}
\hline \multirow{3}{*}{ Variável socioeconômica } & \multirow{2}{*}{\multicolumn{3}{|c|}{ Sexo }} & \multicolumn{6}{|c|}{ Sexo/Autopercepção da saúde } \\
\hline & & & & \multicolumn{3}{|c|}{ Homens } & \multicolumn{3}{|c|}{ Mulheres } \\
\hline & Homens & Mulheres & Total & Positiva & Negativa & Total & Positiva & Negativa & Total \\
\hline Total & 100,0 & 100,0 & 100,0 & 47,1 & 52,9 & 100,0 & 42,4 & 57,6 & 100,0 \\
\hline Até fundamental Incompleto & 70,1 & 71,2 & 70,7 & 40,1 & 59,9 & 100,0 & 34,6 & 65,4 & 100,0 \\
\hline Sem instrução & 31,0 & 33,0 & 32,1 & 35,3 & 64,7 & 100,0 & 29,9 & 70,1 & 100,0 \\
\hline Fundamental incompleto ou equivalente & 39,1 & 38,2 & 38,6 & 43,9 & 56,1 & 100,0 & 38,7 & 61,3 & 100,0 \\
\hline Fundamental completo e Médio Incompleto & 8,5 & 7,7 & 8,0 & 49,2 & 50,8 & 100,0 & 45,8 & 54,2 & 100,0 \\
\hline Fundamental completo ou equivalente & 7,1 & 6,9 & 7,0 & 47,4 & 52,6 & 100,0 & 46,0 & 54,0 & 100,0 \\
\hline Médio incompleto ou equivalente & 1,4 & 0,8 & 1,1 & 58,0 & 42,0 & 100,0 & 44,4 & 55,6 & 100,0 \\
\hline Médio completo e Superior Incompleto & 11,0 & 12,3 & 11,7 & 56,5 & 43,5 & 100,0 & 61,0 & 39,0 & 100,0 \\
\hline Médio completo ou equivalente & 10,2 & 11,8 & 11,1 & 56,4 & 43,6 & 100,0 & 61,2 & 38,8 & 100,0 \\
\hline Superior incompleto ou equivalente & 0,8 & 0,5 & 0,6 & 57,3 & 42,7 & 100,0 & 55,9 & 44,1 & 100,0 \\
\hline Superior completo & 10,4 & 8,8 & 9,5 & 82,3 & 17,7 & 100,0 & 75,7 & 24,3 & 100,0 \\
\hline Superior completo & 10,4 & 8,8 & 9,5 & 82,3 & 17,7 & 100,0 & 75,7 & 24,3 & 100,0 \\
\hline
\end{tabular}

Levando em consideração as variáveis do grupo de estilo de vida, a Tabela 8 apresenta os números relativos da avaliação da saúde e do sexo do idoso, segundo o consumo de bebidas alcoólicas, o tabagismo e as práticas religiosas.

Tabela 8 - Distribuição relativa dos idosos, segundo as variáveis de estilo de vida, de acordo com o sexo e a forma como autoavaliaram sua saúde - PNS, 2013

\begin{tabular}{|c|c|c|c|c|c|c|c|c|c|}
\hline \multirow{3}{*}{ Variáveis de estilo de vida } & \multirow{2}{*}{\multicolumn{3}{|c|}{ Sexo }} & \multicolumn{6}{|c|}{ Sexo/Autopercepção da saúde } \\
\hline & & & & \multicolumn{3}{|c|}{ Homens } & \multicolumn{3}{|c|}{ Mulheres } \\
\hline & Homens & Mulheres & Total & Positiva & Negativa & Total & Positiva & Negativa & Total \\
\hline Total & 100,0 & 100,0 & 100,0 & 47,1 & 52,9 & 100,0 & 42,4 & 57,6 & 100,0 \\
\hline \multicolumn{10}{|l|}{ Bebidas alcóolicas } \\
\hline Não consome & 61,8 & 86,9 & 75,9 & 40,3 & 59,7 & 100,0 & 39,5 & 60,5 & 100,0 \\
\hline Menos de 1 vez por mês & 11,5 & 6,1 & 8,4 & 53,2 & 46,8 & 100,0 & 61,6 & 38,4 & 100,0 \\
\hline Uma ou mais vezes por mês & 26,6 & 7,1 & 15,6 & 60,1 & 39,9 & 100,0 & 61,1 & 38,9 & 100,0 \\
\hline \multicolumn{10}{|l|}{ Tabagismo } \\
\hline Nunca fumou & 39,3 & 69,3 & 56,2 & 51,6 & 48,4 & 100,0 & 42,3 & 57,7 & 100,0 \\
\hline Ex-fumante & 43,8 & 21,4 & 31,1 & 43,8 & 56,2 & 100,0 & 40,9 & 59,1 & 100,0 \\
\hline Fumante & 17,0 & 9,3 & 12,6 & 45,0 & 55,0 & 100,0 & 46,2 & 53,8 & 100,0 \\
\hline \multicolumn{10}{|l|}{ Atividades religiosas } \\
\hline Não frequenta & 38,1 & 23,6 & 30,0 & 46,8 & 53,2 & 100,0 & 41,5 & 58,5 & 100,0 \\
\hline Raramente frequenta & 22,8 & 17,8 & 20,0 & 44,5 & 55,5 & 100,0 & 37,3 & 62,7 & 100,0 \\
\hline Frequentemente & 39,1 & 58,6 & 50,1 & 48,8 & 51,2 & 100,0 & 44,3 & 55,7 & 100,0 \\
\hline
\end{tabular}

O hábito de consumir bebidas alcóolicas se mostrou como um comportamento predominantemente masculino, pelo qual, 38,1\% afirmaram consumir menos de uma vez ou pelo menos uma vez; por outro lado, este hábito estava presente para 13,2\% das 
mulheres. O percentual de homens idosos que não consumiam bebidas alcóolicas foi de $61,8 \%$ e de mulheres idosas, $86,9 \%$.

A percepção negativa da saúde foi apontada por $59,7 \%$ dos idosos do sexo masculino e 60,5\% dos idosos do sexo feminino. Ainda na avaliação negativa da saúde, 46,8\% dos homens e 38,4\% das mulheres que consumiam bebidas alcóolicas menos de uma vez por mês. O grupo de idosos que consumiam bebidas pelo menos uma vez por mês compreende $60,1 \%$ dos homens e $61,1 \%$ das mulheres com avaliação positiva da saúde.

Com relação ao hábito de fumar dos idosos, a maioria dos homens era exfumantes $(43,8 \%)$ e a maioria das mulheres $(69,3 \%)$ nunca tiveram o hábito de fumar.

Verifica-se que idosos, independentemente do sexo, que eram fumantes ou exfumantes, em sua maioria, perceberam sua saúde de forma negativa. Já para aqueles idosos do sexo masculino que nunca fizeram uso do tabaco, a maioria $(51,6 \%)$ avaliou a própria saúde de forma positiva, enquanto $57,7 \%$ das mulheres idosas avaliaram negativamente sua saúde.

Com relação às práticas religiosas, ou seja, a frequência a cultos ou atividades religiosas, $58,6 \%$ das mulheres tinham o hábito de frequentar regularmente, contra $39,1 \%$ dos idosos do sexo masculino.

Para 53,2\% dos idosos do sexo masculino e 58,5\% das idosas que não participavam de alguma atividade religiosa, a saúde foi avaliada de forma negativa. No entanto, a maior diferença entre os sexos pode ser notada na categoria que considera o hábito não regular. Para estes, 55,5\% dos homens e 62,7\% das mulheres perceberam de forma mais negativa a saúde.

Considerando a variável presença de doenças crônicas não transmissíveis, a Tabela 9 traz o percentual de idosos e suas percepções de saúde, de acordo com as categorias de presença de doenças crônicas.

Observa-se que 36,9\% dos idosos apresentavam de duas a três das doenças crônicas consideradas nesta análise e $23,7 \%$ afirmaram não possuir doença alguma no momento da entrevista. Percebe-se que a maioria dos homens $(57,8 \%)$ apresentou nenhuma ou uma doença crônica, enquanto a maioria das mulheres $(54,7 \%)$ possuía duas ou mais doenças crônicas não transmissíveis. 
Tabela 9 - Distribuição relativa dos idosos segundo a quantidade de doenças crônicas não transmissíveis, de acordo com o sexo e a forma como autoavaliaram sua saúde - PNS, 2013

\begin{tabular}{|c|c|c|c|c|c|c|c|c|c|}
\hline \multirow{3}{*}{ Qtde doenças crônicas não transmissíveis } & \multirow{2}{*}{\multicolumn{3}{|c|}{ Sexo }} & \multicolumn{6}{|c|}{ Sexo/Autopercepção da saúde } \\
\hline & & & & \multicolumn{3}{|c|}{ Homens } & \multicolumn{3}{|c|}{ Mulheres } \\
\hline & Homens & Mulheres & Total & Positiva & Negativa & Total & Positiva & Negativa & Total \\
\hline Total & 100,0 & 100,0 & 100,0 & 47,1 & 52,9 & 100,0 & 42,4 & 57,6 & 100,0 \\
\hline \multicolumn{10}{|l|}{ Doenças crônicas não transmissíveis } \\
\hline Nenhuma & 28,2 & 20,2 & 23,7 & 66,0 & 34,0 & 100,0 & 67,6 & 32,4 & 100,0 \\
\hline Uma & 29,6 & 25,1 & 27,1 & 50,2 & 49,8 & 100,0 & 52,3 & 47,7 & 100,0 \\
\hline Duas a três & 33,4 & 39,5 & 36,9 & 34,9 & 65,1 & 100,0 & 32,3 & 67,7 & 100,0 \\
\hline Quatro ou mais & 8,7 & 15,2 & 12,4 & 21,6 & 78,4 & 100,0 & 18,8 & 81,2 & 100,0 \\
\hline
\end{tabular}

Levando em consideração a quantidade de doenças crônicas não transmissíveis que o idoso apresentava e a sua percepção de saúde, observa-se uma correlação positiva entre o número de doenças crônicas e o maior percentual de idosos com avaliação negativa da saúde, ou seja, quanto maior o número de doenças, maior o número relativo de idosos que avaliaram negativamente sua saúde. Dessa forma, em torno de $80 \%$ dos idosos que possuíam quatro ou mais doenças, tanto do sexo masculino como feminino, avaliaram sua saúde forma negativa.

A tabela seguinte traz a distribuição das doenças crônicas não transmissíveis consideradas neste trabalho, segundo o questionário da PNS.

A hipertensão arterial foi a doença crônica mais presente, com 50,6\% dos casos, seguida pelo problema de coluna (dor crônica nas costas ou no pescoço, lombalgia, dor ciática, problemas nas vértebras ou disco), com $28,1 \%$, e pelo colesterol alto, com $24,3 \%$. A pressão alta $(54,8 \%)$ está mais presente em idosas como também os problemas de coluna $(31,2 \%)$ e o colesterol alto (30\%). Já os idosos do sexo masculino apresentaram mais doenças do coração $(12,3 \%)$, tais como infarto, angina, insuficiência cardíaca, e câncer $(6,9 \%)$ do que as mulheres idosas.

Entre os idosos do sexo masculino, as doenças que mais contribuíram para a percepção negativa da saúde foram a doença no pulmão (enfisema pulmonar, bronquite crônica ou doença pulmonar obstrutiva crônica), derrame ou AVC (Acidente Vascular Cerebral), insuficiência renal crônica e asma ou bronquite asmática. Já as doenças mais presentes nas mulheres idosas e que contribuíram para uma percepção mais pobre da saúde foram a insuficiência renal crônica, doenças do coração, diabetes e derrame ou AVC. 
Tabela 10 - Distribuição relativa dos idosos, segundo a presença doenças crônicas não transmissíveis, de acordo com o sexo e a forma como auto avaliaram sua saúde -

PNS, 2013

\begin{tabular}{|c|c|c|c|c|c|c|c|c|c|}
\hline \multirow{3}{*}{$\begin{array}{l}\text { Doenças crônicas não } \\
\text { transmissíveis }\end{array}$} & \multirow{2}{*}{\multicolumn{3}{|c|}{ Sexo }} & \multicolumn{6}{|c|}{ Sexo/Autopercepção da saúde } \\
\hline & & & & \multicolumn{3}{|c|}{ Homens } & \multicolumn{3}{|c|}{ Mulheres } \\
\hline & Homens & Mulheres & Total & Positiva & Negativa & Total & Positiva & Negativa & Total \\
\hline Total & 100,0 & 100,0 & 100,0 & 46,5 & 53,5 & 100,0 & 43,9 & 56,1 & 100,0 \\
\hline Hipertensão arterial & 45,3 & 54,8 & 50,6 & 38,2 & 61,8 & 100,0 & 33,3 & 66,7 & 100,0 \\
\hline Problema de coluna & 24,1 & 31,2 & 28,1 & 32,7 & 67,3 & 100,0 & 27,7 & 72,3 & 100,0 \\
\hline Colesterol alto & 17,0 & 30,0 & 24,3 & 37,5 & 62,5 & 100,0 & 33,3 & 66,7 & 100,0 \\
\hline Diabetes & 16,1 & 19,7 & 18,1 & 30,3 & 69,7 & 100,0 & 23,6 & 76,4 & 100,0 \\
\hline Artrite ou reumatismo & 9,7 & 21,6 & 16,4 & 29,6 & 70,4 & 100,0 & 28,2 & 71,8 & 100,0 \\
\hline Doença do coração & 12,3 & 10,7 & 11,4 & 31,0 & 69,0 & 100,0 & 19,5 & 80,5 & 100,0 \\
\hline Câncer & 6,9 & 4,5 & 5,6 & 44,4 & 55,6 & 100,0 & 36,3 & 63,7 & 100,0 \\
\hline Derrame ou AVC & 5,9 & 4,1 & 4,9 & 18,7 & 81,3 & 100,0 & 24,0 & 76,0 & 100,0 \\
\hline Asma ou bronquite asmática & 4,2 & 5,2 & 4,8 & 26,7 & 73,3 & 100,0 & 31,3 & 68,7 & 100,0 \\
\hline Doença no pulmão & 4,2 & 3,6 & 3,8 & 17,7 & 82,3 & 100,0 & 34,8 & 65,2 & 100,0 \\
\hline Insuficiência renal crônica & 3,3 & 2,4 & 2,8 & 26,7 & 73,3 & 100,0 & 12,2 & 87,8 & 100,0 \\
\hline
\end{tabular}

Quanto à capacidade funcional dos idosos, considerando as atividades básicas da vida diária (AVD) e as atividades instrumentais da vida diária (AIVD), 89,8\% dos idosos responderam não ter nenhuma dificuldade, o que os categoriza como independentes (Tabela 11).

Aproximadamente $88 \%$ dos homens com 60 anos ou mais de idade que apresentaram pelo menos uma das dificuldades avaliaram sua saúde negativamente, contra 76,4\% das idosas dependentes de AIVD e $73 \%$ das que eram dependentes de AVD e AIVD.

Tabela 11 - Distribuição relativa dos idosos segundo a capacidade funcional, de acordo com o sexo e a forma como autoavaliaram sua saúde - PNS, 2013

\begin{tabular}{|c|c|c|c|c|c|c|c|c|c|}
\hline \multirow{3}{*}{ Capacidade funcional } & \multirow{2}{*}{\multicolumn{3}{|c|}{ Sexo }} & \multicolumn{6}{|c|}{ Sexo/Autopercepção da saúde } \\
\hline & & & & \multicolumn{3}{|c|}{ Homens } & \multicolumn{3}{|c|}{ Mulheres } \\
\hline & Homens & Mulheres & Total & Positiva & Negativa & Total & Positiva & Negativa & Total \\
\hline Total & 100,0 & 100,0 & 100,0 & 47,1 & 52,9 & 100,0 & 42,4 & 57,6 & 100,0 \\
\hline \multicolumn{10}{|l|}{ Capacidade funcional } \\
\hline Dependente AIVD & 5,8 & 9,2 & 7,7 & 11,8 & 88,2 & 100,0 & 23,6 & 76,4 & 100,0 \\
\hline Dependente AVD e AIVD & 2,0 & 2,9 & 2,5 & 11,6 & 88,4 & 100,0 & 27,0 & 73,0 & 100,0 \\
\hline Independente & 92,2 & 88,0 & 89,8 & 50,1 & 49,9 & 100,0 & 44,8 & 55,2 & 100,0 \\
\hline
\end{tabular}


As Tabelas 12 e 13 apresentam a distribuição do tipo de dependência das atividades básicas e das atividades instrumentais da vida diária, respectivamente.

Tabela 12 - Distribuição dos idosos, segundo a dependência nas atividades básicas da vida diária, de acordo com o sexo e a forma como autoavaliaram sua saúde PNS, 2013

\begin{tabular}{|c|c|c|c|c|c|c|c|c|c|}
\hline \multirow{3}{*}{$\begin{array}{c}\text { Atividades básicas da vida } \\
\text { diária (AVDs) }\end{array}$} & \multirow{2}{*}{\multicolumn{3}{|c|}{ Sexo }} & \multicolumn{6}{|c|}{ Sexo/Autopercepção da saúde } \\
\hline & & & & \multicolumn{3}{|c|}{ Homens } & \multicolumn{3}{|c|}{ Mulheres } \\
\hline & Homens & Mulheres & Total & Positiva & Negativa & Total & Positiva & Negativa & Total \\
\hline Total & 100,0 & 100,0 & 100,0 & 46,5 & 53,5 & 100,0 & 43,9 & 56,1 & 100,0 \\
\hline \multicolumn{10}{|l|}{ Comer e beber } \\
\hline Dependente & 4,6 & 4,2 & 4,4 & 17,4 & 82,6 & 100,0 & 17,4 & 82,6 & 100,0 \\
\hline Independente & 95,4 & 95,8 & 95,6 & 48,5 & 51,5 & 100,0 & 43,5 & 56,5 & 100,0 \\
\hline \multicolumn{10}{|l|}{ Tomar banho } \\
\hline Dependente & 5,9 & 7,2 & 6,7 & 12,6 & 87,4 & 100,0 & 20,6 & 79,4 & 100,0 \\
\hline Independente & 94,1 & 92,8 & 93,3 & 49,2 & 50,8 & 100,0 & 44,1 & 55,9 & 100,0 \\
\hline \multicolumn{10}{|l|}{ Ir ao banheiro } \\
\hline Dependente & 4,4 & 7,0 & 5,9 & 14,9 & 85,1 & 100,0 & 20,2 & 79,8 & 100,0 \\
\hline Independente & 95,6 & 93,0 & 94,1 & 48,5 & 51,5 & 100,0 & 44,0 & 56,0 & 100,0 \\
\hline \multicolumn{10}{|l|}{ Vestir-se } \\
\hline Dependente & 8,0 & 9,4 & 8,8 & 12,1 & 87,9 & 100,0 & 15,7 & 84,3 & 100,0 \\
\hline Independente & 92,0 & 90,6 & 91,2 & 50,1 & 49,9 & 100,0 & 45,1 & 54,9 & 100,0 \\
\hline \multicolumn{10}{|l|}{ Andar em casa } \\
\hline Dependente & 6,5 & 9,0 & 7,9 & 8,9 & 91,1 & 100,0 & 18,5 & 81,5 & 100,0 \\
\hline Independente & 93,5 & 91,0 & 92,1 & 49,7 & 50,3 & 100,0 & 44,7 & 55,3 & 100,0 \\
\hline \multicolumn{10}{|l|}{ Deitar ou levantar da cama } \\
\hline Dependente & 7,0 & 9,1 & 8,2 & 13,3 & 86,7 & 100,0 & 19,5 & 80,5 & 100,0 \\
\hline Independente & 93,0 & 90,9 & 91,8 & 49,6 & 50,4 & 100,0 & 44,7 & 55,3 & 100,0 \\
\hline \multicolumn{10}{|l|}{ Sentar e levantar da cadeira } \\
\hline Dependente & 6,9 & 8,2 & 7,6 & 16,4 & 83,6 & 100,0 & 18,5 & 81,5 & 100,0 \\
\hline Independente & 93,1 & 91,8 & 92,4 & 49,3 & 50,7 & 100,0 & 44,5 & 55,5 & 100,0 \\
\hline
\end{tabular}

Fonte: Microdados da PNS 2013. Elaboração própria.

Com relação às AVDs, as prevalências de incapacidade funcional foram semelhantes para homens e mulheres idosos em todas as atividades, sendo que comer/beber e ir ao banheiro apresentaram os maiores percentuais de idosos independentes.

Em geral, a grande maioria de idosos que possuíam alguma dependência nas AVDs avaliou a saúde de forma deficitária. Quanto aos idosos do sexo masculino, 91,1\% daqueles que tinham alguma dificuldade em andar pela casa avaliaram sua saúde de forma negativa, contra $84,6 \%$ as idosas. Outra atividade que chama a atenção pelo número relativo de idosos com avaliação negativa da saúde foi a dificuldade de vestir-se sozinho ( $87,9 \%$ dos homens e $84,3 \%$ das mulheres). 
Tabela 13 - Distribuição dos idosos, segundo a dependência nas atividades instrumentais da vida diária, de acordo com o sexo e a forma como autoavaliaram sua saúde - PNS, 2013

\begin{tabular}{|c|c|c|c|c|c|c|c|c|c|}
\hline \multirow{3}{*}{$\begin{array}{l}\text { Atividades instrumentais da vida } \\
\text { diária (AIVDs) }\end{array}$} & \multirow{2}{*}{\multicolumn{3}{|c|}{ Sexo }} & \multicolumn{6}{|c|}{ Sexo/Autopercepção da saúde } \\
\hline & & & & \multicolumn{3}{|c|}{ Homens } & \multicolumn{3}{|c|}{ Mulheres } \\
\hline & Homens & Mulheres & Total & Positiva & Negativa & Total & Positiva & Negativa & Total \\
\hline Total & 100,0 & 100,0 & 100,0 & 46,5 & 53,5 & 100,0 & 43,9 & 56,1 & 100,0 \\
\hline \multicolumn{10}{|l|}{ Fazer compras } \\
\hline Dependente & 12,7 & 19,1 & 16,3 & 18,8 & 81,2 & 100,0 & 21,6 & 78,4 & 100,0 \\
\hline Independente & 87,3 & 80,9 & 83,7 & 51,2 & 48,8 & 100,0 & 47,3 & 52,7 & 100,0 \\
\hline \multicolumn{10}{|l|}{ Administrar finanças } \\
\hline Dependente & 8,9 & 13,3 & 11,4 & 16,4 & 83,6 & 100,0 & 27,3 & 72,7 & 100,0 \\
\hline Independente & 91,1 & 86,7 & 88,6 & 50,1 & 49,9 & 100,0 & 44,7 & 55,3 & 100,0 \\
\hline \multicolumn{10}{|l|}{ Tomar remédios } \\
\hline Dependente & 6,9 & 8,4 & 7,8 & 12,2 & 87,8 & 100,0 & 20,5 & 79,5 & 100,0 \\
\hline Independente & 93,1 & 91,6 & 92,2 & 49,6 & 50,4 & 100,0 & 44,4 & 55,6 & 100,0 \\
\hline \multicolumn{10}{|l|}{ Ir ao médico } \\
\hline Dependente & 17,4 & 24,3 & 21,3 & 21,6 & 78,4 & 100,0 & 24,2 & 75,8 & 100,0 \\
\hline Independente & 82,6 & 75,7 & 78,7 & 52,4 & 47,6 & 100,0 & 48,2 & 51,8 & 100,0 \\
\hline \multicolumn{10}{|l|}{$\begin{array}{l}\text { Utilizar transportes para } \\
\text { deslocamento }\end{array}$} \\
\hline Dependente & 16,3 & 23,8 & 20,5 & 19,7 & 80,3 & 100,0 & 24,3 & 75,7 & 100,0 \\
\hline Independente & 83,7 & 76,2 & 79,5 & 52,4 & 47,6 & 100,0 & 48,0 & 52,0 & 100,0 \\
\hline
\end{tabular}

Quanto às AIVDs (Tabela 13), a maioria dos idosos independentes conseguem tomar remédios sozinhos. Aqueles idosos que apresentavam alguma dificuldade em tomar seus remédios, $87,8 \%$ dos homens e 79,5\% das mulheres perceberam sua saúde de forma negativa. Outro destaque apontado pela tabela é que mesmo para aqueles idosos independentes, o ato de tomar remédios fez com que mais da metade avaliassem negativamente sua saúde.

\subsection{Determinantes da autopercepção de saúde dos idosos}

Nesta seção estão expostas as razões de chances (odds ratio) para a autopercepção negativa de saúde dos idosos. Cada tabela representa um modelo com as razões de chances e o intervalo de confiança para cada sexo. O modelo 1 apresenta as variáveis sociodemográficas representadas por idade e raça ou cor do idoso; no modelo 2 foi acrescentada a região geográfica de moradia do idoso; no modelo 3 foi considerada o nível de escolarização como variável socioeconômica; no modelo 4, além das variáveis já consideradas anteriormente, foram agregadas as variáveis que representam o estilo de 
vida do idoso, aqui sendo representado pelo consumo de bebidas alcoólicas, o tabagismo e as práticas religiosas; e no último modelo foram acrescidas as variáveis que verificam o estado de saúde, sendo avaliado pela presença de doenças crônicas não transmissíveis e a capacidade funcional dos idosos.

A Tabela 14 apresenta o primeiro modelo com as variáveis sociodemográficas e a variável informante, ou seja, as características individuais dos idosos. Observando os resultados, percebe-se que quando o respondente é outra pessoa, morador ou não, que não o próprio idoso, as mulheres com 60 anos ou mais de idade apresentaram 45\% mais chances de avaliarem negativamente a saúde que quando as respostas vêm da própria pessoa idosa.

Tabela 14 - Razões de Chances (RC) do modelo de regressão logística binária para autopercepção negativa de saúde, segundo o sexo do idoso - modelo 1, PNS 2013

\begin{tabular}{|c|c|c|c|c|}
\hline & \multicolumn{4}{|c|}{ Modelo 1} \\
\hline & \multicolumn{4}{|c|}{ Sexo/Razão de chance da autopercepção negativa de saúde } \\
\hline & \multicolumn{2}{|c|}{ Idosos do sexo masculino } & \multicolumn{2}{|c|}{ Idosos do sexo feminino } \\
\hline & $\mathrm{RC}$ & IC $95 \%$ & $\mathrm{RC}$ & IC $95 \%$ \\
\hline \multicolumn{5}{|l|}{ Informante } \\
\hline Outro informante (ref. Próprio idoso) & 1,03 & $(0,81 ; 1,32)$ & $1,45 * *$ & $(1,16 ; 1,82)$ \\
\hline Idade & $1,02 * *$ & $(1,01 ; 1,03)$ & 1,01 & $(0,99 ; 1,02)$ \\
\hline \multicolumn{5}{|l|}{ Raça/cor } \\
\hline Negros (ref. Brancos) & $1,66 * * *$ & $(1,36 ; 2,03)$ & $1,69 * * *$ & $(1,41 ; 2,01)$ \\
\hline Amarelos/Indígenas (ref. Brancos) & 0,74 & $(0,31 ; 1,77)$ & 1,20 & $(0,59 ; 2,46)$ \\
\hline
\end{tabular}

Fonte: Elaboração própria, Pesquisa Nacional de Saúde, 2013.

Nota: Significância estatística: * valor de $p<0,05$; **valor de $p<0,01$; *** valor de $p<0,001$.

A idade é tida como um fator de risco para a percepção negativa de saúde, pois quanto maior a idade, maior a chance de o idoso avaliar sua saúde de forma negativa, e isso é particularmente verdadeiro para os idosos do sexo masculino. Assim, a cada ano de vida, o homem idoso tem $2 \%$ a mais de chance de avaliar negativamente a sua saúde.

Os idosos do sexo masculino que se declararam negros tiveram $66 \%$ a mais de chance de avaliarem sua saúde de forma negativa que os idosos brancos; já as idosas têm $69 \%$ a mais de chance de perceberem negativamente sua saúde que as mulheres idosas da raça/cor branca. 
Para compor o modelo 2, apresentado na Tabela 15, foi agregado às variáveis do modelo anterior a variável de região geográfica de moradia dos idosos no momento da entrevista.

Tabela 15 - Razões de Chances (RC) do modelo de regressão logística binária para autopercepção negativa de saúde, segundo o sexo do idoso - modelo 2, PNS 2013

\begin{tabular}{|c|c|c|c|c|}
\hline & \multicolumn{4}{|c|}{ Modelo 2} \\
\hline & \multicolumn{4}{|c|}{ Sexo/Razão de chance da autopercepção negativa de saúde } \\
\hline & \multicolumn{2}{|c|}{ Idosos do sexo masculino } & \multicolumn{2}{|c|}{ Idosos do sexo feminino } \\
\hline & $\mathrm{RC}$ & IC $95 \%$ & $\mathrm{RC}$ & IC $95 \%$ \\
\hline \multicolumn{5}{|l|}{ Informante } \\
\hline Outro informante (ref. Próprio idoso) & 1,03 & $(0,80 ; 1,32)$ & $1,47 * *$ & $(1,17 ; 1,85)$ \\
\hline Idade & $1,02 * *$ & $(1,01 ; 1,03)$ & 1,01 & $(0,99 ; 1,02)$ \\
\hline \multicolumn{5}{|l|}{ Raça/cor } \\
\hline Negros (ref. Brancos) & $1,51 * * *$ & $(1,21 ; 1,88)$ & $1,51 * * *$ & $(1,25 ; 1,83)$ \\
\hline Amarelos/Indígenas (ref. Brancos) & 0,68 & $(0,28 ; 1,68)$ & 1,20 & $(0,58 ; 2,45)$ \\
\hline \multicolumn{5}{|l|}{ Região de moradia } \\
\hline Norte (ref. Sudeste) & $1,63 * *$ & $(1,13 ; 2,35)$ & $1,51 * *$ & $(1,12 ; 2,03)$ \\
\hline Nordeste (ref. Sudeste) & $1,65 * * *$ & $(1,29 ; 2,13)$ & $1,63 * * *$ & $(1,34 ; 1,99)$ \\
\hline Sul (ref. Sudeste) & $1,42 *$ & $(1,07 ; 1,90)$ & 1,25 & $(0,99 ; 1,56)$ \\
\hline Centro-Oeste (ref. Sudeste) & 1,17 & $(0,87 ; 1,56)$ & $1,31 *$ & $(1,04 ; 1,66)$ \\
\hline
\end{tabular}

Fonte: Elaboração própria, Pesquisa Nacional de Saúde, 2013.

Nota: Significância estatística: *valor de p<0,05; **valor de $p<0,01$; *** valor de $p<0,001$.

A inclusão da variável de região de residência não alterou a significância observada das variáveis raça/cor e informante, apresentadas no Modelo 1. Verifica-se, também, que os idosos do sexo masculino residentes na região Nordeste apresentaram 1,65 vezes mais chances de avaliarem negativamente sua saúde que aqueles residentes na região Sudeste. Já as idosas nordestinas apresentaram 1,63 vezes mais chances. Assim, os idosos que residiam na região Sudeste tem mais chances de avaliarem positivamente sua saúde que, principalmente, os idosos residentes nas regiões Norte e Nordeste do país.

No terceiro modelo, foi acrescentada a variável de escolaridade dos idosos, que representa o nível socioeconômico. Verifica-se que esta variável anulou o efeito da raça dos idosos. Quanto aos idosos que residem na região Nordeste que, apesar de uma 
menor chance de perceberem negativamente a saúde que no modelo 2, ainda possuem chance de $45 \%$ a mais para os homens e $60 \%$ a mais para as mulheres idosas, do que aqueles que residem na região Sudeste do país.

Tabela 16 - Razões de Chances (RC) do modelo de regressão logística binária para autopercepção negativa de saúde, segundo o sexo do idoso - modelo 3, PNS 2013

\begin{tabular}{|c|c|c|c|c|}
\hline & \multicolumn{4}{|c|}{ Modelo 3} \\
\hline & \multicolumn{4}{|c|}{ Sexo/Razão de chance da autopercepção negativa de saúde } \\
\hline & \multicolumn{2}{|c|}{ Idosos do sexo masculino } & \multicolumn{2}{|c|}{ Idosos do sexo feminino } \\
\hline & $\mathrm{RC}$ & IC $95 \%$ & $\mathrm{RC}$ & IC $95 \%$ \\
\hline \multicolumn{5}{|l|}{ Informante } \\
\hline Outro informante (ref. Próprio idoso) & 1,03 & $(0,80 ; 1,32)$ & $1,45 * *$ & $(1,15 ; 1,84)$ \\
\hline Idade & 1,01 & $(0,99 ; 1,03)$ & 1,00 & $(0,98 ; 1,01)$ \\
\hline \multicolumn{5}{|l|}{ Raça/cor } \\
\hline Negros (ref. Brancos) & 1,25 & $(0,99 ; 1,58)$ & 1,17 & $(0,97 ; 1,41)$ \\
\hline Amarelos/Indígenas (ref. Brancos) & 1,02 & $(0,31 ; 3,36)$ & 1,04 & $(0,47 ; 2,30)$ \\
\hline \multicolumn{5}{|l|}{ Região de moradia } \\
\hline Norte (ref. Sudeste) & $1,48 *$ & $(1,02 ; 2,13)$ & $1,50 * *$ & $(1,11 ; 2,03)$ \\
\hline Nordeste (ref. Sudeste) & $1,45 * *$ & $(1,11 ; 1,88)$ & $1,60 * * *$ & $(1,30 ; 1,96)$ \\
\hline Sul (ref. Sudeste) & 1,22 & $(0,91 ; 1,64)$ & $1,13 *$ & $(0,89 ; 1,43)$ \\
\hline Centro-Oeste (ref. Sudeste) & 1,06 & $(0,79 ; 1,43)$ & 1,30 & $(1,02 ; 1,66)$ \\
\hline \multicolumn{5}{|l|}{ Escolaridade } \\
\hline Fund. Completo e Med. Incompleto (ref. Até Ensino Fund. Incompleto) & 0,75 & $(0,50 ; 1,1)$ & $0,66 *$ & $(0,50 ; 0,88)$ \\
\hline Med. Completo e Sup. Incompleto (ref. Até Ensino Fund. Incompleto) & $0,59 * *$ & $(0,43 ; 0,80)$ & $0,36 * * *$ & $(0,28 ; 0,46)$ \\
\hline Superior completo (ref. Até Ensino Fund. Incompleto) & $0,17 * * *$ & $(0,11 ; 0,27)$ & $0,19 * * *$ & $(0,14 ; 0,25)$ \\
\hline
\end{tabular}

Fonte: Elaboração própria, Pesquisa Nacional de Saúde, 2013.

Nota: Significância estatística: *valor de $p<0,05$; ** valor de $p<0,01$; ***valor de $p<0,001$.

Tanto para idosos do sexo masculino quanto para do sexo feminino, as chances de avaliarem a saúde de forma negativa são menores, na medida em que o nível de escolaridade é mais elevado. Com isso, os idosos do sexo masculino e do sexo feminino que possuíam ensino superior completo têm $83 \%$ e $81 \%$, respectivamente, menos chance de avaliarem negativamente sua saúde, em relação àqueles idosos com até ensino fundamental incompleto como nível mais elevado de grau de instrução.

No modelo 4 (Tabela 17) foram acrescidas três variáveis que representam o estilo de vida dos idosos: o consumo de bebidas alcoólicas, o hábito de fumar e as práticas de culto ou religião. 
Tabela 17 - Razões de Chances (RC) do modelo de regressão logística binário para autopercepção negativa de saúde, segundo o sexo do idoso - modelo 4, PNS 2013

\begin{tabular}{|c|c|c|c|c|}
\hline & \multicolumn{4}{|c|}{ Modelo 4} \\
\hline & \multicolumn{4}{|c|}{ Sexo/Razão de chance da autopercepção negativa de saúde } \\
\hline & \multicolumn{2}{|c|}{ Idosos do sexo masculino } & \multicolumn{2}{|c|}{ Idosos do sexo feminino } \\
\hline & $\mathrm{RC}$ & IC $95 \%$ & $\mathrm{RC}$ & IC $95 \%$ \\
\hline \multicolumn{5}{|l|}{ Informante } \\
\hline Outro informante (ref. Próprio idoso) & 1,01 & $(0,79 ; 1,31)$ & $1,45 * *$ & $(1,15 ; 1,84)$ \\
\hline Idade & 1,01 & $(0,99 ; 1,02)$ & 0,99 & $(0,98 ; 1,00)$ \\
\hline \multicolumn{5}{|l|}{ Raça/cor } \\
\hline Negros (ref. Brancos) & 1,23 & $(0,97 ; 1,56)$ & 1,20 & $(0,99 ; 1,45)$ \\
\hline Amarelos/Indígenas (ref. Brancos) & 0,90 & $(0,29 ; 2,75)$ & 1,01 & $(0,45 ; 2,26)$ \\
\hline \multicolumn{5}{|l|}{ Região de moradia } \\
\hline Norte (ref. Sudeste) & 1,39 & $(0,97 ; 1,98)$ & $1,45 *$ & $(1,06 ; 1,98)$ \\
\hline Nordeste (ref. Sudeste) & $1,45 * *$ & $(1,11 ; 1,89)$ & $1,53 * * *$ & $(1,24 ; 1,88)$ \\
\hline Sul (ref. Sudeste) & 1,27 & $(0,94 ; 1,73)$ & 1,16 & $(0,91 ; 1,47)$ \\
\hline Centro-Oeste (ref. Sudeste) & 1,08 & $(0,79 ; 1,47)$ & $1,28 *$ & $(1,01 ; 1,64)$ \\
\hline \multicolumn{5}{|l|}{ Escolaridade } \\
\hline Fund. Completo e Med. Incompleto (ref. Até Ensino Fund. Incompleto) & 0,81 & $(0,54 ; 1,22)$ & $0,68 * *$ & $(0,52 ; 0,90)$ \\
\hline Med. Completo e Sup. Incompleto (ref. Até Ensino Fund. Incompleto) & $0,61 * *$ & $(0,44 ; 0,83)$ & $0,39 * * *$ & $(0,31 ; 0,50)$ \\
\hline Superior completo (ref. Até Ensino Fund. Incompleto) & $0,19 * * *$ & $(0,12 ; 0,30)$ & $0,20 * * *$ & $(0,15 ; 0,27)$ \\
\hline \multicolumn{5}{|l|}{ Consumo de bebidas alcóolicas } \\
\hline Menos de 1 vez por mês (ref. Não consome) & $0,68 *$ & $(0,50 ; 0,93)$ & $0,51 * * *$ & $(0,37 ; 0,72)$ \\
\hline Uma ou mais vezes por mês (ref. Não consome) & $0,51 * * *$ & $(0,39 ; 0,66)$ & $0,56 * *$ & $(0,39 ; 0,80)$ \\
\hline \multicolumn{5}{|l|}{ Tabagismo } \\
\hline Fumante (Nunca fumou) & 1,28 & $(0,94 ; 1,74)$ & 0,83 & $(0,61 ; 1,12)$ \\
\hline Ex-fumante (Nunca fumou) & $1,45 * *$ & $(1,15 ; 1,83)$ & 0,94 & $(0,76 ; 1,17)$ \\
\hline \multicolumn{5}{|l|}{ Atividades religiosas } \\
\hline Não frequenta (ref. Frequentemente) & 1,26 & $(0,95 ; 1,65)$ & 1,15 & $(0,93 ; 1,41)$ \\
\hline Raramente (ref. Frequentemente) & 1,07 & $(0,80 ; 1,43)$ & 1,26 & $(0,99 ; 1,62)$ \\
\hline
\end{tabular}

Fonte: Elaboração própria, Pesquisa Nacional de Saúde, 2013.

Nota: Significância estatística: * valor de $p<0,05 ; * *$ valor de $p<0,01 ; * * *$ valor de $p<0,001$.

A percepção de saúde dos idosos masculinos residente na região Nordeste não sofreu alteração, quando da inclusão das variáveis de estilo de vida no modelo de regressão. Considerando o nível de escolaridade elevado, também continuam percebendo de forma mais positiva a saúde, quando possuem maior escolarização. Os idosos do sexo masculino que consumiam bebidas alcoólicas uma ou mais vezes por mês se mostrou significativo e apresentaram $49 \%$ menos chances de avaliarem sua saúde de forma negativa, do que aqueles que não consumiam bebidas alcoólicas. Os 
homens que eram ex-fumantes tinham $45 \%$ de chance a mais de autoavaliarem negativamente a saúde do que os que nunca haviam feito uso do tabaco.

Com relação às mulheres idosas, houve uma redução nas chances de avaliarem mal a saúde, em todas as regiões geográficas, em relação ao modelo anterior e após a inclusão das variáveis de estilo de vida. As idosas que consumiam bebidas alcoólicas apresentaram menores chances de avaliarem de forma negativa a saúde do que aquelas que não consumiam. A Tabela 18 apresenta o modelo 5 que engloba, também, as variáveis de condição de saúde - doenças crônicas não transmissíveis e capacidade funcional dos idosos.

Quando incluídas as variáveis de condição de saúde, aqueles idosos do sexo masculino que residiam na região Nordeste do país também apresentaram uma chance maior de avaliarem negativamente a saúde. As mulheres idosas residentes nas regiões Norte e Nordeste apresentaram uma maior chance de percepção negativa de saúde no modelo 5, em relação ao modelo anterior, que não considerava as variáveis de condição de saúde.

Para as mulheres, as chances de relatarem negativamente a saúde não apresentaram diferenças significativas, comparando-se ao modelo anterior, em relação ao consumo de bebidas alcoólicas. Já a variável de prática de atividades religiosas se mostrou significativa para as mulheres e, depois de incorporadas as variáveis de saúde ao modelo, as chances de relatarem de forma negativa a saúde foram maiores para aquelas que não frequentavam ou frequentaram raramente alguma prática religiosa do que aquelas que frequentaram regularmente.

As chances de relatarem negativamente a saúde aumentam tanto para idosos do sexo masculino quanto feminino, na medida em que aumentam o número de doenças crônicas não transmissíveis, embora para as mulheres idosas esta chance seja menor que nos idosos masculinos.

A capacidade funcional se mostrou uma variável que se associa com a percepção negativa da saúde de forma diferente para homens e mulheres. Os homens com alguma dependência, seja nas atividades da vida diária ou nas atividades instrumentais da vida diária, apresentam mais chances de perceberem negativamente sua saúde, enquanto entre as idosas esta chance é menor que 2. 
Tabela 18 - Razões de Chances (RC) do modelo de regressão logística binário para autopercepção negativa de saúde, segundo o sexo do idoso - modelo 5, PNS 2013

\begin{tabular}{|c|c|c|c|c|}
\hline & \multicolumn{4}{|c|}{ Modelo 5} \\
\hline & \multicolumn{4}{|c|}{ Sexo/Razão de chance da autopercepção negativa de saúde } \\
\hline & \multicolumn{2}{|c|}{ Idosos do sexo masculino } & \multicolumn{2}{|c|}{ Idosos do sexo feminino } \\
\hline & $\mathrm{RC}$ & IC 95\% & $\mathrm{RC}$ & IC 95\% \\
\hline \multicolumn{5}{|l|}{ Informante } \\
\hline Outro informante (ref. Próprio idoso) & 0,91 & $(0,68 ; 1,21)$ & $1,44 * *$ & $(1,11 ; 1,87)$ \\
\hline Idade & 0,99 & $(0,98 ; 1,01)$ & $0,98 * *$ & $(0,97 ; 0,99)$ \\
\hline \multicolumn{5}{|l|}{ Raça/cor } \\
\hline Negros (ref. Brancos) & 1,27 & $(0,99 ; 1,64)$ & 1,21 & $(0,98 ; 1,50)$ \\
\hline Amarelos/Indígenas (ref. Brancos) & 1,08 & $(0,41 ; 2,86)$ & 0,93 & $(0,35 ; 2,48)$ \\
\hline \multicolumn{5}{|l|}{ Região de moradia } \\
\hline Norte (ref. Sudeste) & $1,90 * *$ & $(1,27 ; 2,83)$ & $1,73 * *$ & $(1,24 ; 2,41)$ \\
\hline Nordeste (ref. Sudeste) & $1,91 * * *$ & $(1,46 ; 2,50)$ & $1,61 * * *$ & $(1,26 ; 2,06)$ \\
\hline Sul (ref. Sudeste) & 1,24 & $(0,90 ; 1,70)$ & 1,02 & $(0,79 ; 1,32)$ \\
\hline Centro-Oeste (ref. Sudeste) & 1,17 & $(0,83 ; 1,65)$ & 1,18 & $(0,91 ; 1,53)$ \\
\hline \multicolumn{5}{|l|}{ Escolaridade } \\
\hline Fund. Completo e Med. Incompleto (ref. Até Ensino Fund. Incompleto) & 0,83 & $(0,52 ; 1,32)$ & $0,71 *$ & $(0,53 ; 0,96)$ \\
\hline Med. Completo e Sup. Incompleto (ref. Até Ensino Fund. Incompleto) & $0,58 * *$ & $(0,41 ; 0,82)$ & $0,39 * * *$ & $(0,30 ; 0,51)$ \\
\hline Superior completo (ref. Até Ensino Fund. Incompleto) & $0,16 * * *$ & $(0,09 ; 0,26)$ & $0,21 * * *$ & $(0,16 ; 0,29)$ \\
\hline \multicolumn{5}{|l|}{ Consumo de bebidas alcóolicas } \\
\hline Menos de 1 vez por mês (ref. Não consome) & 0,76 & $(0,54 ; 1,07)$ & $0,55 * *$ & $(0,38 ; 0,80)$ \\
\hline Uma ou mais vezes por mês (ref. Não consome) & $0,58 * * *$ & $(0,43 ; 0,76)$ & $0,53 * *$ & $(0,37 ; 0,76)$ \\
\hline \multicolumn{5}{|l|}{ Tabagismo } \\
\hline Fumante (Nunca fumou) & 1,24 & $(0,91 ; 1,71)$ & 0,83 & $(0,61 ; 1,13)$ \\
\hline Ex-fumante (Nunca fumou) & 1,10 & $(0,85 ; 1,41)$ & 0,76 & $(0,60 ; 0,96)$ \\
\hline \multicolumn{5}{|l|}{ Atividades religiosas } \\
\hline Não frequenta (ref. Frequentemente) & 1,38 & $(1,03 ; 1,85)$ & $1,23 *$ & $(0,99 ; 1,53)$ \\
\hline Raramente (ref. Frequentemente) & 1,07 & $(0,79 ; 1,43)$ & 1,36 & $(1,05 ; 1,77)$ \\
\hline \multicolumn{5}{|l|}{ Doenças crônicas não transmissíveis } \\
\hline Uma doença (ref. Nenhuma doença) & $2,13 * * *$ & $(1,57 ; 2,88)$ & $1,89 * * *$ & $(1,43 ; 2,50)$ \\
\hline Duas a três doenças (ref. Nenhuma doença) & $5,00 * * *$ & $(3,68 ; 6,79)$ & $4,63 * * *$ & $(3,59 ; 5,97)$ \\
\hline Quatro a mais doenças (ref. Nenhuma doença) & $9,67 * * *$ & $(6,02 ; 15,53)$ & $9,33 * * *$ & $(6,29 ; 13,84)$ \\
\hline \multicolumn{5}{|l|}{ Capacidade funcional } \\
\hline Dependente AVD e AIVD (ref. Independente) & $5,46 * * *$ & $(3,03 ; 9,83)$ & $1,74 *$ & $(1,11 ; 2,72)$ \\
\hline Dependente AIVD (ref. Independente) & $4,99 * *$ & $(1,62 ; 15,36)$ & 1,26 & $(0,61 ; 2,60)$ \\
\hline
\end{tabular}

Por fim, as Tabelas 19 e 20 apresentam os modelos finais - para homens e mulheres, respectivamente - com as variáveis que foram significativas em relação 
à autopercepção de saúde dos idosos, com as razões de chances e intervalos de confiança.

Tabela 19 - Razões de Chances (RC) do modelo de regressão logística binário para autopercepção negativa de saúde - idosos do sexo masculino - modelo final, PNS 2013

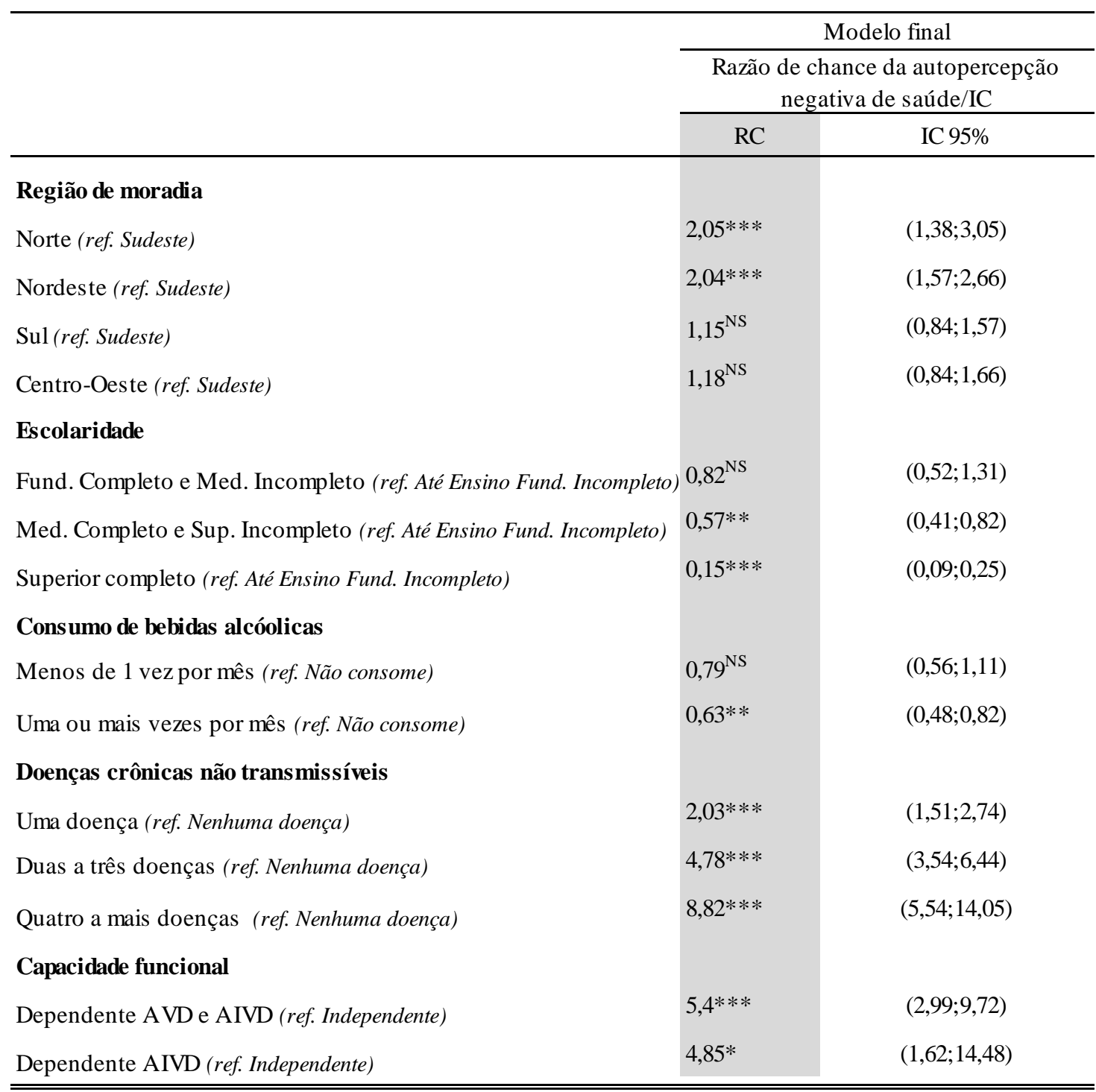

Fonte: Elaboração própria, Pesquisa Nacional de Saúde, 2013.

Nota: Significância estatística: * valor de p<0,05; ** valor de $p<0,01$; *** valor de $p<0,001$; NS: não significativo.

Para os idosos do sexo masculino, os fatores que estavam associados à percepção de saúde foram: a região de moradia (especificamente Norte e Nordeste), o nível de escolaridade (a partir do ensino médio completo), o consumo de bebidas alcoólicas (consumo de uma ou mais vezes por mês), as doenças crônicas não transmissíveis e a capacidade funcional (Tabela 19). 
É possível observar que os idosos do sexo masculino que residiam nas regiões Norte e Nordeste do país tinham duas vezes mais chances que aqueles que residiam na região Sudeste de relatarem sua saúde de forma negativa.

Por outro lado, aqueles idosos com no mínimo ensino médio completo perceberam sua saúde de forma positiva os demais, chegando a $85 \%$ de chance a menor de relatarem a saúde de forma deficitária quando possuíam o ensino superior completo.

A percepção negativa de saúde dos homens que consumiam bebidas alcoólicas foi menor que para aqueles que não consumiam, cerca de $40 \%$ a menos de chance.

Os fatores relacionados à saúde do idoso - doenças crônicas e capacidade funcional - foram aquelas que mais influenciaram na percepção de saúde dos idosos do sexo masculino. Observa-se que conforme aumentam os números de doenças, maiores foram as chances dos homens perceberem sua saúde de forma negativa, chegando a 8,82 vezes a mais para os idosos com quatro ou mais doenças, em relação àqueles com nenhuma doença crônica não transmissível.

A incapacidade funcional também se mostrou associada à percepção de saúde. Idosos com dependência nas atividades instrumentais de vida diária tiveram quase cinco vezes mais chances de autopercepção negativa da saúde.

Para os idosos do sexo feminino, os fatores que estavam associados à percepção de saúde foram: a condição de o idoso ser o informante, a idade, a região de moradia (especificamente Norte e Nordeste), o nível de escolaridade (a partir do ensino médio completo), o consumo de bebidas alcoólicas, as práticas religiosas, as doenças crônicas não transmissíveis e a capacidade funcional (Tabela 20).

As mulheres que não puderam avaliar sua saúde e outro informante o fez, apresentaram $42 \%$ a mais de chances de relatos negativos de saúde.

A idade também foi um fator associado à percepção de saúde das mulheres. Os dados mostraram que quanto maior a idade menor a chance de avaliar negativamente a saúde.

As idosas residentes nas regiões Norte e Nordeste apresentaram mais chances de perceberem de forma negativa a saúde, sendo, respectivamente, $78 \%$ e $64 \%$ a mais de chances que para aqueles que residiam na região Sudeste do país.

Com relação à escolaridade das idosas, quando maior o nível educacional, menor a chance de relatos negativos da saúde, sendo de $79 \%$ a menos de chances de percepção negativa quando a idosa tinha o ensino superior completo. 
Tabela 20 - Razões de Chances (RC) do modelo de regressão logística binário para autopercepção negativa de saúde - idosos do sexo feminino - modelo final, PNS 2013

\begin{tabular}{|c|c|c|}
\hline & \multirow{2}{*}{\multicolumn{2}{|c|}{$\begin{array}{c}\text { Modelo final } \\
\text { Razão de chance da autopercepção } \\
\text { negativa de saúde }\end{array}$}} \\
\hline & & \\
\hline & $\mathrm{RC}$ & IC $95 \%$ \\
\hline \multicolumn{3}{|l|}{ Informante } \\
\hline Outro informante (ref. Próprio idoso) & $1,42^{*}$ & $(1,10 ; 1,86)$ \\
\hline Idade & $0,98^{*}$ & $(0,98 ; 0,99)$ \\
\hline \multicolumn{3}{|l|}{ Região de moradia } \\
\hline Norte (ref. Sudeste) & $1,78^{* * *}$ & $(1,30 ; 2,44)$ \\
\hline Nordeste (ref. Sudeste) & $1,64^{* * *}$ & $(1,30 ; 2,08)$ \\
\hline Sul (ref. Sudeste) & $0,98^{\mathrm{NS}}$ & $(0,76 ; 1,27)$ \\
\hline Centro-Oeste (ref. Sudeste) & $1,18^{\mathrm{NS}}$ & $(0,91 ; 1,53)$ \\
\hline \multicolumn{3}{|l|}{ Escolaridade } \\
\hline Fund. Completo e Med. Incompleto (ref. Até Ensino Fund. Incompleto) & $0,72^{*}$ & $(0,53 ; 0,97)$ \\
\hline Med. Completo e Sup. Incompleto (ref. Até Ensino Fund. Incompleto) & $0,38^{* * *}$ & $(0,29 ; 0,50)$ \\
\hline Superior completo (ref. Até Ensino Fund. Incompleto) & $0,21^{* * *}$ & $(0,15 ; 0,28)$ \\
\hline \multicolumn{3}{|l|}{ Consumo de bebidas alcóolicas } \\
\hline Menos de 1 vez por mês (ref. Não consome) & $0,54^{* *}$ & $(0,37 ; 0,79)$ \\
\hline Uma ou mais vezes por mês ( ref. Não consome) & $0,52^{\star * *}$ & $(0,36 ; 0,74)$ \\
\hline \multicolumn{3}{|l|}{ Atividades religiosas } \\
\hline Não frequenta (ref. Frequentemente) & $1,20^{*}$ & $(1,44 ; 2,52)$ \\
\hline Raramente (ref. Frequentemente) & $1,35^{\star}$ & $(3,54 ; 5,90)$ \\
\hline \multicolumn{3}{|l|}{ Doenças crônicas não transmissíveis } \\
\hline Uma doença (ref. Nenhuma doença) & $1,90^{* * *}$ & $(1,44 ; 2,52)$ \\
\hline Duas a três doenças (ref. Nenhuma doença) & $4,60^{\star \star \star}$ & $(3,54 ; 5,90)$ \\
\hline Quatro a mais doenças (ref. Nenhuma doença) & $9,02^{\star * *}$ & $(6,04 ; 13,47)$ \\
\hline \multicolumn{3}{|l|}{ Capacidade funcional } \\
\hline Dependente AVD e AIVD (ref. Independente) & $1,72^{*}$ & $(1,10 ; 2,69)$ \\
\hline Dependente AIVD (ref. Independente) & $1,29^{\mathrm{NS}}$ & $(0,61 ; 2,69)$ \\
\hline
\end{tabular}

Fonte: Elaboração própria, Pesquisa Nacional de Saúde, 2013.

Nota: Significância estatística: * valor de p<0,05; ** valor de $p<0,01$; *** valor de p<0,001; NS: não significativo.

No modelo final, o consumo de bebidas alcoólicas se mostrou significativo para as mulheres sendo que para aqueles que consumiam as chances de autopercepção negativa de saúde foi menor que para aqueles que não consumiam bebidas alcoólicas. 
Com relação às práticas religiosas, as idosas que não frequentavam ou que frequentavam raramente tiveram mais chances de percepção negativa da saúde que aquelas que realizavam esta prática frequentemente.

A presença de doenças crônicas não transmissíveis se mostrou como um fator determinante na percepção de saúde das idosas. Para aquelas com quatro ou mais doenças crônicas, a chance de relato negativo de saúde foi de 9 vezes a mais que para aqueles sem doença alguma.

Neste trabalho algumas diferenças entre os fatores associados às percepções de saúde dos idosos do sexo masculino e feminino foram observadas.

Primeiro o informante da pesquisa bem como a idade do idoso só interferiu na percepção de saúde dos idosos do sexo feminino. Os idosos do sexo masculino residentes nas regiões Norte e Nordeste do país apresentaram mais chances de relatos negativos que as idosas destas regiões.

As variáveis de escolaridade e o hábito de consumir bebidas alcoólicas tiveram comportamentos semelhantes para os homens e mulheres. Para aqueles com níveis mais elevados de escolarização, a percepção negativa de saúde foi menor; da mesma forma que para aqueles que consumiam bebidas alcoólicas mais de uma por mês.

A prática de atividades religiosas somente teve impacto na percepção de saúde das mulheres idosas, sendo que para aquelas mulheres que raramente frequentavam algum evento religioso a chance de perceberem a saúde de forma negativa era maior.

Os dados mostram que a presença de doenças crônicas não transmissíveis e as incapacidades funcionais foram as que apresentaram maiores impactos na percepção de saúde dos idosos. Os homens tiveram maiores chances de relatarem a saúde de forma negativa que as mulheres quando da presença de doenças crônicas, exceto para aqueles com quatro ou mais doenças. Neste caso a chance das idosas foi mais elevada que dos homens.

A incapacidade funcional afetou principalmente os idosos do sexo masculino com mais chances de percepção negativa da saúde quando dependentes nas atividades instrumentais da vida diária, que para as idosas do sexo feminino. 


\section{DISCUSSÃO}

A Pesquisa Nacional de Saúde apontou que a população idosa, objeto deste estudo, constituía 26,4 milhões de pessoas, o que representava $13,2 \%$ da população do país, em 2013, sendo que 43,6\% eram homens e 56,4 mulheres com 60 anos ou mais de idade. A maior parte da população estava concentrada nas regiões Nordeste e Sudeste do Brasil e, em termos relativos, a população idosa se concentrava nas regiões Sudeste e Sul do país, seguindo as projeções para 2030 (IBGE, 2013). No entanto, as regiões Centro-Oeste e Norte do país terão as maiores taxas de crescimento do número de idosos, em 2030, com relação ao ano de 2000.

Neste trabalho identificou-se que 55,6\% dos idosos avaliaram a própria saúde de forma negativa. Este resultado diverge de alguns trabalhos como de Confortin et al (2015) que identificou a prevalência de avaliações positivas de saúde de 52,2\% quando avaliados os idosos do Sul do Brasil. Esta divergência pode estar relacionada na forma de categorização da variável de percepção de saúde, na forma de como foi realizada a pesquisa.

A maior parte dos idosos $(78,5 \%)$ respondeu às questões da pesquisa, sendo que apenas $21,5 \%$ dos respondentes eram compostos por outras pessoas. Com relação à avaliação da saúde do idoso com informações fornecidas por outras pessoas, 53,4\% das mulheres e 64,9\% dos homens tiveram avaliação negativa da saúde. Este resultado é semelhante ao encontrado por Campos (2009) com a pesquisa de autoavaliação de saúde de idosos do município de São Paulo. No entanto, independentemente de o idoso ser o informante, em geral o percentual de idosos com percepção positiva da sua saúde, em geral, diminuiu conforme a idade foi aumentando.

Observou-se também que os idosos negros, ou seja, aqueles que se declararam da cor de pele preta ou parda, tanto do sexo masculino $(59,7 \%)$ quanto do sexo feminino $(64,1 \%)$, realizaram a avaliação de sua saúde de forma negativa mais que os idosos que se declararam brancos, e os idosos, tanto homens como mulheres, residentes nas regiões Norte e Nordeste do país se destacam pelos menores percentuais de avaliações positivas da saúde.

A autopercepção negativa de saúde foi associada à baixa escolaridade do idoso. Observou-se que quanto maior o grau de escolaridade dos idosos, tanto do sexo masculino quanto do feminino, melhor era a avaliação da própria saúde. Este fato foi 
encontrado também por Campos, (2009) no qual idosos com nenhum ano de estudo apresentaram mais chances de avaliar negativamente que aqueles com mais de 8 anos de estudos. Níveis elevados de escolarização fornecem mais acesso à informação e, com isso, mais poder de decisão, de escolhas, tais como hábitos saudáveis de alimentação e melhor qualidade de vida, principalmente devido à escolarização estar associada à renda Robert (2009).

Observou-se a predominância do hábito de consumir bebidas alcoólicas e o tabagismo entre idosos do sexo masculino, sendo que $60,1 \%$ daqueles que consumiam bebidas alcoólicas uma vez ou mais por mês perceberam de forma positiva a saúde. Por outro lado, as práticas religiosas eram mais predominantes entre as idosas $(58,6 \%)$, sendo que $62,7 \%$ das idosas que não tinham esse hábito regular avaliaram negativamente sua saúde.

Outra correlação positiva pode ser observada, quando se considerou a quantidade de doenças crônicas não transmissíveis das quais as pessoas idosas alegavam ser portadoras. Com isso, quanto maior o número de doenças crônicas, maior o percentual de idosos que avaliaram de forma negativa a saúde. As doenças do pulmão, o derrame, a insuficiência renal crônica e asma ou bronquite asmática foram as mais presentes e as que mais contribuíram para a percepção negativa da saúde dos idosos do sexo masculino. Para as idosas, a avaliação negativa da saúde foi recorrente para a maioria que possuía insuficiência renal crônica, doenças do coração, diabetes e derrame.

A capacidade funcional dos idosos também foi um determinante de avaliação negativa da saúde. A maioria dos idosos que relataram ter alguma dependência avaliou a saúde de forma deficitária. As atividades de andar pela casa e tomar os medicamentos sozinhos foram destaques para avaliação negativa da saúde tanto para homens quanto para mulheres.

No presente estudo, as mulheres idosas que responderam à pesquisa a respeito de sua própria condição, tiveram menos chance de avaliar a saúde de forma negativa, quando comparadas com as avaliações que foram respondidas por outra pessoa que não a própria idosa. Para os idosos do sexo masculino, esta variável não foi significativa, ou seja, as avaliações de saúde não fizeram diferença se respondidas pelo próprio idoso ou por outra pessoa.

Tanto para homens quanto para mulheres, a variável idade se mostrou significativa, sendo que quanto maior a idade maior a chance de avaliar de forma negativa a própria saúde, apenas quando controlado por informante, e raça ou cor da 
pele do idoso. Dachs (2002) identificou, no estudo dos determinantes das desigualdades na autopercepção de saúde pela PNAD 1998, que a idade é um determinante do estado de saúde, uma vez que a probabilidade de relatos de saúde ruim aumentava a partir dos 65 anos de idade. No entanto, as variáveis região de residência, escolaridade, de estilo de vida e de saúde anularam o efeito da idade na percepção de saúde, tanto para homens quanto para mulheres idosas.

Os idosos negros, tanto do sexo masculino quanto feminino, também perceberam de forma negativa a própria saúde, quando consideradas as variáveis sociodemográficas e de região de residência. A escolaridade, por exemplo, anulou o efeito da raça na percepção de saúde dos idosos, como ocorrido com a idade.

Para mais de $70 \%$ da população respondente, o nível mais elevado de instrução foi o do ensino fundamental incompleto. Para os idosos do sexo masculino, o nível de escolarização foi um determinante de percepção negativa de saúde, principalmente para aqueles residentes nas regiões Norte e Nordeste do país. Já para as idosas que residiam nestas regiões bem como na região Sul apresentaram mais chances de perceberem negativamente a própria saúde, quando controlado pela escolarização das mulheres idosas. Em ambos os sexos, o nível mais elevado de escolaridade se mostrou significativamente relacionado com uma menor percepção negativa de saúde.

O consumo de bebidas alcoólicas se mostrou significativo para uma percepção positiva de saúde de homens e mulheres. O tabagismo se mostrou relacionado com a percepção de saúde apenas quando os homens idosos eram ex-fumantes. Estes tinham mais chances de avaliarem a própria saúde de forma negativa. Souza (2012) levantou que a autopercepção negativa de saúde estava associada aos ex-fumantes residentes em comunidade, e estudos como o de Freitas et al. (2010) levantou elementos como dificuldade respiratória, declínio da capacidade funcional e força muscular que podem estar relacionados para a percepção negativa da saúde.

Para as mulheres, o tabagismo não foi significativo e não se mostrou uma variável que influencie a percepção da saúde, quando consideradas as variáveis de escolaridade, região de residência e o consumo de bebidas alcoólicas. Ainda considerando o estilo de vida, as idosas que não tinham o hábito regular de práticas religiosas perceberam negativamente sua saúde, em detrimento daqueles que frequentavam regularmente cultos ou alguma religião. Um fator apontado por Campos (2009) diz respeito à religião bem como cultura que podem interferir nos 
comportamentos e hábitos e que estão relacionados com consumo de bebidas alcoólicas, tabagismo, questões alimentares, etc.

As variáveis de condição de saúde - doenças crônicas não transmissíveis e capacidade funcional - foram as que apresentaram maior prevalência na autopercepção de saúde. Tanto para os idosos do sexo masculino quanto para as idosas, a presença de doenças crônicas e a incapacidade funcional influenciaram a percepção negativa da saúde. No entanto, para os homens, estas variáveis tiveram maior prevalência do que para as idosas, na percepção deficitária de sua saúde. Quando agregadas ao modelo, aumentaram consideravelmente as chances de os idosos do sexo masculino residentes nas regiões Norte e Nordeste avaliarem negativamente sua saúde, de forma mais significativa do que para as idosas.

No Estudo SABE realizado por Alves (2005) foi identificado que quanto maior a incapacidade, maior a chance do idoso de autoperceber sua saúde como ruim e este foi o principal determinante da autoavaliação negativa de saúde. No entanto, o estudo Bambuí (LIMA-COSTA, 2004), a capacidade funcional, como variável de exposição, não foi associada à percepção negativa de saúde.

Como apontado por Lima-Costa (2007), a presença de doenças permite uma associação com autoavaliação de saúde negativa, pois as morbidades podem trazer limitações e dificuldades de autocuidado, o que pode proporcionar a autopercepção negativa de saúde do idoso.

Com relação aos resultados por macrorregiões, Vasconcelos e Gomes (2012) consideram as diferenças sociais e econômicas entre as regiões brasileiras, diferenças estas devido ao processo histórico de desenvolvimento, industrialização e urbanização de cada região. As autoras ainda apontam para indicadores demográficos nas regiões Norte e Nordeste do Brasil apontarem para uma transição demográfica atrasada em relação às demais regiões do país.

Em resumo, os idosos do sexo masculino residentes nas regiões Norte e Nordeste do país que possuíam menor escolaridade e que tinham mais doenças crônicas, bem como eram dependentes nas atividades da vida diária e nas atividades instrumentais, ou apenas nas últimas, foram os que mais perceberam negativamente sua saúde.

As mulheres com 60 anos ou mais de idade, residentes nas regiões Norte e Nordeste, com menor escolaridade, que não frequentavam atividades religiosas, possuíam doenças crônicas ou eram dependentes nas atividades da vida diária e nas atividades instrumentais foram as que mais avaliaram sua saúde de forma negativa. 
Percebe-se, ainda, que as avaliações feitas por outras pessoas foram mais negativas do que as realizadas pelas próprias idosas.

Pagotto et al. (2013) em um trabalho de revisão sistemática da literatura acerca da autoavaliação da saúde em idosos, as autores levantaram que este indicador foi empregado no Brasil como variável desfecho pela primeira vez na PNAD, em 1998, para avaliar a percepção negativa de saúde da população em geral. Já para a população idosa, esse desfecho foi estudado pela primeira vez em 2004. As autoras ainda apontam que não há na literatura valores de referência definindo o que seria aceitável em termos de saúde autoavaliada em idosos; assim, resta comparar os resultados de diferentes artigos e analisar os fatores associados similares e divergentes.

A heterogeneidade de fatores associados à autoavaliação negativa indica que a saúde dos idosos é definida por determinantes que se aproximam do conceito ampliado de saúde. É recomendável a padronização das perguntas e respostas de pesquisa sobre autoavaliação de saúde em idosos, já que essas informações possibilitarão conhecer, acompanhar e comparar resultados para orientar a tomada de decisão no tocante à formulação de políticas de saúde para Brasil e a América Latina. 


\section{CONSIDERAÇÕES FINAIS}

A realização de estudos que possam identificar os determinantes sociais de saúde dos idosos e como eles se relacionam tem se tornado indispensável para a redução das desigualdades em saúde. O bem-estar físico, mental e social, bem como a ausência de enfermidades devem ser levados em consideração, quando se tenta definir o estado de saúde dos indivíduos.

Este estudo buscou identificar as relações entre percepção da saúde dos idosos com diversos fatores e verificar se havia diferença entre os sexos. Identificar e analisar estas associações são pontos importantes para a elaboração de políticas públicas específicas, visando ao bem-estar e à equidade. Ações ou políticas voltadas para cada determinante social de saúde podem provocar a redução das desigualdades de saúde existentes na população idosa. Sugere-se que ações integradas dos determinantes sociais relacionados à autopercepção negativa de saúde podem contribuir para a promoção da saúde e do bem-estar dos idosos.

De qualquer forma, deve-se considerar que políticas de conscientização do processo de envelhecer com saúde, bem como novas oportunidades de ocupação e lazer podem interferir na perspectiva individual do idoso. a autoavaliação do estado de saúde é um indicador recomendado pela Organização Mundial da Saúde para verificar a saúde das populações. Dessa forma, conhecer os fatores que influenciam na percepção de saúde dos idosos poderá contribuir para identificar quais dimensões da saúde precisam ser fortalecidas para que esse grupo tenha atenção adequada às suas necessidades.

Na última década, no Brasil surgiram programas voltados para os idosos, como as "escolas abertas", as "universidades para a terceira idade" e os "grupos de convivência de idosos". Encorajando a busca da autoexpressão e a exploração de identidades de um modo que era exclusivo da juventude, eles abrem espaços para que uma experiência inovadora possa ser vivida coletivamente, e indicam que a sociedade brasileira é hoje mais sensível aos problemas do envelhecimento. Contudo, o sucesso dessas iniciativas é proporcional à precariedade dos mecanismos de que dispomos para lidar com a velhice avançada. A nova imagem do idoso não oferece instrumentos capazes de enfrentar a decadência de habilidades cognitivas e controles físicos e emocionais que são fundamentais, na nossa sociedade, para que um indivíduo seja reconhecido como um ser autônomo, capaz de um exercício pleno dos direitos de cidadania. 
Outro ponto interessante relativo à autopercepções em geral, é que quem observa transforma. Em busca de qualidade de vida e bem estar, o conhecimento de si próprio torna-se fundamental para as mudanças sociais (de hábitos, costumes, comportamentos) necessárias para o sucesso pessoal e coletivo.

A visão de um universo quântico considera a existência de uma relação entre a consciência (mente) e o mundo material (corpo), pois este, em sua essência, é constituído de probabilidades de manifestações. Na perspectiva quântica, o elemento definidor da escolha das possibilidades será a consciência do observador. Esse mecanismo, chamado de efeito observador determina que o mundo é forjado de acordo com as nossas crenças e que infinitas possibilidades estão disponíveis.

Outra forma de se obter sucesso no processo de envelhecimento é promover a saúde para além da área de saúde. Um artigo para reflexão elaborado por Borges et al. (2013) levanta tempestivamente esta questão. O artigo faz uma abordagem quântica e transpessoal do cuidado de enfermagem. No entanto as autoras apontam para um novo campo de tratamento e os sistemas de cuidado da saúde não apenas na prática de enfermagem, colocando em evidência a importância das relações humanas nas intervenções de saúde. 


\section{REFERÊNCIAS BIBLIOGRÁFICAS}

ALVES, J.E.D. A polêmica Malthus versus Condorcet reavaliada à luz da transição demográfica. Rio de Janeiro: ENCE/IBGE, 2002.

ALVES, J.E.D. A transição demográfica e a janela de oportunidade. São Paulo: Instituto Fernand Braudel de Economia Mundial; 2008.

ALVES, J. E. D., VASCONCELOS, D. CARVALHO, A.A., Estrutura etária, bônus demográfico e população economicamente ativa: cenários de longo prazo e suas implicações para o mercado de trabalho. Texto para Discussão, 10, Cepal/IPEA, Brasília, pp. 2010. 1-38, Disponível em: http://www.eclac.cl/publicaciones/xml/1/42471/CEPAL_10_MIOLO.pdf

ARAÚJO, E.M. et al. The use of the variable of race/color within Public Health: possibilities and limits. Interface - Comunic., Saúde, Educ., v.13, n.31, p.383-94, out./dez. 2009.

ARAÚJO, J. D. Polarização epidemiológica no Brasil. Epidemol. Serv. Saúde, v.21, n.4. Brasília, dezembro, 2012.

BARON-EPEL O, KAPLAN G. General subjective health status or age-related subjective helth status: does it make a difference? Social Science and Medicine. 2001; 53(9): 19373-1381.

BAILIS, D.S., SEGALL, A., CHIPPERFIELD, J.G. Two views of self-rated general health status. Social Science and Medicine, v.56, n.2, p.203-217, jan. 2003.

BLAXTER, M., A comparison of measures of inequality in morbidity, in J.FOX, ed., Health inequalities in European countries. Gower: Aldershot. 1989.

BLAZER, D. G. How do you feel about Health outcomes in late life and selfperceptions 
of health and well-being. Gerontologist, v.48, p. 415-422, 2008.

BORGES, M. S., SANTOS, D. S., O campo de cuidar: uma abordagem quântica e transpessoal do cuidado de enfermagem. Cienc. Cuid. Saude. 2013. Jul/Set; 12(3):606-611.

BRITO, F. Transição demográfica e desigualdades sociais no Brasil. Revista brasileira de Estudos Populacionais, São Paulo, v. 25, n. 1, p 5-26, jan-jun. 2008.

CAMPOS, N. O. B. Os determinantes das condições de saúde dos idosos do município de São Paulo em uma perspectiva de vida. Belo Horizonte: Codeplar/UFMG, 2009.

CARVALHO, A. T., et al. Desigualdades na autoavaliação de saúde: uma análise para populações do Brasil e de Portugal. Caderno de Saúde Pública. Rio de Janeiro 31(11): 2449-2461, 2015.

CHOR, D.; Desigualdades em saúde no Brasil: é preciso ter raça. Desigualdades em saúde no Brasil. Cad. Saúde Pública, Rio de Janeiro, 29(7):1272-1275, jul, 2013.

CONFEDERAÇÃO INTERNACIONAL SOBRE POPULAÇÃO E DESENVOLVIMENTO. 1994, Cairo. Relatório da Conferência Internacional sobre População e Desenvolvimento. Brasília: CNPD, 1994.

CONFORTIN, S. C. et al. Autopercepção positive de saúde em idosos: estudo populacional no Sul do Brasil. Cad. Saúde Pública. Rio de Janeiro, 31(5):1049-1060. Maio, 2015.

DACHS, J.N.W. Determinantes das desigualdades na autopercepção do estado de saúde no Brasil: análise dos dados da PNAD/1998. Ciência \& Saúde Coletiva. 2002; 7(4):641-657.

DAMACENA, G. N. et al. O processo de desenvolvimento da Pesquisa Nacional de Saúde no Brasil, 2013. Epidemiol. Serv. Saúde [online]. 2015, vol.24, n.2, pp.197-206. 
(http://www.scielo.br/pdf/ress/v24n2/2237-9622-ress-24-02-00197.pdf) Acessado em 23/06/2016.

DAMIAN, J. et al. Determinants of self-assessed health among Spanish older people living at home. Journal of Epidemiology and Community Health, v. 53, n. 7, p. 412416, July, 1999.

DEBERT, G. G. Metamorfoses da Velhice, In Botelho, A. e Schwarcz (orgs) Agenda brasileira - temas de uma sociedade em mudança. São Paulo, Companhia das Letras, 542-553, 2011.

FERNÁNDEZ-BALLESTEROS, R. Envejecimiento activo: Contribuciones de la psicología. Ediciones Pirámide, 2009.

FREITAS, D. H. M.; CAMPOS, F. C. A.; LINHARES, L. Q.; SANTOS, C. R.; FERREIRA, C. B.; DINIZ, B. S.; TAVARES, A. Autopercepção de saúde e desempenho cognitivo em idosos residentes na comunidade. Ver. Psiq. Clin, v.37, p. 32-35, 2010.

FONSECA, A. O Envelhecimento Bem-Sucedido. In C.Paúl \& A. Fonseca (Eds.), Envelhecer em Portugal (pp. 281-311). Lisboa: Climepsi, 2005.

FONTES, A. P., NERI, A. L. Resiliência e velhice: revisão de literatura. Ciência e Saúde Coletiva, 20 (5):1475-1495, 2015.

HARTMANN, A. C. V. C. Fatores associados a autopercepção de saúde em idosos de Porto Alegre. Instituto de Geriatria e Gerontologia/PUC-RS. Porto Alegre, 2008. $73 \mathrm{p}$.

HOSMER, D. and LEMESHOW, S. Applied Logistic Regression. New York: John Wiley \& Sons, 1989. 
INSTITUTO BRASILEIRO DE GEOGRAFIA E ESTATÍSTICA (IBGE). Pesquisa Nacional de Saúde 2013 [Internet]. Rio de Janeiro: IBGE; 2013. Disponível em: http://www.ibge.gov.br/home/estatistica/populacao/pns/2013/

INSTITUTO BRASILEIRO DE GEOGRAFIA E ESTATÍSTICA (IBGE). Pesquisa nacional de saúde 2013: percepção do estado de saúde, estilos de vida e doenças crônicas. Rio de Janeiro. 2014.

INSTITUTO BRASILEIRO DE GEOGRAFIA E ESTATÍSTICA (IBGE). Projeção da População do Brasil por Sexo e Idade para o Período 1980-2050. 2008. Disponível em: < http://biblioteca.ibge.gov.br/visualizacao/livros/liv41229.pdf>. Acesso em: 21 jan. 2016.

KEONG, A.M.P.A, A auto-percepção do envelhecimento em idosas viúvas. Faculdade de psicologia de Lisboa. Seção de Psicologia Clínica e da Saúde/ Núcleo de Psicologia Dinâmica. Lisboa, 2010.

LEBRÃO, M.L., et al. Saúde, Bem-estar e Envelhecimento - O projeto Sabe no município de São Paulo. Rev. Bras. Epidemol. 2005; 8(2):127:41.

LIMA-COSTA, M. F., PEIXOTO, S. V., MATOS, D. L., FIRMO, J. O. A., UCHÔA E. A influência de respondente substituto na percepção de saúde de idosos: um estudo baseado na Pesquisa Nacional por Amostra de Domicílios $(1998,2003)$ e na coorte de Bambuí, Minas Gerais, Brasil. Cad. Saúde Pública. 2007a;23(8):1893-902.

LIMA-COSTA, M. F., MATOS, D. L., FIRMO, J. O. A., UCHÔA E. Differences in self-rated health among older adults according to socioeconomic circumstances: the Bambuí Health and Aging Study. Cad. Saúde Pública. 2005, 21(3):830-9.

LOPES, E.S.L. \& RABELO, D.F. Qualidade de vida na velhice: indicadores nacionais e internacionais. Revista Kairós Gerontologia, 9(2): 209-26, 2006.

MARLOT, M. Status Syndrome. London: Bloomsbury Publishing; 2004. 
NERI, A.L. (2007). Qualidade de vida na velhice e subjetividade. In: Neri, A.L. (Org.). Qualidade de vida na velhice: enfoque multidisciplinar. Campinas, SP: Alínea: 13-60.

OLIVEIRA, M.C. A segunda transição demográfica: nova teoria ou mais do mesmo? In: População e desenvolvimento em debate: contribuições da Associação Brasileira de Estudos Populacionais. Belo horizonte: APEB, 2012.

ORGANIZAÇÃO MUNDIAL DA SAÚDE. Envelhecimento ativo: uma política de saúde. Brasília: Organização Pan-Americana da Saúde, 2005.

ORGANIZAÇÃO MUNDIAL DA SAÚDE. Organização Pan-Americana da Saúde. Prevenção de doenças crônicas: um investimento vital. Genebra. Organização Mundial da Saúde; 2005. 36p.

PAGOTTO, V.; NAKATANI, A. Y. K.; SILVEIRA E. Fatores associados à autoavaliação de saúde ruim em idosos usuários do sistema Único de Saúde de Goiânia- Goiás. Cad. Saúde Pública, Rio de Janeiro, v.27, n.8, p.1593-1602, ago. 2011.

PAGOTTO V., BACHION, M. M., SILVEIRA, E. A. Autoavaliação da saúde por idosos brasileiros: revisão sistemática da literatura. Ver. Panam Salud Publica. 2013;33(4):302-10.

PAIM, J., TRAVASSOS, C., ALMEIDA, C., BAHIA L., MACINKO, J. Health in Brazil. The Brazilian health system: history, advances, and challenges. 2011; Lancet. 377 (9779): 1778-1797.

PAN AMERICAN HEALTH ORGANIZATION. World Health Organization. Health situation in the Americas: Basic indicators 2012. Folheto de indicadores. Organização Pan-Americana da Saúde. 2012 [acessado em fev. 2017]. Disponível em: http://www.paho.org/salud-en-las-americas2012/index.php?option=com_content \&view=article \&id=9\&Itemid=124\&lang=pt . 
PEREIRA, E. F. et al. Qualidade de vida: abordagens, conceitos e avaliação. Ver. Bras. Educ. Fís. Esporte, São Paulo, v.26, n.2, p241-50, abr./jun. 2012.

PINHEIRO, L., GALIZA, M., FONTOURA, N. Novos arranjos familiares, velhas convenções sociais de gênero: a licença-parental como política pública para lidar com essas tensões. Revista Estudos Feministas. 2009; 17(3):851-859.

RABELO, D. F. et al. Qualidade de vida, condições e autopercepção da saúde entre idosos hipertensos e não hipertensos. Revista Kairós Gerontologia, 13(2), ISSN 2176901X, São Paulo, novembro 2010: 115-130.

REDE INTERGERENCIAL DE INFORMAÇÕES PARA SAÚDE. Demografia e Saúde, Contribuição para análise de situações e tendências. Brasília, 2009.

PRATA, P. R. A (1992) Transição epidemiológica no Brasil. Cad. Saúde Pública, Rio de Janeiro, 8(2), pp. 168-175.

ROBERT A.S., CHEREPANOV D., PALTA M., DUNHAM N.C., FEENY D., FRYBACK D.G. Socioeconomic status and age variations in health-related quality of life: results from the National Health Measurement Study. J Gerontol B Psychol Sci Soc Sci 2009; 64:S378-89.

RON, P. Elderly people's attitudes and perceptions of aging and old age: the role of cognitive dissonance? International Journal of Geriatric Psychiatry 22(7), 656-662, 2007.

SALOMON, J. A., TANDON, A., MURRAY, C. J. L. Comparability of self-rated health: cross sectional multi-country survey using anchoring vignettes. BMJ 2004; $328: 258-258$.

SANTOW, G. (1999). The mortality, epidemiological and health transitions: their revelance for the study of health and mortality. In: UNITED NATIONS. Health and Mortality issues of global concern. Proceedings of the Symposium on Health and Mortality. Brussels, 19-22 november. New York: United Nations, Chap. 1, pp. 39-53. 
SCHMIDT M.I., DUNCAN B.B., AZEVEDO e SILVA, MENEZES A.M., MONTEIRO C.A., BARRETO S.M., CHOR D, MENEZES P.R. (2011) Chronic noncommunicable diseases in Brazil: burden and current challenges. Lancet. 377 (9781): 1949-1961.

SILVA, M.E. Saúde mental e idade avançada. In C. Pául \& A. Fonseca (Eds.), Envelhecer em Portugal (pp. 137-156). Lisboa: Climepsi, 2005.

SIPD, 2007. Sistema Integrado de Pesquisas Domiciliares (SIPD) do IBGE. Ministério do Planejamento, Orçamento e Gestão / Instituto Brasileiro de Geografia e Estatística - IBGE / Diretoria de Pesquisas / Coordenação de Trabalho e Rendimento. $\begin{array}{llll}\text { Rio de Janeiro: } & 2007 .\end{array}$ (http://www.ibge.gov.br/home/estatistica/indicadores/sipd/). Acessado em 24/06/2016).

SOARES, L. T. R. (2000) América Latina: transição epidemiológica ou retrocesso social? Acta Paul Enf, São Paulo, 13(número especial), Parte I, PP. 55-64.

SOUZA, M. S. Estudo populacional sobre os determinantes da autopercepção de saúde em idosos residentes em comunidade. Dissertação de Mestrado. Universidade Estadual do Sudoeste da Bahia. Programa de pós-graduação em Enfermagem e Saúde. Bahia, 2012.

SOUZA-JUNIOR, P. R. B. et al. Desenho da amostra da Pesquisa Nacional de Saúde 2013. Epidemiol. Serv. Saúde [online]. 2015, vol.24, n.2, pp.207-216. (http://www.scielo.br/pdf/ress/v24n2/2237-9622-ress-24-02-00207.pdf) Acessado em 23/06/2016.

TAVARES, D., M. S. et al. Preditores da qualidade de vida de idosos urbanos e rurais. Revista Baiana de enfermagem, Salvador, v. 29, n. 4, p 361-371, out/dez. 2015.

VASCONCELOS, A. M. N., GOMES, M. M. F. Transiçãa demográfica: a experiência brasileira. Epidemiologia e Serviços de Saúde, v.21, n.4, 2012. Pp.539548. 
VASCONCELOS, A. M. N., GOMES, M. M. F., FRANÇA, E., Transição epidemiológica na América Latina: diferentes realidades. In: anais do V Congresso de la Asociación Latinoamericada de Población, Montevideo, Uruguay, del 23 al 26 de octubre de 2012.

VERAS, R. Fórum. Envelhecimento populacional e as informações de saúde da PNAD: demandas e desafios contemporâneos. Introdução. Cad Saude Publica, v.23, n.10, p. 2463-2466, 2007. DOI: 10.1590/S0102- 311X2007001000020.

WORLD HEALTHY ORGANIZATION. Active ageing: a policy framework. Geneva, 2002. Disponível em: <http://apps.who.int/iris/bitstream/10665/67215/1/WHO_NMH_NPH_02.8.pdf >.Acesso em: 3 junho 2016.

WORLD HEALTHY ORGANIZATION. Growing older - staying well: ageing and physical activity in everyday life. Geneva, 1998.

WRONG, L. R. Subsídios para políticas orientadas ao bem-estar do idoso sob a ótica de uma sociedade para todas as idades. In: WRONG, L. R. (org). O envelhecimento da população brasileira e o aumento da longevidade: subsídios para políticas orientadas ao bem-estar do idoso. Belo Horizonte: Codeplar/UFMG, ABEP, 2001. Pp. 11-22. 


\section{APÊNDICES}

\section{Apêndice A - Descrição das variáveis}

\section{Quadro 1A - Variável dependente}

\begin{tabular}{|c|c|l|l|}
\hline Variável & $\begin{array}{c}\text { Código } \\
\text { na PNS }\end{array}$ & Descrição na PNS & Categorização da PNS \\
\hline $\begin{array}{c}\text { Autopercepção } \\
\text { de saúde }\end{array}$ & N001 & $\begin{array}{l}\text { Em geral, como o(a) } \\
\text { se(a) avalia a sua } \\
\text { saúde? }\end{array}$ & $\begin{array}{l}\text { Muito boa } \\
\text { Boa } \\
\text { Regular } \\
\text { Ruim } \\
\text { Muito ruim }\end{array}$ \\
\hline
\end{tabular}

Fonte: Elaboração própria com base no questionário da PNS.

\section{Quadro 2A - Variáveis sociodemográficas}

\begin{tabular}{|c|c|c|l|}
\hline Variável & Código na PNS & Descrição na PNS & Categorização da PNS \\
\hline Idade & C008 & Idade & \multicolumn{1}{|c|}{ contínua } \\
\hline Raça/Cor & C009 & Cor ou raça & $\begin{array}{l}\text { Branca } \\
\text { Preta } \\
\text { Amarela } \\
\text { Parda } \\
\text { Indígena }\end{array}$ \\
\hline
\end{tabular}

Fonte: Elaboração própria com base no questionário da PNS.

Quadro 3A - Variável região de moradia

\begin{tabular}{|c|c|c|c|}
\hline Variável & Código na PNS & Descrição na PNS & Categorização da PNS \\
\hline Regiao & V0001 & $\begin{array}{l}\text { Unidade da } \\
\text { Federação }\end{array}$ & $\begin{array}{c}26 \text { estados e o Distrito } \\
\text { Federal }\end{array}$ \\
\hline
\end{tabular}

Fonte: Elaboração própria com base no questionário da PNS. 


\section{Quadro 4A - Variável de escolaridade}

\begin{tabular}{|c|c|c|l|}
\hline Variável & $\begin{array}{c}\text { Código na } \\
\text { PNS }\end{array}$ & Descrição na PNS & \multicolumn{1}{c|}{ Categorização da PNS } \\
\hline & & $\begin{array}{c}\text { Nível de instrução } \\
\text { mais elevado } \\
\text { alcançado (pessoas } \\
\text { escolaridade } 5 \text { anos ou mais } \\
\text { de idade) }\end{array}$ & $\begin{array}{l}\text { Sem instrução } \\
\text { Fundamental incompleto ou equivalente } \\
\text { Fundamental completo ou equivalente } \\
\text { VDD004dio incompleto ou equivalente } \\
\text { Médio completo ou equivalente } \\
\text { Superior incompleto ou equivalente } \\
\text { Superior completo }\end{array}$ \\
\hline
\end{tabular}

Fonte: Elaboração própria com base no questionário da PNS.

Nota: Variável derivada do morador. Encontra-se descrita no dicionário de variáveis de pessoas.

Quadro 5A - Variáveis de estilo de vida

\begin{tabular}{|c|c|c|l|}
\hline Variável & $\begin{array}{c}\text { Código na } \\
\text { PNS }\end{array}$ & \multicolumn{1}{|c|}{ Descrição na PNS } & \multicolumn{1}{|c|}{ Categorização da PNS } \\
\hline $\begin{array}{c}\text { Consumo de } \\
\text { bebidas } \\
\text { alcoólicas }\end{array}$ & P027 & $\begin{array}{c}\text { Com que frequência o(a) } \\
\text { sr(a) costuma consumir } \\
\text { alguma bebida alcoólica? }\end{array}$ & $\begin{array}{l}\text { Não bebo nunca } \\
\text { Menos de uma vez por mês } \\
\text { Uma vez ou mais por mês }\end{array}$ \\
\hline Tabagismo & P050 & $\begin{array}{c}\text { Atualmente o(a) sr(a) fuma } \\
\text { algum produto do tabaco? }\end{array}$ & $\begin{array}{l}\text { Sim, diariamente } \\
\text { Sim, menos que diariamente } \\
\text { Não fumo atualmente }\end{array}$ \\
\cline { 2 - 5 } & P052 & $\begin{array}{c}\text { E no passado, o(a) sr(a) } \\
\text { fumou algum produto do } \\
\text { tabaco diariamente? }\end{array}$ & $\begin{array}{l}\text { Sim } \\
\text { Não }\end{array}$ \\
\hline $\begin{array}{c}\text { Atividades } \\
\text { religiosas }\end{array}$ & M019 & $\begin{array}{c}\text { Nos últimos 12 meses, } \\
\text { com que frequência o(a) } \\
\text { sr(a) compareceu a cultos } \\
\text { ou atividades da sua } \\
\text { religião ou de outra } \\
\text { religião? }\end{array}$ & $\begin{array}{l}\text { Mais de uma vez por semana } \\
\text { Uma vez por semana } \\
\text { De 2 vezes por semana } \\
\text { Algumas vezes no ano } \\
\text { Uma vez no ano } \\
\text { Nenhuma vez }\end{array}$ \\
\hline
\end{tabular}

Fonte: Elaboração própria com base no questionário da PNS. 


\section{Quadro 6A - Variáveis de condições de saúde: doenças crônicas não transmissíveis}

\begin{tabular}{|c|c|c|c|}
\hline Variável & $\begin{array}{l}\text { Código na } \\
\text { PNS } \\
\end{array}$ & Descrição na PNS & Categorização da PNS \\
\hline Hipertensão & Q002 & $\begin{array}{l}\text { Algum médico já lhe deu diagnóstico de } \\
\text { hipertensão arterial (pressão alta)? }\end{array}$ & $\begin{array}{l}\text { Sim } \\
\text { Apenas durante a gravidez } \\
\text { Não }\end{array}$ \\
\hline Diabetes & Q030 & $\begin{array}{l}\text { Algum médico já lhe deu diagnóstico de } \\
\text { diabetes? }\end{array}$ & $\begin{array}{l}\text { Sim } \\
\text { Apenas durante a gravidez } \\
\text { Não }\end{array}$ \\
\hline Colesterol alto & Q060 & $\begin{array}{l}\text { Algum médico já lhe deu diagnóstico de } \\
\text { colesterol alto? }\end{array}$ & $\begin{array}{l}\text { Sim } \\
\text { Não }\end{array}$ \\
\hline Coração & Q063 & $\begin{array}{l}\text { Algum médico já the deu diagnóstico de } \\
\text { doença do coração, tais como infarto, angina, } \\
\text { insuficiência cardíaca ou outra? }\end{array}$ & $\begin{array}{l}\text { Sim } \\
\text { Não }\end{array}$ \\
\hline Derrame & Q068 & $\begin{array}{l}\text { Algum médico já the deu diagnóstico de AVC } \\
\text { (Acidente Vascular Cerebral) ou derrame? }\end{array}$ & $\begin{array}{l}\text { Sim } \\
\text { Não }\end{array}$ \\
\hline Asma & Q074 & $\begin{array}{l}\text { Algum médico já the deu diagnóstico de asma } \\
\text { ou bronquite asmática? }\end{array}$ & $\begin{array}{l}\text { Sim } \\
\text { Não }\end{array}$ \\
\hline Artrite & Q079 & $\begin{array}{l}\text { Algum médico já the deu diagnóstico de artrite } \\
\text { ou reumatismo? }\end{array}$ & $\begin{array}{l}\text { Sim } \\
\text { Não }\end{array}$ \\
\hline Coluna & Q084 & $\begin{array}{l}\mathrm{O} \text { (a) sr(a) tem algum problema de coluna, } \\
\text { como dor crônica nas costas ou no pescoço, } \\
\text { lombalgia, dor ciática, problemas nas vértebras } \\
\text { ou disco? }\end{array}$ & $\begin{array}{l}\text { Sim } \\
\text { Não }\end{array}$ \\
\hline Bronquite & Q116 & $\begin{array}{l}\text { Algum médico já lhe deu diagnóstico de } \\
\text { alguma doença no pulmão, tais como enfisema } \\
\text { pulmonar, bronquite crônica ou DPOC } \\
\text { (Doença Pulmonar Obstrutiva Crônica)? }\end{array}$ & $\begin{array}{l}\text { Sim } \\
\text { Não }\end{array}$ \\
\hline Câncer & Q120 & $\begin{array}{l}\text { Algum médico já lhe deu diagnóstico de } \\
\text { câncer? }\end{array}$ & $\begin{array}{l}\text { Sim } \\
\text { Não }\end{array}$ \\
\hline $\begin{array}{l}\text { Insuficiência } \\
\text { renal }\end{array}$ & Q124 & $\begin{array}{l}\text { Algum médico já lhe deu diagnóstico de } \\
\text { insuficiância renal crônica? }\end{array}$ & $\begin{array}{l}\text { Sim } \\
\text { Não }\end{array}$ \\
\hline
\end{tabular}

Fonte: Elaboração própria com base no questionário da PNS. 


\section{Quadro 7A - Variáveis de condições de saúde: capacidade funcional}

\begin{tabular}{|c|c|c|c|}
\hline Variável & \begin{tabular}{|c|} 
Código na \\
PNS
\end{tabular} & Descrição na PNS & Categorização da PNS \\
\hline \multicolumn{4}{|c|}{ Atividades Básicas da Vida Diária (AVD) } \\
\hline Comer e beber & K001 & $\begin{array}{l}\text { Em geral, que grau de dificuldade tem para comer sozinho(a) } \\
\text { com um prato colocado à sua frente, incluindo segurar um } \\
\text { garfo, cortar alimentos e beber em um copo? }\end{array}$ & $\begin{array}{l}\text { Não consegue } \\
\text { Tem grande dificuldade } \\
\text { Tem pequena dificuldade } \\
\text { Não tem dificuldade }\end{array}$ \\
\hline Tomar banho & K004 & $\begin{array}{l}\text { Em geral, que grau de dificuldade tem para tomar banho } \\
\text { sozinho (a) incluindo entrar e sair do chuveiro ou banheira? }\end{array}$ & $\begin{array}{l}\text { Não consegue } \\
\text { Tem grande dificuldade } \\
\text { Tem pequena dificuldade } \\
\text { Não tem dificuldade }\end{array}$ \\
\hline Ir ao banheiro & K007 & $\begin{array}{l}\text { Em geral, que grau de dificuldade tem para ir ao banheiro } \\
\text { sozinho(a) incluindo sentar e levantar do vaso sanitário? }\end{array}$ & $\begin{array}{l}\text { Não consegue } \\
\text { Tem grande dificuldade } \\
\text { Tem pequena dificuldade } \\
\text { Não tem dificuldade }\end{array}$ \\
\hline Vestir-se & K010 & $\begin{array}{l}\text { Em geral, que grau de dificuldade tem para se vestir } \\
\text { sozinho(a) incluindo calçar meias e sapatos, fechar o zíper, e } \\
\text { fechar e abrir botões? }\end{array}$ & $\begin{array}{l}\text { Não consegue } \\
\text { Tem grande dificuldade } \\
\text { Tem pequena dificuldade } \\
\text { Não tem dificuldade }\end{array}$ \\
\hline Andar em casa & K013 & $\begin{array}{l}\text { Em geral, que grau de dificuldade tem para andar em casa } \\
\text { sozinho(a) de um cômodo a outro da casa, em um mesmo } \\
\text { andar, como do quarto para a sala e cozinha? }\end{array}$ & \begin{tabular}{|l} 
Não consegue \\
Tem grande dificuldade \\
Tem pequena dificuldade \\
Não tem dificuldade
\end{tabular} \\
\hline $\begin{array}{l}\text { Deitar ou } \\
\text { levantar da } \\
\text { cama }\end{array}$ & K016 & $\begin{array}{l}\text { Em geral, que grau de dificuldade tem para deitar ou levantar } \\
\text { da cama sozinho(a)? }\end{array}$ & \begin{tabular}{|l} 
Não consegue \\
Tem grande dificuldade \\
Tem pequena dificuldade \\
Não tem dificuldade
\end{tabular} \\
\hline $\begin{array}{l}\text { Sentar e } \\
\text { levantar da } \\
\text { cadeira }\end{array}$ & K019 & $\begin{array}{l}\text { Em geral, que grau de dificuldade tem sentar ou levantar da } \\
\text { cadeira sozinho(a)? }\end{array}$ & $\begin{array}{l}\text { Não consegue } \\
\text { Tem grande dificuldade } \\
\text { Tem pequena dificuldade } \\
\text { Não tem dificuldade }\end{array}$ \\
\hline \multicolumn{4}{|c|}{ Atividades Instrumentais da Vida Diária (AIVD) } \\
\hline Fazer compras & K022 & $\begin{array}{l}\text { Em geral, que grau de dificuldade tem para fazer compras } \\
\text { sozinho(a), por exemplo de alimentos, roupas ou } \\
\text { medicamentos? }\end{array}$ & \begin{tabular}{|l} 
Não consegue \\
Tem grande dificuldade \\
Tem pequena dificuldade \\
Não tem dificuldade \\
\end{tabular} \\
\hline $\begin{array}{l}\text { Administrar } \\
\text { finanças }\end{array}$ & K025 & $\begin{array}{l}\text { Em geral, que grau de dificuldade tem para administrar as } \\
\text { finanças sozinho(a) (cuidar do seu próprio dinheiro)? }\end{array}$ & \begin{tabular}{|l} 
Não consegue \\
Tem grande dificuldade \\
Tem pequena dificuldade \\
Não tem dificuldade
\end{tabular} \\
\hline $\begin{array}{l}\text { Tomar } \\
\text { remédios }\end{array}$ & K028 & $\begin{array}{l}\text { Em geral, que grau de dificuldade tem para tomar os remédios } \\
\text { sozinho(a)? }\end{array}$ & \begin{tabular}{|l} 
Não consegue \\
Tem grande dificuldade \\
Tem pequena dificuldade \\
Não tem dificuldade \\
Não faz uso de medicamentos \\
\end{tabular} \\
\hline Ir ao médico & K031 & $\begin{array}{l}\text { Em geral, que grau de dificuldade tem para ir ao médico } \\
\text { sozinho(a)? }\end{array}$ & $\begin{array}{l}\text { Não consegue } \\
\text { Tem grande dificuldade } \\
\text { Tem pequena dificuldade } \\
\text { Não tem dificuldade }\end{array}$ \\
\hline $\begin{array}{c}\text { Utilizar } \\
\text { transportes } \\
\text { para } \\
\text { deslocamento }\end{array}$ & K034 & $\begin{array}{l}\text { Em geral, que grau de dificuldade tem para sair sozinho(a) } \\
\text { utilizando um transporte como ônibus, metrô, táxi, carro, etc? }\end{array}$ & $\begin{array}{l}\text { Não consegue } \\
\text { Tem grande dificuldade } \\
\text { Tem pequena dificuldade } \\
\text { Não tem dificuldade }\end{array}$ \\
\hline
\end{tabular}

Fonte: Elaboração própria com base no questionário da PNS. 


\section{Apêndice B - Tabelas descritivas: números absolutos}

Tabela 1B - Distribuição absoluta dos idosos, segundo as variáveis sociodemográficas, de acordo com o sexo e a forma como autoavaliaram sua saúde - PNS, 2013

\begin{tabular}{|c|c|c|c|c|c|c|c|c|c|}
\hline \multirow{3}{*}{ Variáveis Sociodemográficas } & \multirow{2}{*}{\multicolumn{3}{|c|}{ Sexo }} & \multicolumn{6}{|c|}{ Sexo/Autopercepção da saúde } \\
\hline & & & & \multicolumn{3}{|c|}{ Homens } & \multicolumn{3}{|c|}{ Mulheres } \\
\hline & Homens & Mulheres & Total & Positiva & Negativa & Total & Positiva & Negativa & Total \\
\hline Total & 11.517 .634 & 14.890 .197 & 26.407 .831 & 5.354 .804 & 6.162 .830 & 11.517 .634 & 6.541 .335 & 8.348 .862 & 14.890 .197 \\
\hline \multicolumn{10}{|l|}{ Informante } \\
\hline Próprio idoso & 8.471 .517 & 12.265 .910 & 20.737 .426 & 4.000 .911 & 4.470 .605 & 8.471 .517 & 5.387 .673 & 6.878 .236 & 12.265 .910 \\
\hline Outro informante & 3.046 .117 & 2.624 .287 & 5.670 .405 & 1.418 .214 & 1.627 .904 & 3.046 .117 & 922.356 & 1.701 .932 & 2.624 .287 \\
\hline \multicolumn{10}{|l|}{ Faixa etária } \\
\hline 60 a 64 anos & 3.632 .199 & 4.788 .023 & 8.420 .223 & 1.878 .506 & 1.753 .693 & 3.632 .199 & 2.200 .515 & 2.587 .508 & 4.788 .023 \\
\hline 65 a 70 anos & 3.378 .195 & 4.227 .208 & 7.605 .402 & 1.622 .761 & 1.755 .434 & 3.378 .195 & 1.805 .302 & 2.421 .905 & 4.227.208 \\
\hline 71 a 74 anos & 1.667 .580 & 2.027 .556 & 3.695 .135 & 791.698 & 875.881 & 1.667 .580 & 776.172 & 1.251 .383 & 2.027 .556 \\
\hline 75 a 80 anos & 1.550 .288 & 2.039 .360 & 3.589 .648 & 572.454 & 977.834 & 1.550 .288 & 793.105 & 1.246 .255 & 2.039 .360 \\
\hline Mais de 80 anos & 1.289 .372 & 1.808 .051 & 3.097 .423 & 553.705 & 735.667 & 1.289 .372 & 734.934 & 1.073 .117 & 1.808 .051 \\
\hline \multicolumn{10}{|l|}{ Raça/cor } \\
\hline Negros (pretos e pardos) & 5.258 .482 & 6.585 .874 & 11.844 .356 & 2.119 .711 & 3.138 .771 & 5.258 .482 & 2.362 .031 & 4.223 .844 & 6.585 .874 \\
\hline Brancos & 6.075 .068 & 8.088 .879 & 14.163 .947 & 3.188 .458 & 2.886 .610 & 6.075 .068 & 3.856 .487 & 4.232 .392 & 8.088 .879 \\
\hline Amarelos e Indígenas & 183.792 & 212.769 & 396.560 & 110.957 & 72.835 & 183.792 & 91.511 & 121.258 & 212.769 \\
\hline
\end{tabular}

Fonte: Microdados da PNS 2013. Elaboração própria.

Tabela 2B - Distribuição absoluta dos idosos, segundo a região geográfica de residência, de acordo com o sexo e a forma como autoavaliaram sua saúde - PNS, 2013

\begin{tabular}{|c|c|c|c|c|c|c|c|c|c|}
\hline \multirow{3}{*}{ Região de residência } & \multirow{2}{*}{\multicolumn{3}{|c|}{ Sexo }} & \multicolumn{6}{|c|}{ Sexo/Autopercepção da saúde } \\
\hline & & & & \multicolumn{3}{|c|}{ Homens } & \multicolumn{3}{|c|}{ Mulheres } \\
\hline & Homens & Mulheres & Total & Positiva & Negativa & Total & Positiva & Negativa & Total \\
\hline Total & 11.517.634 & 14.890 .197 & 26.407 .831 & 5.419 .125 & 6.098 .509 & 11.517.634 & 6.310 .029 & 8.580 .168 & 14.890 .197 \\
\hline Norte & 680.471 & 748.087 & 1.428 .558 & 254.812 & 425.659 & 680.471 & 259.416 & 488.671 & 748.087 \\
\hline Nordeste & 2.936 .370 & 3.724 .845 & 6.661 .215 & 1.104 .835 & 1.831 .535 & 2.936 .370 & 1.229 .835 & 2.495 .010 & 3.724 .845 \\
\hline Sudeste & 5.424 .503 & 7.226 .770 & 12.651 .274 & 2.883 .957 & 2.540 .547 & 5.424 .503 & 3.443 .211 & 3.783 .559 & 7.226 .770 \\
\hline Sul & 1.719 .674 & 2.261 .138 & 3.980 .813 & 813.378 & 906.296 & 1.719 .674 & 1.004 .446 & 1.256 .692 & 2.261 .138 \\
\hline Centro-Oeste & 756.616 & 929.356 & 1.685 .971 & 362.143 & 394.472 & 756.616 & 373.121 & 556.235 & 929.356 \\
\hline
\end{tabular}


Tabela 3B - Distribuição absoluta dos idosos, segundo o nível de escolaridade, de acordo com o sexo e a forma como autoavaliaram sua saúde - PNS, 2013

\begin{tabular}{|c|c|c|c|c|c|c|c|c|c|}
\hline \multirow{3}{*}{ Variável socioeconômica } & \multirow{2}{*}{\multicolumn{3}{|c|}{ Sexo }} & \multicolumn{6}{|c|}{ Sexo/Autopercepção da saúde } \\
\hline & & & & \multicolumn{3}{|c|}{ Homens } & \multicolumn{3}{|c|}{ Mulheres } \\
\hline & Homens & Mulheres & Total & Positiva & Negativa & Total & Positiva & Negativa & Total \\
\hline Total & 11.517 .634 & 14.890 .197 & 26.407.831 & 5.419 .125 & 6.098.509 & 11.517 .634 & 6.310 .029 & 8.580 .168 & 14.890 .197 \\
\hline Até fundamental Incompleto & 8.069 .475 & 10.597 .635 & 18.667 .110 & 3.232 .216 & 4.837 .259 & 8.069 .475 & 3.671 .066 & 6.926 .570 & 10.597 .635 \\
\hline Sem instrução & 3.568 .184 & 4.907 .351 & 8.475 .535 & 1.257 .807 & 2.310 .376 & 3.568 .184 & 1.466 .796 & 3.440 .555 & 4.907 .351 \\
\hline Fundamental incompleto ou equivalente & 4.501 .291 & 5.690 .284 & 10.191 .576 & 1.974 .408 & 2.526 .883 & 4.501 .291 & 2.204 .270 & 3.486 .014 & 5.690 .284 \\
\hline Fundamental completo e Médio Incompleto & 982.503 & 1.139 .990 & 2.122 .493 & 483.607 & 498.895 & 982.503 & 522.117 & 617.873 & 1.139 .990 \\
\hline Fundamental completo ou equivalente & 816.849 & 1.023 .424 & 1.840 .274 & 387.526 & 429.324 & 816.849 & 470.341 & 553.083 & 1.023 .424 \\
\hline Médio incompleto ou equivalente & 165.653 & 116.566 & 282.219 & 96.081 & 69.572 & 165.653 & 51.776 & 64.790 & 116.566 \\
\hline Médio completo e Superior Incompleto & 1.264 .003 & 1.836 .633 & 3.100 .637 & 714.171 & 549.832 & 1.264 .003 & 1.120 .719 & 715.914 & 1.836 .633 \\
\hline Médio completo ou equivalente & 1.176 .633 & 1.758 .506 & 2.935 .139 & 664.132 & 512.502 & 1.176 .633 & 1.077 .010 & 681.496 & 1.758 .506 \\
\hline Superior incompleto ou equivalente & 87.370 & 78.128 & 165.498 & 50.040 & 37.330 & 87.370 & 43.710 & 34.418 & 78.128 \\
\hline Superior completo & 1.201 .653 & 1.315 .938 & 2.517 .591 & 989.131 & 212.522 & 1.201 .653 & 996.127 & 319.811 & 1.315 .938 \\
\hline Superior completo & 1.201 .653 & 1.315 .938 & 2.517 .591 & 989.131 & 212.522 & 1.201 .653 & 996.127 & 319.811 & 1.315 .938 \\
\hline
\end{tabular}

Fonte: Microdados da PNS 2013. Elaboração própria.

Tabela 4B - Distribuição absoluta dos idosos, segundo as variáveis de estilo de vida, de acordo com o sexo e a forma como autoavaliaram sua saúde - PNS, 2013

\begin{tabular}{|c|c|c|c|c|c|c|c|c|c|}
\hline \multirow{3}{*}{ Variáveis de estilo de vida } & \multirow{2}{*}{\multicolumn{3}{|c|}{ Sexo }} & \multicolumn{6}{|c|}{ Sexo/Autopercepção da saúde } \\
\hline & & & & \multicolumn{3}{|c|}{ Homens } & \multicolumn{3}{|c|}{ Mulheres } \\
\hline & Homens & Mulheres & Total & Positiva & Negativa & Total & Positiva & Negativa & Total \\
\hline Total & 11.517.634 & 14.890 .197 & 26.407 .831 & 5.419 .125 & 6.098 .509 & 11.517 .634 & 6.310 .029 & 8.580 .168 & 14.890 .197 \\
\hline \multicolumn{10}{|l|}{ Bebidas alcóolicas } \\
\hline Menos de 1 vez por mês & 1.327 .229 & 904.162 & 2.231 .391 & 706.687 & 620.542 & 1.327 .229 & 557.406 & 346.756 & 904.162 \\
\hline Uma ou mais vezes por mês & 3.069 .374 & 1.051 .168 & 4.120 .542 & 1.843 .611 & 1.225 .763 & 3.069 .374 & 642.454 & 408.713 & 1.051 .168 \\
\hline Não consome & 7.121 .031 & 12.934 .867 & 20.055 .898 & 2.868 .827 & 4.252 .204 & 7.121 .031 & 5.110 .169 & 7.824 .698 & 12.934 .867 \\
\hline \multicolumn{10}{|l|}{ Tabagismo } \\
\hline Fumante & 1.954 .230 & 1.385 .127 & 3.339 .357 & 880.305 & 1.073 .924 & 1.954 .230 & 639.280 & 745.847 & 1.385 .127 \\
\hline Ex-fumante & 5.041 .108 & 3.179 .620 & 8.220 .727 & 2.207 .525 & 2.833 .582 & 5.041 .108 & 1.301 .695 & 1.877 .925 & 3.179 .620 \\
\hline Nunca fumou & 4.522 .297 & 10.325 .450 & 14.847 .746 & 2.331 .294 & 2.191 .002 & 4.522 .297 & 4.369 .054 & 5.956 .396 & 10.325 .450 \\
\hline \multicolumn{10}{|l|}{ Atividades religiosas } \\
\hline Não frequenta & 4.390 .563 & 3.519 .474 & 7.910 .037 & 2.054 .454 & 2.336 .109 & 4.390 .563 & 1.461 .219 & 2.058 .255 & 3.519 .474 \\
\hline Raramente frequenta & 2.628 .370 & 2.649 .294 & 5.277 .665 & 1.169 .928 & 1.458 .443 & 2.628 .370 & 988.453 & 1.660 .841 & 2.649 .294 \\
\hline Frequentemente & 4.498 .701 & 8.721 .428 & 13.220 .129 & 2.194 .744 & 2.303 .957 & 4.498 .701 & 3.860 .357 & 4.861 .072 & 8.721 .428 \\
\hline
\end{tabular}


Tabela 5B - Distribuição absoluta dos idosos, segundo a quantidade de doenças crônicas não transmissíveis, de acordo com o sexo e a forma como autoavaliaram sua saúde - PNS, 2013

\begin{tabular}{|c|c|c|c|c|c|c|c|c|c|}
\hline \multirow{3}{*}{ Qtde doenças crônicas não transmissíveis } & \multirow{2}{*}{\multicolumn{3}{|c|}{ Sexo }} & \multicolumn{6}{|c|}{ Sexo/Autopercepção da saúde } \\
\hline & & & & \multicolumn{3}{|c|}{ Homens } & \multicolumn{3}{|c|}{ Mulheres } \\
\hline & Homens & Mulheres & Total & Positiva & Negativa & Total & Positiva & Negativa & Total \\
\hline Total & 11.517 .634 & 14.890 .197 & 26.407 .831 & 5.419 .125 & 6.098 .509 & 11.517 .634 & 6.310 .029 & 8.580 .168 & 14.890 .197 \\
\hline \multicolumn{10}{|l|}{ Doenças crônicas não transmissíveis } \\
\hline Nenhuma & 3.253 .000 & 3.010 .522 & 6.263 .522 & 2.147 .094 & 1.105 .905 & 3.253 .000 & 2.033 .744 & 976.779 & 3.010 .522 \\
\hline Uma & 3.408 .709 & 3.734 .758 & 7.143 .468 & 1.710 .963 & 1.697 .746 & 3.408 .709 & 1.951 .732 & 1.783 .026 & 3.734 .758 \\
\hline Duas a três & 3.848 .939 & 5.886 .484 & 9.735 .423 & 1.343 .589 & 2.505 .350 & 3.848 .939 & 1.901 .033 & 3.985 .451 & 5.886 .484 \\
\hline Quatro ou mais & 1.006 .986 & 2.258 .432 & 3.265 .418 & 217.478 & 789.508 & 1.006 .986 & 423.520 & 1.834 .912 & 2.258 .432 \\
\hline
\end{tabular}

Tabela 6B - Distribuição absoluta dos idosos, segundo a presença de doenças crônicas não transmissíveis, de acordo com o sexo e a forma como autoavaliaram sua saúde - PNS, 2013

\begin{tabular}{|c|c|c|c|c|c|c|c|c|c|}
\hline \multirow{3}{*}{$\begin{array}{l}\text { Doenças crônicas não } \\
\text { transmissíveis }\end{array}$} & \multirow{2}{*}{\multicolumn{3}{|c|}{ Sexo }} & \multicolumn{6}{|c|}{ Sexo/Autopercepção da saúde } \\
\hline & & & & \multicolumn{3}{|c|}{ Homens } & \multicolumn{3}{|c|}{ Mulheres } \\
\hline & Homens & Mulheres & Total & Positiva & Negativa & Total & Positiva & Negativa & Total \\
\hline Total & 11.517 .634 & 14.890 .197 & 26.407 .831 & 5.354 .804 & 6.162 .830 & 11.517 .634 & 6.541 .335 & 8.348 .862 & 14.890 .197 \\
\hline Hipertensão arterial & 5.216 .941 & 8.158 .174 & 13.375 .114 & 1.991 .334 & 3.225 .607 & 5.216 .941 & 2.714 .069 & 5.444 .104 & 8.158 .174 \\
\hline Diabetes & 1.851 .551 & 2.928 .419 & 4.779 .971 & 561.279 & 1.290 .273 & 1.851 .551 & 689.829 & 2.238 .590 & 2.928 .419 \\
\hline Colesterol alto & 1.955 .222 & 4.465 .590 & 6.420 .812 & 733.773 & 1.221 .448 & 1.955 .222 & 1.485 .782 & 2.979 .808 & 4.465 .590 \\
\hline Doença do coração & 1.415 .029 & 1.600 .159 & 3.015 .188 & 438.367 & 976.662 & 1.415 .029 & 312.339 & 1.287 .820 & 1.600 .159 \\
\hline Derrame ou AVC & 683.793 & 615.277 & 1.299 .070 & 127.569 & 556.224 & 683.793 & 147.447 & 467.829 & 615.277 \\
\hline Asma ou bronquite asmática & 482.670 & 775.187 & 1.257 .857 & 128.960 & 353.710 & 482.670 & 242.278 & 532.908 & 775.187 \\
\hline Artrite ou reumatismo & 1.119 .860 & 3.219 .599 & 4.339 .458 & 331.187 & 788.673 & 1.119 .860 & 907.678 & 2.311 .920 & 3.219 .599 \\
\hline Problema de coluna & 2.779 .540 & 4.641 .126 & 7.420 .666 & 907.719 & 1.871 .821 & 2.779 .540 & 1.287 .139 & 3.353 .988 & 4.641 .126 \\
\hline Doença no pulmão & 486.179 & 529.218 & 1.015 .397 & 86.205 & 399.974 & 486.179 & 184.085 & 345.133 & 529.218 \\
\hline Câncer & 800.311 & 673.417 & 1.473 .727 & 355.403 & 444.908 & 800.311 & 244.190 & 429.227 & 673.417 \\
\hline Insuficiência renal crônica & 376.649 & 356.818 & 733.468 & 100.728 & 275.922 & 376.649 & 43.501 & 313.317 & 356.818 \\
\hline
\end{tabular}

Fonte: Microdados da PNS 2013. Elaboração própria.

Tabela 7B - Distribuição absoluta dos idosos, segundo a capacidade funcional, de acordo com o sexo e a forma como autoavaliaram sua saúde - PNS, 2013

\begin{tabular}{|c|c|c|c|c|c|c|c|c|c|}
\hline \multirow{3}{*}{ Capacidade funcional } & \multirow{2}{*}{\multicolumn{3}{|c|}{ Sexo }} & \multicolumn{6}{|c|}{ Sexo/Autopercepção da saúde } \\
\hline & & & & \multicolumn{3}{|c|}{ Homens } & \multicolumn{3}{|c|}{ Mulheres } \\
\hline & Homens & Mulheres & Total & Positiva & Negativa & Total & Positiva & Negativa & Total \\
\hline Total & 11.517.634 & 14.890 .197 & 26.407.831 & 5.419 .125 & 6.098 .509 & 11.517.634 & 6.310 .029 & 8.580 .168 & 14.890.197 \\
\hline \multicolumn{10}{|l|}{ Capacidade funcional } \\
\hline Dependente AIVD & 669.443 & 1.366 .528 & 2.035 .971 & 78.929 & 590.514 & 669.443 & 323.183 & 1.043 .345 & 1.366 .528 \\
\hline Dependente AVD e AIVD & 232.365 & 425.866 & 658.232 & 26.897 & 205.468 & 232.365 & 115.133 & 310.733 & 425.866 \\
\hline Independente & 10.615 .826 & 13.097 .802 & 23.713 .628 & 5.313 .299 & 5.302 .527 & 10.615 .826 & 5.871 .713 & 7.226 .089 & 13.097 .802 \\
\hline
\end{tabular}


Tabela 8B - Distribuição absoluta dos idosos, segundo a dependência ou não nas atividades básicas da vida diária, de acordo com o sexo e a forma como autoavaliaram sua saúde - PNS, 2013

\begin{tabular}{|c|c|c|c|c|c|c|c|c|c|}
\hline \multirow{3}{*}{$\begin{array}{c}\text { Atividades básicas da vida } \\
\text { diária (AVDs) }\end{array}$} & \multirow{2}{*}{\multicolumn{3}{|c|}{ Sexo }} & \multicolumn{6}{|c|}{ Sexo/Autopercepção da saúde } \\
\hline & & & & \multicolumn{3}{|c|}{ Homens } & \multicolumn{3}{|c|}{ Mulheres } \\
\hline & Homens & Mulheres & Total & Positiva & Negativa & Total & Positiva & Negativa & Total \\
\hline Total & 11.517 .634 & 14.890 .197 & 26.407 .831 & 5.354 .804 & 6.162 .830 & 11.517 .634 & 6.541 .335 & 8.348 .862 & 14.890 .197 \\
\hline \multicolumn{10}{|l|}{ Comer e beber } \\
\hline Dependente & 525.677 & 623.807 & 1.149 .484 & 91.551 & 434.126 & 525.677 & 108.425 & 515.382 & 623.807 \\
\hline Independente & 10.991 .957 & 14.266 .390 & 25.258 .346 & 5.327 .574 & 5.664 .383 & 10.991 .957 & 6.201 .604 & 8.064 .786 & 14.266 .390 \\
\hline \multicolumn{10}{|l|}{ Tomar banho } \\
\hline Dependente & 681.353 & 1.076 .460 & 1.757 .813 & 86.060 & 595.293 & 681.353 & 221.915 & 854.544 & 1.076 .460 \\
\hline Independente & 10.836 .281 & 13.813 .737 & 24.650 .018 & 5.333 .065 & 5.503 .216 & 10.836 .281 & 6.088 .114 & 7.725 .623 & 13.813 .737 \\
\hline \multicolumn{10}{|l|}{ Ir ao banheiro } \\
\hline Dependente & 507.287 & 1.037 .625 & 1.544 .912 & 75.747 & 431.540 & 507.287 & 209.369 & 828.256 & 1.037 .625 \\
\hline Independente & 11.010 .347 & 13.852 .572 & 24.862 .919 & 5.343 .378 & 5.666 .969 & 11.010 .347 & 6.100 .660 & 7.751 .912 & 13.852 .572 \\
\hline \multicolumn{10}{|l|}{ Vestir-se } \\
\hline Dependente & 925.827 & 1.396 .714 & 2.322 .541 & 112.382 & 813.444 & 925.827 & 219.560 & 1.177 .154 & 1.396 .714 \\
\hline Independente & 10.591 .807 & 13.493 .483 & 24.085 .290 & 5.306 .743 & 5.285 .064 & 10.591 .807 & 6.090 .469 & 7.403.014 & 13.493 .483 \\
\hline \multicolumn{10}{|l|}{ Andar em casa } \\
\hline Dependente & 745.835 & 1.335 .129 & 2.080 .964 & 66.679 & 679.156 & 745.835 & 246.689 & 1.088 .440 & 1.335 .129 \\
\hline Independente & 10.771 .799 & 13.555 .068 & 24.326 .867 & 5.352 .446 & 5.419 .353 & 10.771 .799 & 6.063 .340 & 7.491 .728 & 13.555 .068 \\
\hline \multicolumn{10}{|l|}{ Deitar ou levantar da cama } \\
\hline Dependente & 804.827 & 1.348 .200 & 2.153 .027 & 106.822 & 698.005 & 804.827 & 262.649 & 1.085 .551 & 1.348 .200 \\
\hline Independente & 10.712 .807 & 13.541 .997 & 24.254 .804 & 5.312 .304 & 5.400 .504 & 10.712 .807 & 6.047 .380 & 7.494 .617 & 13.541 .997 \\
\hline \multicolumn{10}{|l|}{ Sentar e levantar da cadeira } \\
\hline Dependente & 799.367 & 1.215 .645 & 2.015 .012 & 130.698 & 668.670 & 799.367 & 225.002 & 990.643 & 1.215 .645 \\
\hline Independente & 10.718 .267 & 13.674 .552 & 24.392 .819 & 5.288 .428 & 5.429 .839 & 10.718 .267 & 6.085 .027 & 7.589 .525 & 13.674 .552 \\
\hline
\end{tabular}

Tabela 9B - Distribuição absoluta dos idosos, segundo a dependência ou não nas atividades instrumentais da vida diária, de acordo com o sexo e a forma como autoavaliaram sua saúde - PNS, 2013

\begin{tabular}{|c|c|c|c|c|c|c|c|c|c|}
\hline \multirow{3}{*}{$\begin{array}{l}\text { Atividades instrumentais } \\
\text { da vida diária (AIVDs) }\end{array}$} & \multirow{2}{*}{\multicolumn{3}{|c|}{ Sexo }} & \multicolumn{6}{|c|}{ Sexo/Autopercepção da saúde } \\
\hline & & & & \multicolumn{3}{|c|}{ Homens } & \multicolumn{3}{|c|}{ Mulheres } \\
\hline & Homens & Mulheres & Total & Positiva & Negativa & Total & Positiva & Negativa & Total \\
\hline Total & 11.517.634 & 14.890 .197 & 26.407 .831 & 5.354 .804 & 6.162 .830 & 11.517 .634 & 6.541 .335 & 8.348 .862 & 14.890 .197 \\
\hline \multicolumn{10}{|l|}{ Fazer compras } \\
\hline Dependente & 1.467 .683 & 2.843 .052 & 4.310 .735 & 276.143 & 1.191 .540 & 1.467 .683 & 615.415 & 2.227 .638 & 2.843 .052 \\
\hline Independente & 10.049 .951 & 12.047 .145 & 22.097 .096 & 5.142 .983 & 4.906 .969 & 10.049 .951 & 5.694 .614 & 6.352 .530 & 12.047 .145 \\
\hline \multicolumn{10}{|l|}{ Administrar finanças } \\
\hline Dependente & 1.027 .315 & 1.987 .207 & 3.014 .522 & 168.631 & 858.684 & 1.027.315 & 542.543 & 1.444 .664 & 1.987.207 \\
\hline Independente & 10.490 .319 & 12.902 .990 & 23.393.309 & 5.250 .494 & 5.239 .825 & 10.490.319 & 5.767 .486 & 7.135.504 & 12.902 .990 \\
\hline \multicolumn{10}{|l|}{ Tomar remédios } \\
\hline Dependente & 796.252 & 1.253 .218 & 2.049 .470 & 97.190 & 699.061 & 796.252 & 256.488 & 996.730 & 1.253 .218 \\
\hline Independente & 10.721 .382 & 13.636 .979 & 24.358 .361 & 5.321 .935 & 5.399 .447 & 10.721 .382 & 6.053 .541 & 7.583 .438 & 13.636 .979 \\
\hline \multicolumn{10}{|l|}{ Ir ao médico } \\
\hline Dependente & 2.007 .799 & 3.622 .647 & 5.630 .445 & 433.063 & 1.574 .735 & 2.007 .799 & 876.608 & 2.746 .038 & 3.622 .647 \\
\hline Independente & 9.509 .835 & 11.267 .550 & 20.777 .386 & 4.986 .062 & 4.523 .773 & 9.509 .835 & 5.433 .421 & 5.834 .130 & 11.267 .550 \\
\hline \multicolumn{10}{|l|}{$\begin{array}{l}\text { Utilizar transportes para } \\
\text { deslocamento }\end{array}$} \\
\hline Dependente & 1.878 .095 & 3.546 .144 & 5.424 .238 & 369.704 & 1.508 .390 & 1.878 .095 & 860.546 & 2.685 .598 & 3.546 .144 \\
\hline Independente & 9.639 .539 & 11.344 .053 & 20.983 .593 & 5.049 .421 & 4.590 .119 & 9.639 .539 & 5.449 .483 & 5.894 .570 & 11.344 .053 \\
\hline
\end{tabular}




\section{Apêndice C - Razões de chances e Intervalos de Confiança}

Tabela 1C - Razões de chances e intervalos de confiança dos cinco modelos para idosos do sexo masculino, segundo os fatores associados à percepção de saúde PNS, 2013

\begin{tabular}{|c|c|c|c|c|c|c|c|c|c|c|}
\hline & \multicolumn{10}{|c|}{ Idosos do sexo masculino } \\
\hline & \multicolumn{2}{|c|}{ Modelo 1} & \multicolumn{2}{|c|}{ Modelo 2} & \multicolumn{2}{|c|}{ Modelo3 } & \multicolumn{2}{|c|}{ Modelo 4} & \multicolumn{2}{|c|}{ Modelo 5} \\
\hline & $\mathrm{RC}$ & IC 95\% & $\mathrm{RC}$ & IC 95\% & $\mathrm{RC}$ & IC 95\% & $\mathrm{RC}$ & IC 95\% & $\mathrm{RC}$ & IC 95\% \\
\hline $\begin{array}{l}\text { Informante } \\
\text { (ref. Próprio idoso) }\end{array}$ & & & & & & & & & & \\
\hline Outro informante & 1,03 & $(0,81 ; 1,32)$ & 1,03 & $(0,80 ; 1,32)$ & 1,03 & $(0,80 ; 1,32)$ & 1,01 & $(0,79 ; 1,31)$ & 0,91 & $(0,68 ; 1,21)$ \\
\hline $\begin{array}{l}\text { Idade } \\
\text { Raça/cor } \\
\text { (ref. Brancos) }\end{array}$ & 1,02 & $(1,01 ; 1,03)$ & 1,02 & $(1,01 ; 1,03)$ & 1,01 & $(0,99 ; 1,03)$ & 1,01 & $(0,99 ; 1,02)$ & 0,99 & $(0,98 ; 1,01)$ \\
\hline Negros & 1,66 & $(1,36 ; 2,03)$ & 1,51 & $(1,21 ; 1,88)$ & 1,25 & $(0,99 ; 1,58)$ & 1,23 & $(0,97 ; 1,56)$ & 1,27 & $(0,99 ; 1,64)$ \\
\hline Amarelos/Indígenas & 0,74 & $(0,31 ; 1,77)$ & 0,68 & $(0,28 ; 1,68)$ & 1,02 & $(0,31 ; 3,36)$ & 0,90 & $(0,29 ; 2,75)$ & 1,08 & $(0,41 ; 2,86)$ \\
\hline $\begin{array}{l}\text { Região de moradia } \\
\text { (ref. Sudeste) }\end{array}$ & & & & & & & & & & \\
\hline Norte & & & 1,63 & $(1,13 ; 2,35)$ & 1,48 & $(1,02 ; 2,13)$ & 1,39 & $(0,97 ; 1,98)$ & 1,90 & $(1,27 ; 2,83)$ \\
\hline Nordeste & & & 1,65 & $(1,29 ; 2,13)$ & 1,45 & $(1,11 ; 1,88)$ & 1,45 & $(1,11 ; 1,89)$ & 1,91 & $(1,46 ; 2,50)$ \\
\hline Sul & & & 1,43 & $(1,07 ; 1,90)$ & 1,22 & $(0,91 ; 1,64)$ & 1,27 & $(0,94 ; 1,73)$ & 1,24 & $(0,90 ; 1,70)$ \\
\hline Centro-Oeste & & & 1,17 & $(0,87 ; 1,56)$ & 1,06 & $(0,79 ; 1,43)$ & 1,08 & $(0,79 ; 1,47)$ & 1,17 & $(0,83 ; 1,65)$ \\
\hline $\begin{array}{l}\text { Escolaridade } \\
\text { (ref. Até Ensino Fund. Incompleto) }\end{array}$ & & & & & & & & & & \\
\hline Fund. Completo e Med. Incompleto & & & & & & $(0,50 ; 1,1)$ & 0,81 & $(0,54 ; 1,22)$ & 0,83 & $(0,52 ; 1,32)$ \\
\hline Med. Completo e Sup. Incompleto & & & & & 0,59 & $(0,43 ; 0,80)$ & 0,61 & $(0,44 ; 0,83)$ & 0,58 & $(0,41 ; 0,82)$ \\
\hline Superior completo & & & & & 0,17 & $(0,11 ; 0,27)$ & 0,19 & $(0,12 ; 0,30)$ & 0,16 & $(0,09 ; 0,26)$ \\
\hline $\begin{array}{l}\text { Consumo de bebidas alcóolicas } \\
\text { (ref. Não consome) }\end{array}$ & & & & & & & & & & \\
\hline Menos de 1 vez por mês & & & & & & & 0,68 & $(0,50 ; 0,93)$ & 0,76 & $(0,54 ; 1,07)$ \\
\hline Uma ou mais vezes por mês & & & & & & & 0,51 & $(0,39 ; 0,66)$ & 0,58 & $(0,43 ; 0,76)$ \\
\hline Tabagismo (Nunca fumou) & & & & & & & & & & \\
\hline Fumante & & & & & & & 1,28 & $(0,94 ; 1,74)$ & 1,24 & $(0,91 ; 1,71)$ \\
\hline Ex-fumante & & & & & & & 1,45 & $(1,15 ; 1,83)$ & 1,10 & $(0,85 ; 1,41)$ \\
\hline $\begin{array}{l}\text { Atividades religios as } \\
\text { (ref. Frequentemente) }\end{array}$ & & & & & & & & & & \\
\hline Não frequenta & & & & & & & 1,26 & $(0,95 ; 1,65)$ & 1,38 & $(1,03 ; 1,85)$ \\
\hline Raramente & & & & & & & 1,07 & $(0,80 ; 1,43)$ & 1,07 & $(0,79 ; 1,43)$ \\
\hline $\begin{array}{l}\text { Doenças crônicas não transmissíve } \\
\text { (ref. Nenhuma doença) }\end{array}$ & & & & & & & & & & \\
\hline Uma doença & & & & & & & & & 2,13 & $(1,57 ; 2,88)$ \\
\hline Duas a três doenças & & & & & & & & & 5,00 & $(3,68 ; 6,79)$ \\
\hline Quatro a mais doenças & & & & & & & & & 9,67 & $(6,02 ; 15,53)$ \\
\hline $\begin{array}{l}\text { Capacidade funcional } \\
\text { (ref. Independente) }\end{array}$ & & & & & & & & & & \\
\hline Dependente AVD e AIVD & & & & & & & & & 5,46 & $(3,03 ; 9,83)$ \\
\hline Dependente AIVD & & & & & & & & & 4,99 & $(1,62 ; 15,36)$ \\
\hline
\end{tabular}


Tabela 2C - Razões de chances e intervalos de confiança dos cinco modelos para idosas do sexo feminino, segundo os fatores associados à percepção de saúde - PNS, 2013

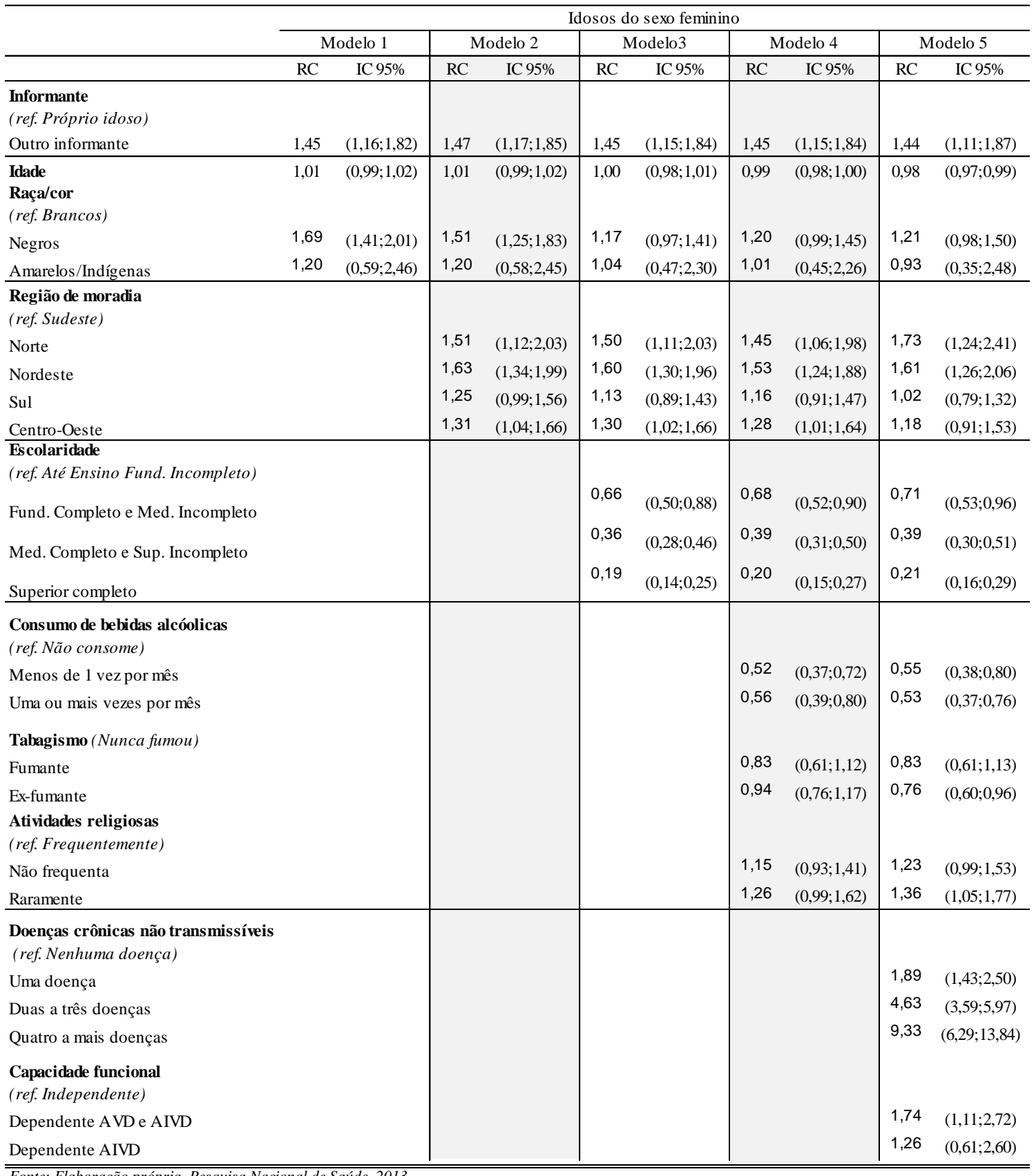

Fonte: Elaboração própria, Pesquisa Nacional de Saúde, 2013.

Nota: Significância estatística: *valor de $p<0,05 ; * *$ valor de $p<0,01$; *** valor de $p<0,001$ 
Tabela 3C - Razões de chances e intervalos de confiança dos modelos finais para os idosos do sexo masculino e feminino, segundo os fatores que foram significativos e associados à percepção de saúde - PNS, 2013

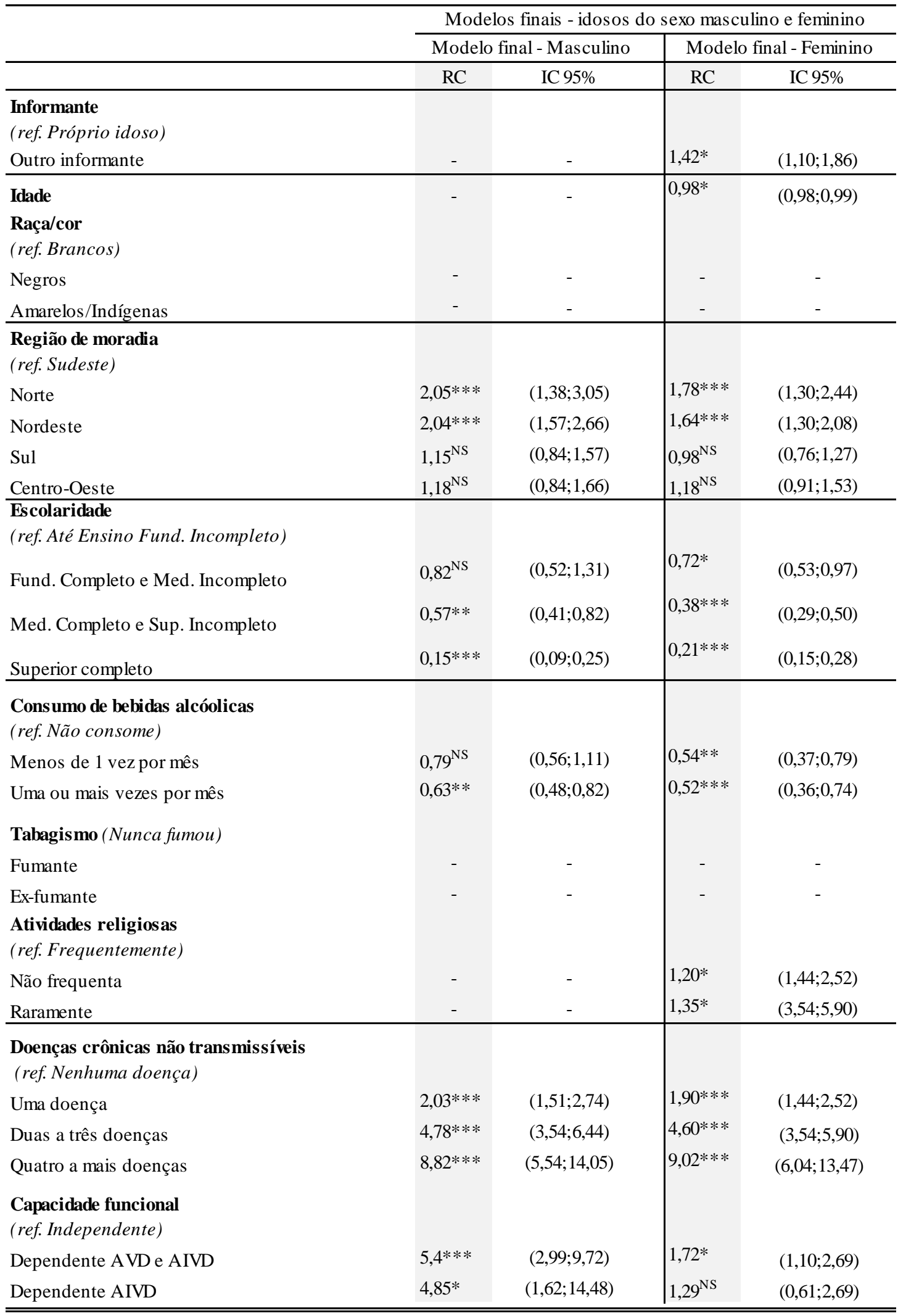

Fonte: Elaboração própria, Pesquisa Nacional de Saúde, 2013.

Nota: Significância estatística: * valor de p<0,05; **valor de p<0,01; ***valor de p<0,001; NS: não significativo. 